SAND $90-2882 \cdot U C-814$

Unlimited Release

Printed April 1992

Yucca Mountain Site Characterization Project

- An Investigation of the Impact of Conceptual Model Uncertainty on the Estimated Performance of a Hypothetical High-Level Nuclear Waste Repository Site in Unsaturated, Fractured Tuff

D. P. Gallegos, P. I. Pohl, C. D. Updegraff

Prepared by

Sandia National Laboratories

Albuquerque, New Mexico 87185 and Livermore, California 94550

for the United States Department of Energy

under Contract DE-AC04-76DP00789 
"Prepared by Yucca Mountain Site Characterization Project (YMSCP) participants as part of the Civilian Radioactive Waste Management Program (CRWM). The YMSCP is managed by the Yucca Mountain Project Office of the U.S. Department of Energy, DOE Field Office, Nevada (DOE/NV) YMSCP work is sponsored by the Office of Geologic Repositories (OGR) of the DOE Office of Civilian Radioactive Waste Management (OCRWM)."

Issued by Sandia National Laboratories, operated for the United States Department of Energy by Sandia Corporation.

NOTICE: 'This report was prepared as an account of work sponsored by an agency of the United States Government. Neither the United States Government nor any agency thereof, nor any of their employees, nor any of their contractors, subcontractors, or their employees, makes any warranty, express or implied, or assumes any legal liability or responsibility for the accuracy, completeness, or usefulness of any information, apparatus, product, or process disclosed, or represents that its use would not infringe privately owned rights. Reference herein to any specific commercial product, process, or service by trade name, trademark, manufacturer, or otherwise, does not necessarily constitute or imply its endorsement, recommendation, or favoring by the United States Government, any agency thereof or any of their contractors or subcontractors. The views and opinions expressed herein do not necessarily state or reflect those of the United States Govermment, any agency there of or any of their contractors.

Printed in the Urited States of America. 'This report has been reproduced directly from the best available copy.

Available 10 DOE and DOF contractors from

Office of Scientifis and 'lechnical Information

$\mathrm{POBO} 62$

Oak Ridge, 'T'N :378:31

Prices available from (615) 576-8401, FTS 626-8401

Available to the public from

National Technical Information Service

US Department of Commerce

5285 Port Royal Rd

Springfield, VA 22161

N'TIS price codes

Printed copy: A()5

Microfiche copy: $A 0$ 
SAND90-2882

DE92 012685

Unlimited Release

Printed April 1992

\title{
AN INVESTIGATION OF THE IMPACT OF CONCEPTUAL MODEL UNCERTAIN'TY ON THE ESTIMATED PERFORMANCE OF A HYPOTHETICAL HIGH-LEVEL NUCLEAR WASTE REPOSITORY SITE IN UNSATURATED, FRACTURED TUFF
}

\author{
D.P. Gallegos \\ P.I. Pohl \\ C.D. Updegraff* \\ Sandia National Laboratories \\ Waste Management Systems Division \\ Albuquerque, NM 87185
}

\begin{abstract}
Performance assessment modeling for High Level Waste (HLW) disposal incorporates three different types of uncertainty. These include data and parameter uncertainty, modeling uncertainty (which includes conceptual, mathematical, and numerical), and uncertainty associated with predicting the future state of the system. In this study, the potential impact of conceptual model uncertainty on the estimated performance of a hypothetical high-level radioactive waste disposal site in unsaturated, fractured tuff has been assessed for a given group of conceptual models. This was accomplished by taking a series of six, one-dimensional conceptual models, which differed only by the fundamental assumptions used to develop them, and conducting ground-water flow and radionuclide transport simulations. Complementary cumulative distribution functions (CCDFs) representing integrated radionuclide release to the water table indicate that differences in the basic assumptions used to develop conceptual models can have a significant impact on the estimated performance of the site. Because each of the conceptual models employed the same mathematical and numerical models, contained the same data and parameter values and ranges, and did not consider the possible future states of the system, changes in the CCDF could be attributed primarily to differences in conceptual modeling assumptions. Studies such as this one could help prioritize site characterization activities by identifying critical and uncertain assumptions used in model development, thereby providing guidance as to where reduction of uncertainty is most important.
\end{abstract}

\footnotetext{
* GRAM, Inc.
}

Albuquerque, NM 87112

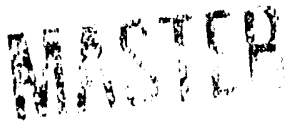


This work was performed under the auspices of the U.S. Department of Energy, Office of Civilian Radioactive Waste Management, Yucca Mountain Project, under contract DE-AC04-76DP000789. The studies described in this report were performed under WBS Number 1.2.1.4.7. 


\section{CONTENTS}

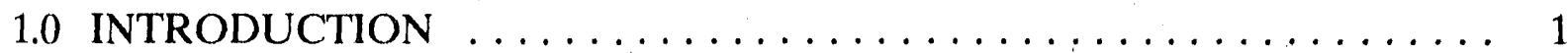

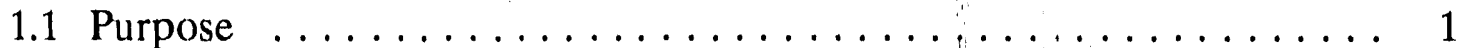

1.2 Background ......................... 2

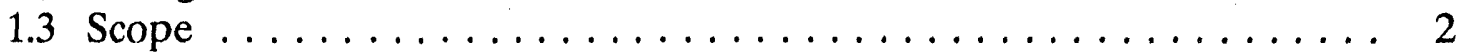

1.4 Procedure to Assess Impact of Alternative Conceptual Models . . . . . . 4

2.0 DEFINITION OF ALTERNATIVE CONCEPTUAL MODELS . . . . . . 5

2.1 Conceptual Models and Conceptual Model Uncertainty . . . . . . . . 5 5

2.2 Approach to Choosing Alternative Conceptual Models . . . . . . . . . . 5

2.3 Summary of Conceptual Models Chosen . . . . . . . . . . . 8

3.0 PROCEDURE FOR ANALYSES $\ldots \ldots \ldots \ldots \ldots \ldots \ldots \ldots \ldots \ldots \ldots \ldots$

3.1 Mathematical and Numerical Models $\ldots \ldots \ldots \ldots \ldots$

3.1 .1 Ground Water Flow Analysis . . . . . . . . . . . . 13

3.1 .2 Radionuclide Transport Analysis . . . . . . . . . . 22

3.2 Flow and Transport Coupling .................. 24

3.3 CCDF Generation ....................... 25

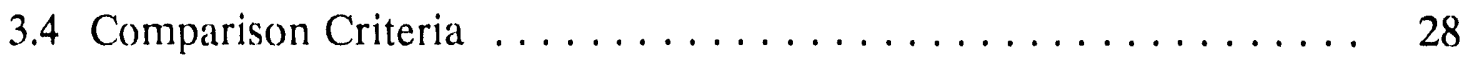

4.0 RESULTS . . . . . . . . . . . . . . . . . . . . . . . . . . 29

4.1 Ground Water Flow Simulations . . . . . . . . . . . . . . . 29

4.1.1 Matrix-Dominated Flow Model . . . . . . . . . . . . . . . . . 29

4.1.2 Fracture-Dominated Flow Model . . . . . . . . . . . . 31

4.1.3 Simultaneous Fracture and Matrix Flow Model . . . . . . . . 35

4.1.4 Alternative Stratigraphic Layering Flow Model . . . . . . . . . 46

4.2 Radionuclide Transport Simulations . . . . . . . . . . . . . . . 49

4.3 Assessment of Alternative Conceptual Models . . . . . . . . . . . 54

5.0 SUMMARY AND CONCLUSIONS $\ldots \ldots \ldots \ldots \ldots \ldots \ldots \ldots$

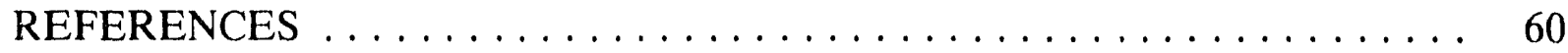

APPENDIX - RIB and SEPDB Databases $\ldots \ldots \ldots \ldots \ldots$ 


\section{FIGURES}

Figure

Page

2.1. Generalized Flow Chart of the Major Assumptions Needed to Develop a Conceptual Model for an Unsaturated, Fractured Flow

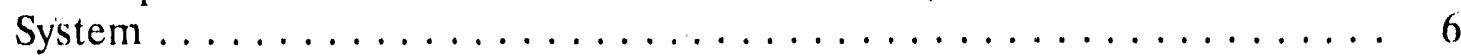

2.2. Basic Stratigraphy and Boundary Conditions Assumed for Alternative Conceptual Models .......................... 9

2.3. Schematic Representation of Conceptual Models Tested ........... 12

3.1. Source Term Release Rates for Isotopes Considered . . . . . . . . . . 25

4.1. All Matrix Flow Model - Pressure Head . . . . . . . . . . . . . . . 29

4.2. All Matrix Flow Model - Total Head ................... 30

4.3. All Matrix Flow Model - Moisture Content ................ 31

4.4. All Matrix Flow Model - Saturation .................. 32

4.5. All Fracture Flow Model - Pressure Head ................ 32

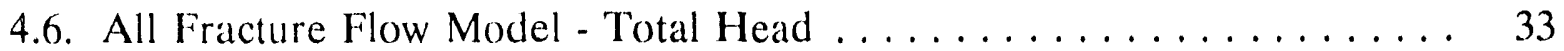

4.7. All Fracture Flow Model - Saturation . . . . . . . . . . . . . . . 34

4.8. All Fracture Flow Model - Moisture Content ................ 34

4.9. Matrix/Fracture Flow Model (Large Transfer Coefficient) - Pressure Head ............................. 35

4.10. Matrix Fracture Flow Model (Large Transfer Coefficient) - Head Difference ............................ 36

4.11. Matrix/Fracture Flow Model (Large Transfer Coefficient) -. Total Head ............................ 36

4.12. Matrix/Fracture Flow Model (Large Transfer Coefficient) - Darcy Velocity ..............................

4.13. Matrix/Fracture Flow Model (Large Transfer Coefficient) Saturation

4.14. Matrix/Fracture Flow' Model (Large Transfer Coefficient) - Moisture Content . . . . . . . . ....................

4.15. Matrix/Fracture Flow Model (Medium Transfer Coefficient) - Pressure Head ................................. 40

4.16. Matrix/Fracture Flow Model (Medium Transfer Coefficient) - Total

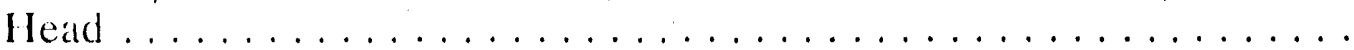

4.17. Matrix/Fracture Flow Model (Medium Transfer Coefficient) - Head Difference ............................ 41

4.18. Matrix/Fracture Flow Model (Medium Transfer Coefficient) -

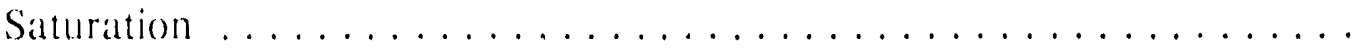

4.19. Matrix/Fracture Fiow Model (Medium Transfer Coefficient) - Moisture

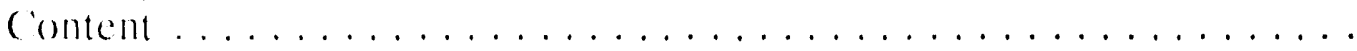

4.20. Matrix/Fracture Flow Model (Medium Transfer Coefficient) - Darcy

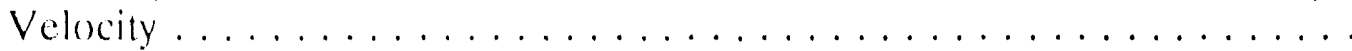

4.21. Matrix/Iracture Flow Model (Small Transfer Coefficient) - Pressure Head . . . . . . . . . . . . . . . . . . . . . . . 


\section{FIGURES (cont.)}

Figure

4.22. Matrix/Fracture Flow Model (Small Transfer Coefficient) - Head

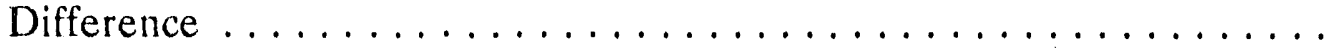

4.23. Matrix/Fracture Flow Model (Small Transfer Coefficient) - Total Head .............................. 44

4.24. Matrix/Fracture Flow Model (Small Transfer Coefficient) Saturation ........................... 45

4.25. Matrix/Fracture Flow Model (Small Transfer Coefficient) - Moisture Content . . . . . . . . . . . . . . . . . . . . . . . .

4.26. Matrix/Fracture Flow Model (Small Transfer Coefficient) - Darcy Velocity . . . . ....................... 46

4.27. Four-Layer Stratigraphy Flow Model - Pressure Head . . . . . . . . . . . 47

4.28. Four-Layer Stratigraphy Flow Model - Total Head . . . . . . . . . . . 48

4.29. Four-Layer Stratigraphy Flow Model - Saturation . . . . . . . . . . . 48

4.30. Four-Layer Stratigraphy Flow Model - Moisture Content . . . . . . . . . . 49

4.31. Four-Layer Stratigraphy Flow Model - Darcy Velocity . . . . . . . . . . . . 50

4.32. Pore Velocities for All-Fracture, All-Matrix and Fracture/Matrix Conceptual Models. ........................ 51

4.33. Release Rates to Water Table for ${ }^{129} 1 \ldots \ldots \ldots \ldots \ldots \ldots \ldots \ldots \ldots \ldots$

4.34. CCDF Curves for Conceptual Models That Consider Matrix Flow and

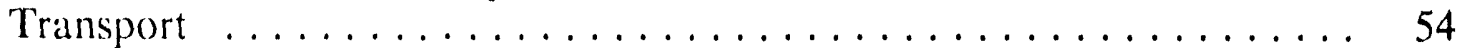

4.35. CCDF Curves for Fracture Dominated Flow and Transport Conceptual

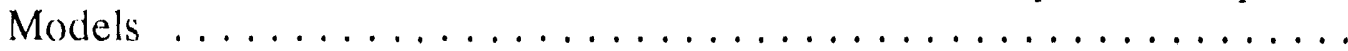

4.36. CCDF Curves for Conceptual Models That Contain Matrix Flow and

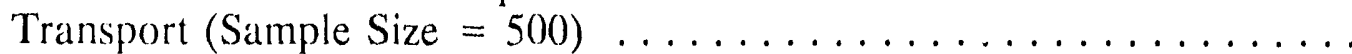

48

49

\section{TABLES}

Table

3.1. Matrix and Fracture Properties . . . . . . . . . . . . . . . . . 18

3.2. Grid Block Thicknesses for Matrix Flow Problem . . . . . . . . . . . . . 19

3.3. Grid Block Thicknesses for Fracture-Dominated Flow Problem . . . . . . 20 20

3.4. Grid Block Thicknesses for Four-Layer Stratigraphy Problem . . . . . . . 22

3.5. Parameters Varied in Transport Analysis . . . . . . . . . . . . . 26

3.6. Retardation Factors Used in Transport Analyses . . . . . . . . . . . . . . 27

4.1. Summary of Conceptual Model Properties . . . . . . . . . . . . . . 51

4.2. Cumulative Isotope Release to Water Table using NEFTRAN II . . . . 52 


\section{ACKNOWLEDGEMENT}

The authors would like to thank R.G. Knowlton and N.E. Olague of Sandia National Laboratories for their technical assistance and recommendations during the preparation of this report. The authors would also like to thank E.J. Bonano and M.L. Wilson for their valuable review comments. 


\subsection{INTRODUC'TION}

The U.S. Department of Energy is responsible for the design, construction, operation, and decommissioning of a site for the deep geologic disposal of high-level radioactive waste ( $\mathrm{jLW}$ ). This necessarily involves site characterization and the use of performance assessment to demonstrate compliance with the regulations for HLW disposal set forth by the U.S. Environmental Protection Agency (EPA, 1985) and the U.S. Nuclear Regulatory Commission (NRC, 1986). Within the EPA standard, the definition of "performance assessment" specifically states that the assessment will consider the associated uncertainties involved in estimating cumulative release of radionuclites to the accessible environment. In addition, the EPA Containment Requirements (40 CFR 191.13) require that a reasonable expectation that compliance with $\$ 191.13$ (a) will be achieved. To provide a reasonable expectation through modeling, the models used in an analysis must adequately represent the real system and must consider and/or incorporate all sources of uncertainty, as practicably as possible.

Performance assessment modeling for HLW disposal incorporates three different types of uncertainty. These include data and parameter uncertainty, modeling uncertainty, and uncertainty associated with predicting the future state of the system. Traditionally, the majority of the efforts in uncertainty analysis have been directed toward treating data and parameter uncertainty; consequently', little effort has been made to treat model uncertainty. Model uncertainty includes conceptual model uncertainty, mathematical model uncertainty, and uncertainties resulting from implementing the mathematical model in a computer code (e.g., coding errors, computational limitations, user errors). Currently there is no systematic approach designed to address the uncertainty in conceptual models, nor has the impact of conceptual model uncertainty on a given regulatory performance measure been demonstrated.

\subsection{Purpose}

The purpose of this investigation is to take a first step at addressing conceptual model uncertainty. This will be accomplished by assessing, qualitatively, the relative impact that alternative conceptual models for a given system have on the integrated release of radionuclides at a point along a transport migration path. The source of radionuclides is a hypothetical HLW repository located in unsaturated, fractured tuff. The assessment is qualitative only in the sense that the uncertainty associated with each of the conceptual models is not quantified as part of the comparison. The results from the individual conceptual models, however, are quantitative. In general, studies such as the one presented in this report could help prioritize site characterization activitics by

\footnotetext{
1 The United States court of Appeals, $1^{\text {st }}$ (ircuit, 7/17/87, valeated the EPA HI.W slandard 4) (FR 191 and remanded the EPA individual protection and ground waler protection requirements for further consideration. While this action by the court may result in numcrical critcria that differ from the EPA's original values, the content and form of the requirements are not expected to change. Therefore, the nature of the calculations mede in this report and the accompanying complarisons are expected to be relevant to any revised EPA standards.
} 
identifying critical and uncertain assumptions used in model development, thereby providing guidance as to where reduction of uncertainty is most important.

\subsection{Background}

A knowledge of previously developed conceptual models is important in assessing the impact of conceptual model uncertainty. A number of investigators have recognized the existence of numerous alternative conceptual models, but few have intercompared results from the models. Parsons et al. (1989) reviewed and evaluated several conceptual models for ground water flow and solute transport at a HLW repository site located in unsaturated, fractured tuff formations. Their evaluations concentrated primarily on the fundamental assumptions made in the development of the conceptual models and the possible implications those assumptions could have on performance assessment modeling. However, hecause many of the specific assumptions and the modeling intentions of each of the conceptual models were different, a meaningful comparison of results from the models was difficult. Parsons et al. also reviewed existing information on flow and transport in unsaturated and saturated, fractured rock (much of which was specific to Yucca Mountain), and recognized that, given the existing information, a single defensible conceptual model for such a system does not exist. Rather, several alternative conceptual models are plausible.

Many investigators have realized the iniportance of conceptual model uncertainty and the fact that quantifying and reducing this uncertainty will increase confidence in the analysis (Bonano and Cranwell, 1988; Davis et al., 199(); de Marsily, 1990)). International cooperative studies, such as INTRACOIN (INTRACOIN, 1986), INTRAVAL (IN'TR AVAL, 1987), HYDROCOIN (NRC, 1988; SKI, 1990), and GEOVAL (Davis and Goodrich, 1990), have implicitly recognized the problem of model uncertainty and, in principle, provide approaches to reducing model uncertainty (including conceptual, mathematical, and numerical model uncertainty) through the process of model validation and verification.

\subsection{Scope}

A conceptual model is defined here as the set of assumptions and simplifications that describe the physical system and the behavior of the system. In this study, the uncertainty in conceptual models is assessed by taking a number of alternative conceptual models for a single site and graphically comparing flow and transport results from cath. That is, in this semsitivity-analysis-type approach, the impact of fundanental atsumprtions used (o) develop unigue conceptual models is qualitatively assesseci by phenting and comparing the guantitative flow and transport simulation results of each conceptral molel.

This invertigation is mot intended to be exhaustive in terms of the conceptual models 
chosen; rather, the emphasis was placed on elucidating the potential impact of uncertainty in conceptual models on the results of a performance assessment. In fact, only a limited number of conceptual models could be assessed because, although numerous conceptual models are conceivable, time constraints and existing mathematical and numerical techniques precluded the quantitative analysis of many of them. Although the range of conceptual models was limited in this investigation by the aforementioned constraints, in a real performance assessment one must consider all plausible conceptual models, independent of mathematical and numerical modeling capabilities.

Some important qualifications should be noted for this analysis. These are listed below, and are due mainly to the limited scope of this investigation, and also to the numerical and mathematical limitations of the calculational tools applied.

- A limited number (6) of conceptual models were analyzed.

- The analysis was confined to one-dimensional models.

- All of the models were based on a continuum approach. Ground water flow models assumed Darcy's Law to be valid.

- The analysis assumed steady-state ground water flow fields.

- A limited number of single-membered radionuclide chains were transported.

- Radionuclide transport was modeled using an advective/dispersion equation with constant, $\mathrm{K}_{\mathrm{d}}$-based retardation factors.

- Gas phase transport was not included in the analysis.

- The analysis assumed the system could be treated as isothermal.

- Uncertainty in transport parameters only was assumed when generating the complementary cumulative distribution functions (CCDF).

- No atlempt wals made to quantify the uncertainty in the fundamental assumptions made. That is, conceptual model uncertainty was not quantified.

- Integrated releatse of radionuclides to the water table was the only performance measure used for comparison of alternative conceptual mordels.

- ()nly "present condition" realizations were simulated. That is, disruptive or allernative scenarios were not considered. 
- The investigation is preliminary and based on limited data; therefore, the results should not be taken as representative of a potential repository located at Yucca Mountain, Nevada.

\subsection{Procedure to Assess Impact of Alternative Conceptual Models}

A number of plausible, alternative conceptual models were defined based on a general understanding of observations made at the potential HLW disposal site at Yucca Mountain, Nevada and at other unsaturated, fractured tuff sites. For this investigation, liberal interpretations of any observations were allowed. That is, unless there existed outright, conclusive evidence that a given conceptual model could not exist, then that model was considered plausible. However, the probability of each conceptual model was not estimated and the uncertainty associated with each model was not quantified.

For the most part, each of the alternative conceptual models in this investigation are based on the same system geometry, boundary conditions, and parameter values, but are differentiated by fundamentally different assumptions of the flow and transport mechanisms in the system. Quantitative analysis of ground water flow and radionuclide transport for each of the conceptual models was conducted. Flow simulations were conducted using the DCM3D code (Updegraff and Lee, 1991). The resulting ground water flow velocities were used in the NEFTRAN II code (Olague et al., 1991) to simulate transport of radionuclides from the repository to the water table. Transport parameters (such as dispersivity and retardation factors) were assumed to have some uncertainty associated with them. As a result, transport simulations of radionuclide release to the water table could be expressed probabilistically in terms of a CCDF of total integrated release. This CCDF was the performance measure used in this study to compare alternative conceptual models with each other. 


\subsection{DEFINITION OF ALTERNATIVE CONCEPTUAL MODELS}

\subsection{Conceptual Models and Conceptual Model Uncertainty}

Flow and transport models used in performance assessment are, without exception, built upon a set of fundamental assumptions and simplifications $c$ a physical system and on how that system behaves. This set of assumptions and simplifications is referred to as the "conceptual model" of the system. The development of a conceptual model generally involves simplifying the real system so that it can be represented with a tractable mathematical model that, in turn, can be solved using analytical and/or numerical techniques. The conceptual model, therefore, provides a description of the geometry of the system, the boundary and initial conditions associated with the system, the physical and chemical processes occurring within the system, and a description of how those processes occur (i.e., the variables and parameters chosen to represent those processes).

Because models are by definition, simplifications of reality: uncertainty is inherent within them. The large degree of uncertainty associated with a conceptual model for an HIW repository site is generally the result of the large spatial and temporal scales of interest and the inability to test the performance of a real site under post-waste-emplacement conditions over regulatory time frames. In addition, the "real" system is often poorly characterized, making the development of a defensible conceptual model a difficult task.

Large uncertainties imply that only limited information is available to support or refute alternative conceptual models. Consequently, a number of alternative conceptual models may be plausible for a single site. Furthermore, it is not clear whether the uncertainty associated with each conceptual model can be quantified with an adequate degree of confidence or how that uncertainty would be represented. As a result, performance assessment would have to acknowledge in some manner all the plausible conceptual models to ensure that all the possible realizations of a given site's behavior have been considered. In this investigation, conceptual model uncertainty is represented in terms of a number of alternative conceptual models; the alternative models are treated as mutually exclusive and are evaluated independently.

\subsection{Approach to Choosing Alternative Conceptual Models}

A simple, but systematic approach for choosing and defining conceptual models is illustrated in Figure 2.1. An approach such as this provides a way to define alternative conceptual models, so that the fundamental assumptions that segregated the models are explicit, and therefore, can easily be articulated. Note that although some of the fundamental assumptions illustrated in Figure 2.1 apply to both flow and transport (e.g., dimensionality), the figure does not explicitly include some transport assumptions (e.g., matrix diffusion). A more generalized tlow chant that included transpont could be developed hased on the same idea. In practice, the flow chart should be much more 


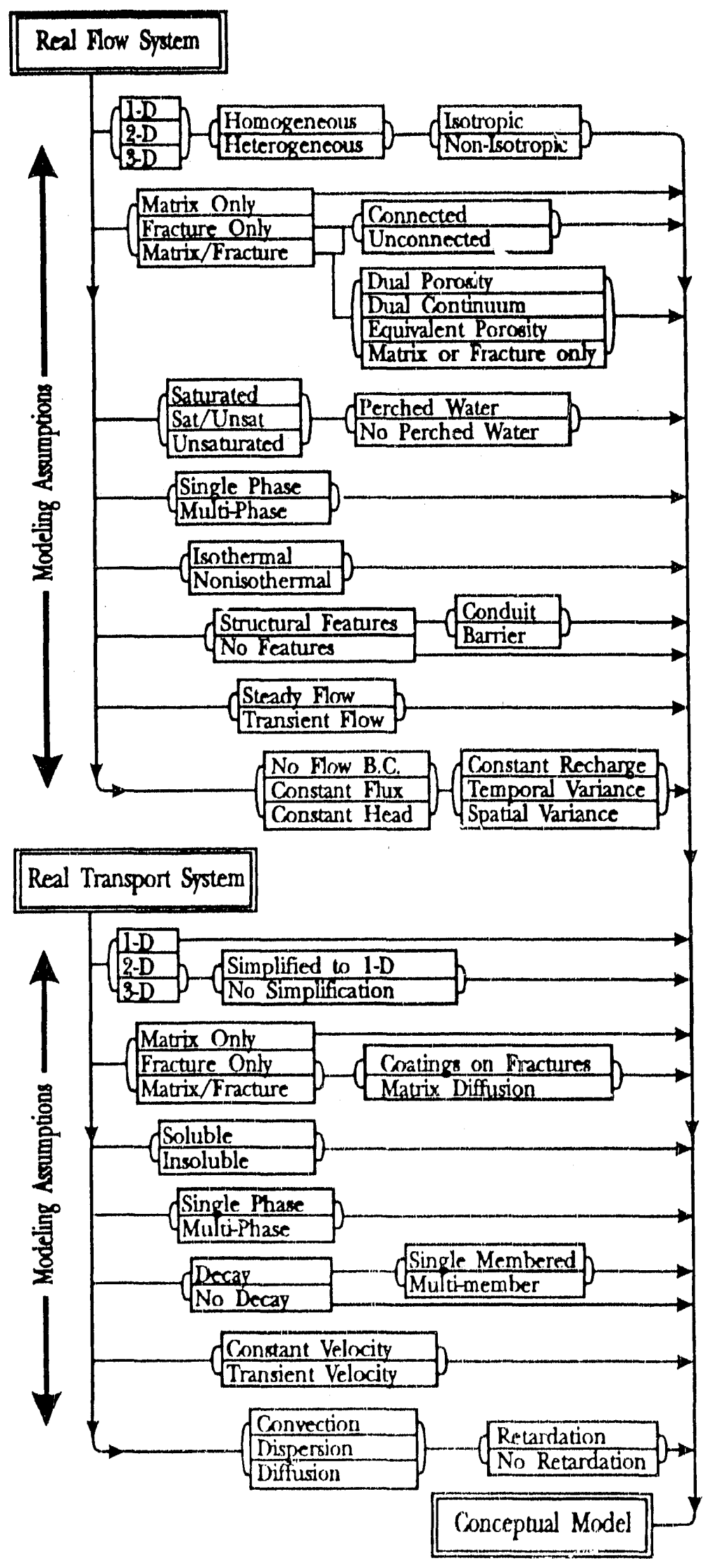

Figure 2.1. Generalized Flow Chart of the Major Assumprions Needed to Develop a Conceptual Model for an Unsaturated, Fractured Flow System 
detailed in order to allow for the consideration of all the assumptions, both implicit and explicit, that need to be made.

Although Figure 2.1 depicts a sequential decision-making process for developing the conceptual model, this is not necessarily the case. For example, the decision of whether flow is fracture dominated, matrix dominated, or a combination of the two does not depend on the dimensionality of the model. Rather, several of the modeling assumptions are made in parallel and not in series. The assumption of whether or not there exists resistance to flow and transport across the fracture/matrix interface, though, obviously requires a prior assumption that both fracture and matrix play a role in flow and transport. The use of a flow chart provides a systematic method for documenting assumptions.

Specifically, some of the key assumptions that go into the development of flow and transport conceptual models for HLW disposal in unsaturated, fractured media are

- dimensionality (one-, two-, or three-dimensional);

- steady-state or transient flow conditions;

- isothermal versus nonisothermal;

- single phase or multiphase flow and transport;

- matrix and/or fracture flow and transport;

- degree of interaction between the matrix and the fractures (for example, do fracture coatings impact matrix/fracture transfer for flow and transport);

- interconnectedness of fracture networks;

- structural features (e.g., faults);

- stratigraphy (i.e., number of hydrogeologic units and dip);

- boundary and initial conditions; and

- solute retardation mechanisms.

This is by no means a complete list of all the considerations that go into the development of a conceptual model. The assumptions that go into each conceptual model will be not only site specific, but also purpose specific. Note that this list does not include assumptions concerning parameter values and their distributions because linese are really beyond our definition of conceptual model. Also, some of these 
assumptions are generic for the development of flow and transport modeling in any medium and not just unsaturated and fractured media.

\subsection{Summary of Conceptual Models Chosen}

As stated earlier, each of the alternative conceptual models in this investigation is based on the same system geometry, boundary conditions, and parameter values (i.e., material properties), but is differentiated from the rest by fundamentally different assumptions of the flow and transport mechanisms in the system. A schematic illustrating the basic stratigraphy and boundary conditions is presented in Figure 2.2. All of the conceptual models chosen assume a spatially and temporally uniformly distributed flux at the repository horizon equal to $0.1 \mathrm{~mm} / \mathrm{yr}$. Steady-state ground water flow through a onedimensional system, from the base of the repository to the water table, was assumed. Five of the six models assumed the fifteen hydrogeologic layers or units shown in Figure 2.2. The sixth model assumed an equivalent four-layer stratigraphy based on average properties from the fifteen-layer case. Only four radionuclide species $\left({ }^{(*)} \mathrm{T}:{ }^{129} \mathrm{I},{ }^{135} \mathrm{Cs}\right.$, and ${ }^{237} \mathrm{~Np}$ ) were released from the repository and transported. The transport model assumes a single, dominant, nonbranching transport path. Radionuclide retardation factors were based on the distribution coefficient $\left(K_{d}\right)$ for each radionuclide. No other chemical reactions were included. Gas phase transport was also not included. The final result of the simulations was total integrated release of radionuclides at the water table.

The conceptual models chosen are nominally distinguished in terms of one or two fundamental assumptions. These alternative conceptual models were chosen because they address some fundamental assumptions of flow and transport that are considered critical to site performance for a site located in an unsaturated, fractured medium. The different conceptual models are described below.

\section{(1) Matrix-dominated flow and transport}

This is a single-continum model that assumes that all the ground water flux through the system occurs only in the porous matrix. This implicitly assumes that either any water that enters fractures is immediately imbibed by the matrix or that water never enters the fractures. The former case would require that the resistance to flow across the fracture face into the matrix be negligible, and that no transfer is allowed from the matrix to the fracture. Given certain materials, these assumptions may be reasonable for low fluxes; under such conditions, water can be held in the unsaturated matrix by capillary suction forces. Also, under low infiltration conditions, pulses of infiltrating water may be dampened spatially and temporally before they reach the repository horizon. As a result of these flow assumptions, solutes in the liquid phase can only be transported through the matrix.

(2) Eracture-dominated flow and transport

This is another single-continum model; however, this model assumes that all the ground water flux through the system occurs only in the fractures. If the model does not include 


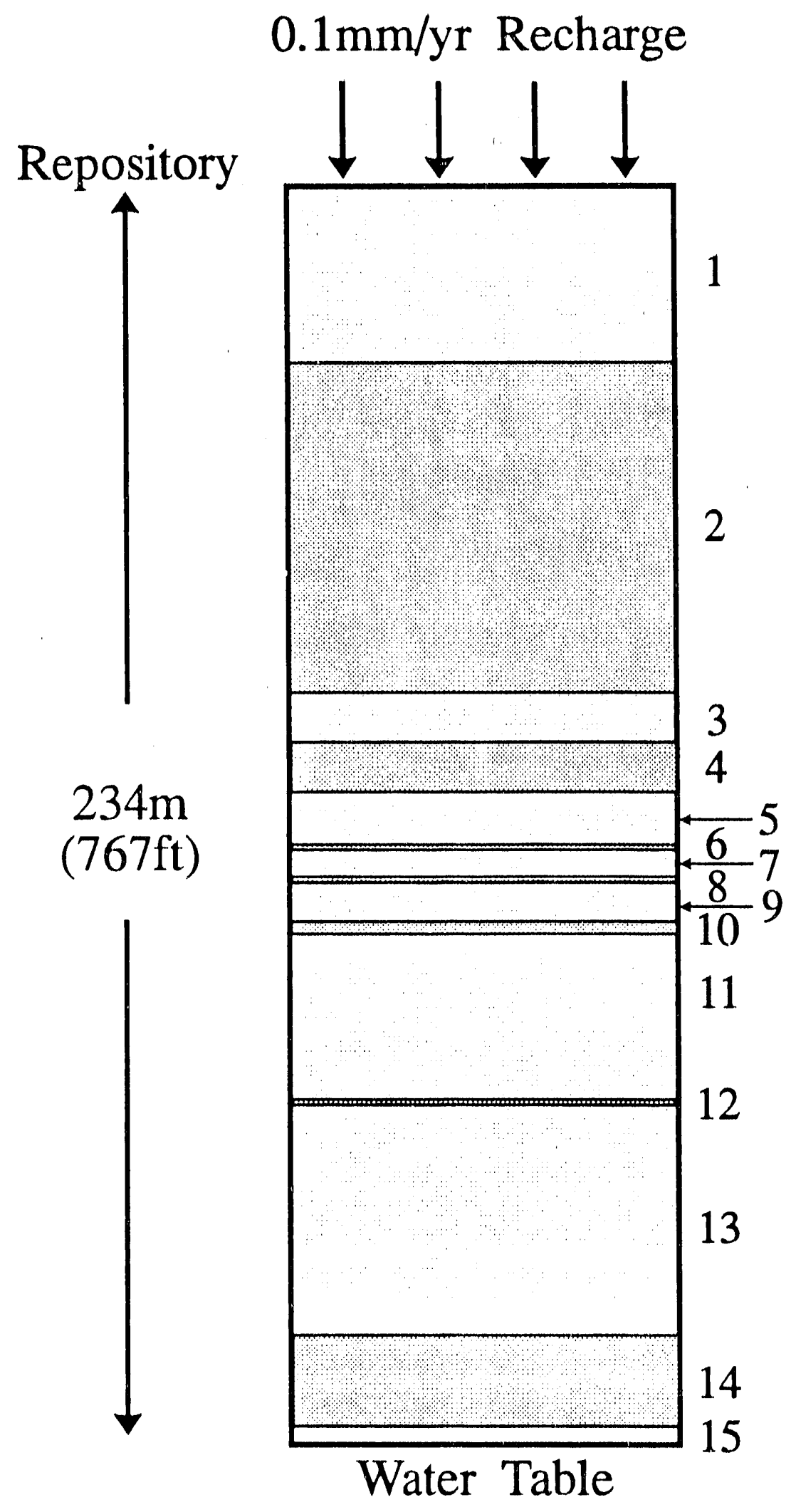

Figure 2.2. Basic Stratigraphy and Boundary Conditions Assumed for Alternative Conceptual Models 
an interacting matrix, then it implicitly assumes that none of the water that enters fractures is imbibed by a matrix. Because the system is not fully saturated throughout, this assumption implies that the resistance to flow across the fracture face into the matrix is extremely large. This could be the result of coatings on the fracture face or the inability of water to wet the matrix rock (i.e., capillary suction is not present if water does not wet the surface). Fracture dominated flow could also be conceptualized for a system in which a given flux through the fractures had been established and then the net flux from fracture to matrix was equal to zero. This would probably only oceur in a system that was effectively saturated. This model also implicitly assumes that the fractures in the system are connected throughout. This conceptual model assumes that transport of radionuclides occurs only in the fractures. Also retardation of radionuclides was assumed not to occur in the fracture continumm (that is, fracture retardation factors were set equal to 1 ).

(3) Fracture dominated flow and transport, but with matrix diffusion of radionuclides The ground water flow mathematical model is identical to the second model described above. However, conceptually, immobile matrix water is assumed to play a role in radionuclide transport in this model. The presence of the immobile phase provides a storage volume for which solutes can diffuse in and out of (termed "matrix diffusion"). Radionuclidas may also be sorbed onto the matrix rock and consequently be retarded whereas they are conceptualized as not being retarded in the fractures. Transport of radionuclides in and out of the matrix is modeled as a linear function of the concentrations in the fracture and matrix water, and is assumed directly proportional to a mass-exchange coefficient. The mass-exchange coefficient is a measure of the resistance to transport across the fracture/matrix interface.

\section{(4) Simulaneous matrix and fracture flow and either matrix or fracture transport}

This is a dual-continuum flow model assuming that the flux through the system occurs in both the fractures and the matrix simultaneously. The amount of water that transfers from fracture to matrix (or matrix to fracture) is a function of the pressure difference across the fracture/matrix interface and a transfer factor that indicates either the propensity or resistance to flow across this interface. Note that the flow transfer factor is not the same parameter as the transport mass exchange coefficient. Solute transport at any given point along the transport path, however, only occurs in either the fracture or the matrix, but not both simultaneously. Transport can switch from fracture to matrix (or matrix to fracture), from one point to the next along the path. Transport is assumed to occur in the medium (fracture or matrix) that has the highest pore velocity. For transport modeling, the medium (fracture or matrix) in which no transport is oceurring is considered immobile. However, transfer of dissolved radionuclides from the mobile ligund to the immobile liguid (as in model 3) is not comsidered in this model. Again, retardation is assumed mot to occur in the fractures.

(5) Simmlaneous matrix and fracture flow and equivalent-porous-medium transport This ground water flow conceptual model is identical to the dual-eontinum model used in the fourth model described above. However, radionuclide tramsport is described using 
an equivalent-porous-medium approximation. The equivalent-porous-medium approximation uses single, equivalent (combined) values for the matrix and fracture transport velocities and retardation factors. That is, matrix and fracture velocities at each point along the migration path are combined to produce a single, equivalent velocity at that point. The model assumes that a concentration equilibrium always exists between the matrix and fracture and that there exists zero resistance to transport across the matrix/fracture interface. Retardation factors for the fractures were assumed to equal to 1. Erickson et al. (1986) and Dudley et al. (1988) provide some guidance for the conditions under which an equivalent-porous-medium approach is applicable. Leigh (1991) has demonstrated the use of the equivalent-porous-medium approach for transport modeling using the NEFTRAN code.

(6) An alternative stratigraphic representation of the hydrogeologic system different from the stratigraphy used in the five prior conceptual models

A dual-continuum ground water flow model similar to the fourth model described above was assumed, but with a simplified hydrogeologic stratigraphic representation of the system. The distance from the repository to the water table remained the same; however, the fifteen hydrogeologic units used in the previous five conceptual models were combined to form four "equivalent" units. The properties in the four equivalent layers were derived as arithmetic averages of the properties in the layers from which they were composed. Radionuclide transport was treated in the same manner as in the fourth conceptual model.

A schematic representation of the alternative conceptual models is presented in Figure 2.3 . 

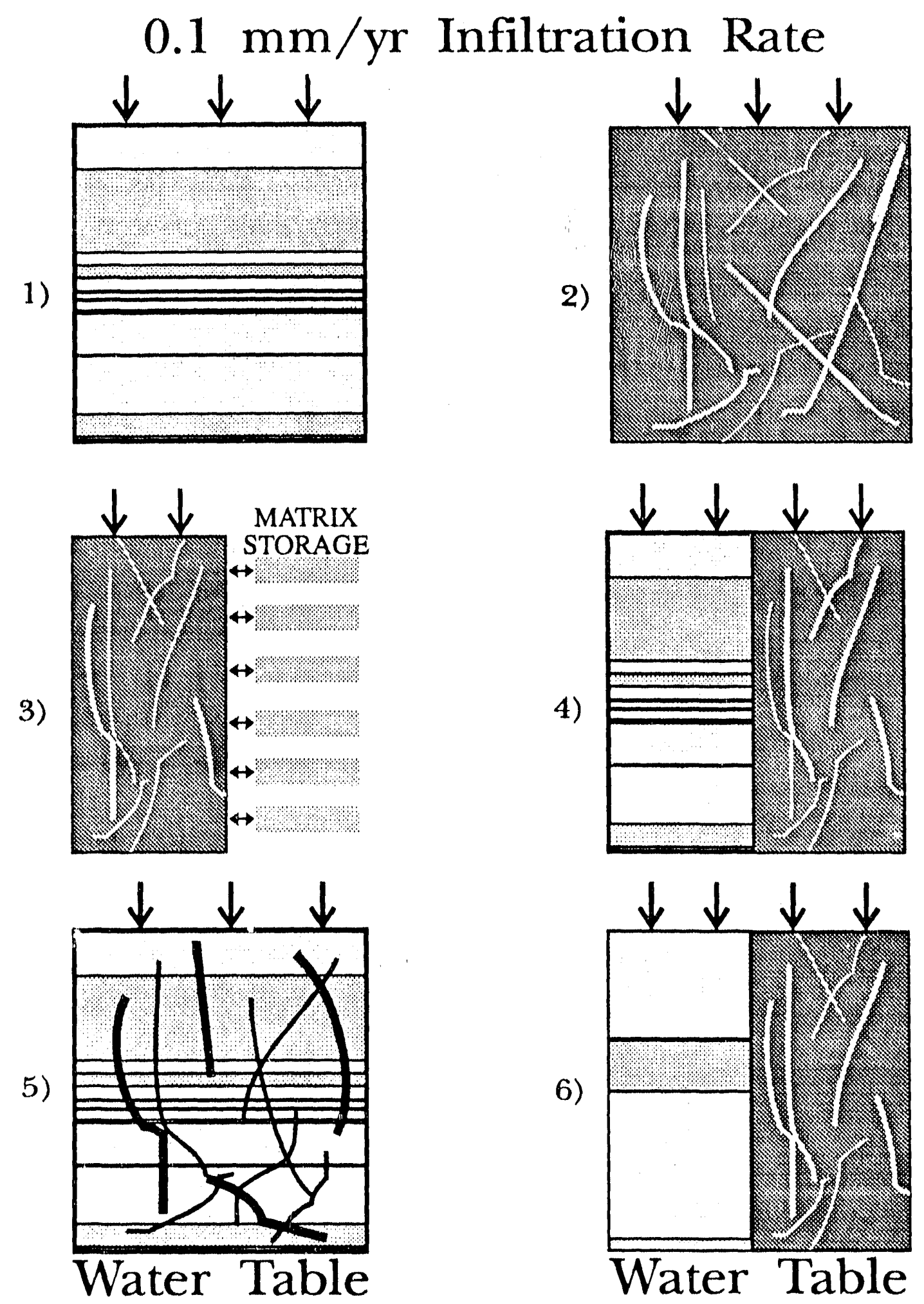

1) All Matrix

3) Fracture w/ Matrix Diffusion

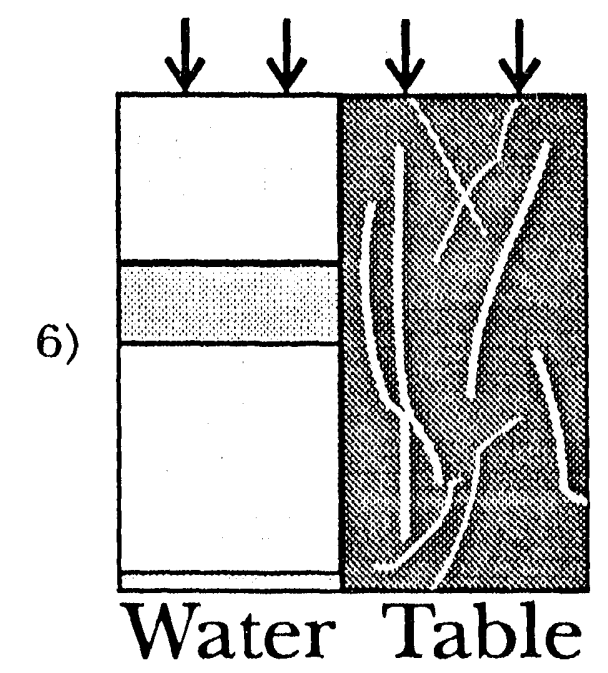

5) Equivalent Porous Medium

2) All Fracture

4) Dual Continuum

6) Four-Layer Stratigraphy

Figure 2.3. Schematic Representation of Conceptual Models Tested 
an equivalent-porous-mediun approximation. The equivalent-porous-medium approximation uses single, equivalent (combined) values for the matrix and fracture transport velocities and retardation factors. That is, matrix and fracture velocities at each point along the migration path are combined to produce a single, equivalent velocity at that point. The model assumes that a concentration equilibrium always exists botween the matrix and fracture and that there exists zero resistance to transport across the matrix/fracture interface. Retardation factors for the fractures were assumed to equal to 1. Erickson et al. (1986) and Dudley et al. (1988) provide some guidance for the enditions under which an equivalent-porous-medium approach is applicable. Leigh (199) lias demonstrated the use of the equivalent-porous-medium approach for transport modeling using the NEFTRAN code.

(6) An allernativestratigraphic representation of the hydrogeologic system different from the stratigruphy used in the five prior conceptual models

A dual-continuum ground water flow model similar to the fourth model described above was assumed, hut with a simplified hydrogeologic stratigraphic representation of the system. The distance from the repository to the water table remained the same; however, the fifteen hydrogeologic units used in the previous five conceptual models were combined to form four "equivalent" units. The properties in the four equivalent layers were derived as arithmetic averages of the properties in the layers from which they were composed. Radionuclide transport was treated in the same manner as in the fourth conceptual model.

A schematic representation of the alternative conceptual models is presented in Figure 2.3 . 


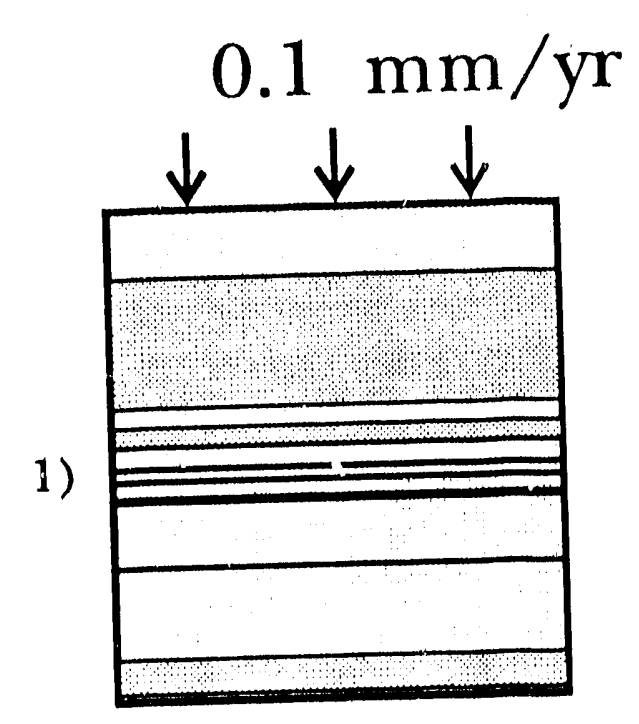

\section{Infiltration Rate}

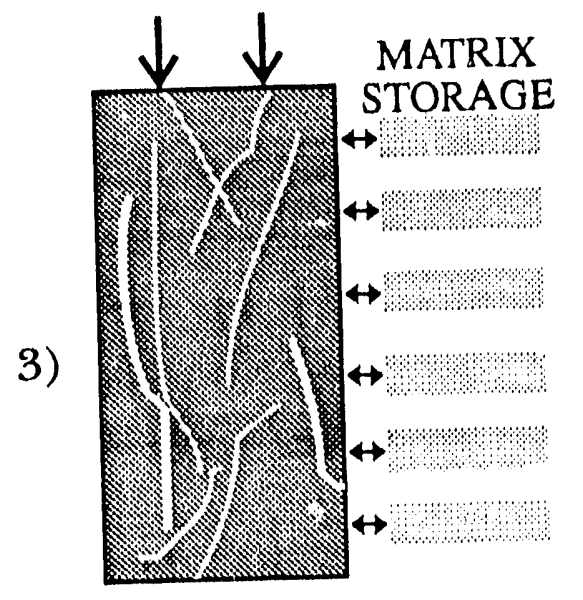

2)
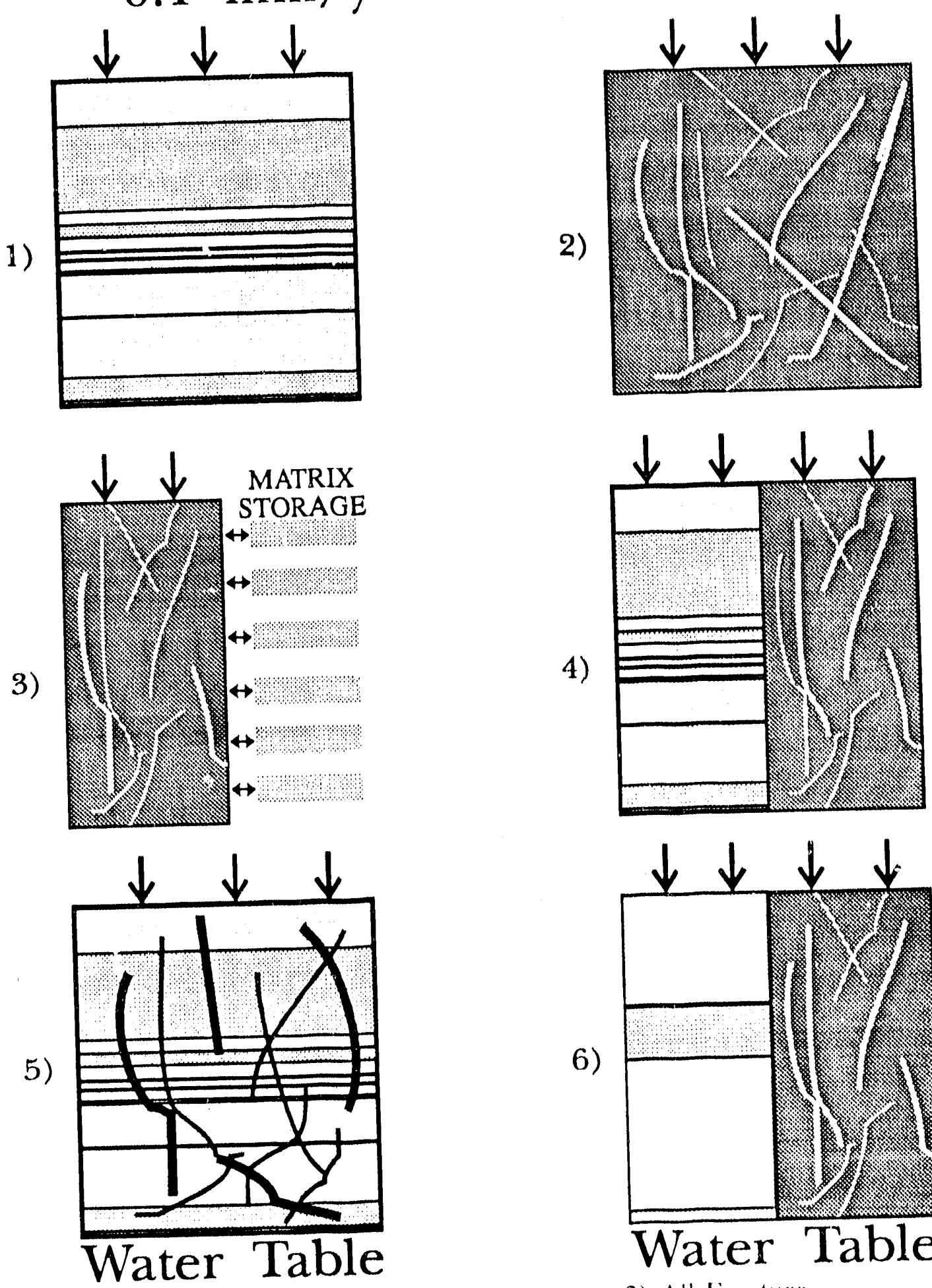

4)

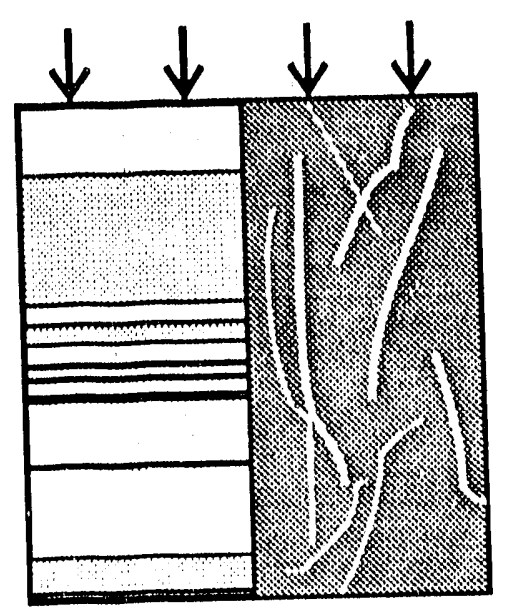

1) All Matrix

3) Fracture w/ Matrix Diffusion

5) Equivalent Porous Medium

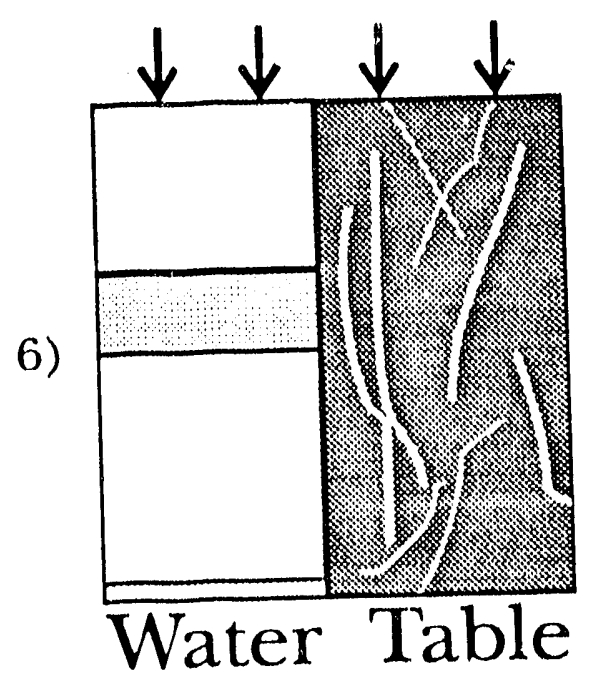
2) All Fracture
4) Dual Continumm
6) Four-I ayer Stratigraphy

Figure 2.3. Schematic Representation of Conceptual Models 'Tested 


\subsection{PROCEDURE FOR ANAI,YSES}

\subsection{Mathematical and Numerical Models}

Quantitative analysis of ground water flow and radionuclide transport for each of the conceptual models was conducted using the DCM3I) (Updegraff and lee, |(9)1) ground water flow and NEFTRAN II (Olague et al., 1991) radionuclide transport computer codes. A description of each of these mathematical/numerical models is provided below along with information specific to these conceptual models.

\subsubsection{Ground Water Flow Analysis}

DCM3D (Dual Continum Model 3D) (Updegraff and Lee, 19(91) was used to simulate the flow field for all the conceptual models described in Section 2.3. DCM3D is a computer code designed to model three-dimensional ground-water flow in an unsaturated, fractured, porous medium. The model implemented in DC.M3D uses a dual-continum concept to model flow. One continuum represents the fractures and the other represents the porous matrix. Flow in the two continua are coupled by a transfer term which depends on the pressure head difference hetween the two continua, the saturated and relative hydraulic conductivity of the porous matrix, the fracture specific surface, and the fracture spacing.

DCM3D solves the following ground-water flow equations for the porous matrix and fracture continua, respectively:

$$
C_{m} \frac{\partial h_{m}}{\partial t}=\nabla \cdot\left(\underline{\mathbf{K}}_{\mathbf{m}}\left(\nabla h_{m}+\nabla z\right)\right) \cdots \Gamma+Q_{m}
$$

and

$$
C_{f} \frac{\partial h_{f}}{\partial t}=\nabla \cdot\left(\underline{\mathbf{K}}_{\underline{g}}\left(\nabla h_{f}+\nabla z\right)\right)+\Gamma+Q_{f}
$$

where

$h_{\mathrm{m}}=$ pressure head in the porous matrix continuum

$h_{\mathrm{f}}=$ pressure head in the fracture continuum

$C_{\mathrm{m}}=$ specific storage coefficient of the porous matrix continum

$C_{\mathrm{r}}=$ specific storage coefficient of the fracture continuum

$\underline{\mathbf{K}}_{\mathrm{m}} \quad=$ hydraulic conductivity tensor for the porous matrix continuum

$\underline{\mathbf{K}}_{\mathrm{f}} \quad=$ hydraulic conductivity tensor for the fracture continuum

$Q_{\mathrm{m}}=$ volumetric porous matrix continuum source term per unit volume of continua 
$Q_{1}=$ volumetric fracture continumm source term per unit volume of continua

$\Gamma \cdot=$ porous matrix continumm to fracture continumm tanafier term

$z \quad=\quad$ direction distance

$1=$ time.

The porons" matrix and fracture continua hydraulic conductivities are related to the salturated and relattive hydranlic conductivities as follows:

$$
\underline{\mathbf{K}}_{\underline{m}}=\underline{\mathbf{K}}_{\underline{\underline{m}}} K_{r m}^{\prime}\left(h_{m}\right)
$$

and

$$
\underline{\mathbf{K}}_{\mathfrak{g}}=\underline{\mathbf{K}}_{\underline{\underline{s}}} k_{r j}\left(h_{j}\right)
$$

where

$\underline{\mathbf{K}}_{\text {sm }}=$ siturated hydraulic conductivity tensor of the porous matrix $\underline{\mathbf{K}}_{\mathbf{r}}=\begin{aligned} & \text { continuum } \\ & \text { saturated hydraulic conductivity tensor of the fracture continuum }\end{aligned}$ $K_{r m}=$ relative hydraulic conductivity of the porous matrix continuum $K_{\mathrm{ri}}=$ relative hydraulic conductivity of the fracture continuum

The porous matrix and fracture continua relative hydraulic conductivities are defined by the van (Genuchten relationships (see Equation 3-7 and Equation 3-8) and, therefore, depend on the porous matrix and fracture continua pressure head, respectively. The porous matrix and fracture continua specific storage coefficients are defined, respectively, as:

$$
C_{m}^{\prime} n_{m} S_{m} \beta+S_{m} \alpha_{b_{m}}\left(1-n_{m}\right)+n_{m} \frac{\partial S_{m}}{\partial h_{m}}
$$

and

$$
\left(, \quad n, S, \beta, S, \alpha_{1,},\left(1, n_{1}\right)+n_{1} \frac{\partial S_{1}}{\partial h_{1}}\right.
$$

where

$$
\begin{aligned}
& S_{11}=\text { porous malrix continumm degree of saturation } \\
& s_{1}=\text { fracture continum degree of saluration } \\
& \|_{111} \quad \text { perous malrix contimumum porosity } \\
& n_{1}=\text { fracture continum porosity } \\
& \alpha_{b_{m}}=\text { porous matrix comlinumm compressibility } \\
& \alpha_{b,}=\text { fracture contimum compressibility } \\
& \beta \quad \therefore \quad \text { waller compressibility. }
\end{aligned}
$$


The porous matrix and fracture degrees of saturation are defined by the van Genuchten relationship (see Equation 3-7) and, therefore, are dependent on the pressure head in the porous matrix and fractures, respectively.

DCM.3I) uses the var Genuchten equations (van Genuchten, 1980) to define the saturation and relative hydraulic conductivity characteristic curves for both the matrix and fractures. These equations are:

$$
S_{c^{\prime}}=\frac{S-S_{r}}{1-S_{r}}=\left(\frac{1}{1+\left(\alpha h_{c}\right)^{n}}\right)^{\prime \prime}
$$

and

$$
k_{r}=\sqrt{S_{t^{\prime}}}\left(1-\left(1-S_{t^{\prime}}^{1 / m}\right)^{m}\right)^{2}
$$

where

$S$ is the degree of saturation;

$S_{c}$ is the effective salturation;

$S_{r}$ is the residual saturation;

$h_{c}$ is the capillary head;

$k_{\mathrm{r}}$ is the relative hydraulic conductivity.

$m, n$, and $\alpha$ are parameters where $m$ is related to $n$ by $m=1-1 / n$. The van Genuchten equations are assumed applicable for both matrix and fractures.

The transfer term $(\Gamma)$ depends on the fracture specific surface $\left(A_{s}\right)$, a pseudo-length between the matrix centroid and the fractures $(l)$, the matrix saturated hydraulic conductivity $\left(K_{\mathrm{sm}}\right)$, the matrix relative hydraulic conductivity $\left(K_{\mathrm{rm}}\right)$ and the difference between the matrix pressure head $\left(h_{m}\right)$ and the fracture pressure head $\left(h_{f}\right)$ (Updegraff and Lee, 1991). The transfer term is estimated as:

$$
I^{\prime}=A_{s} \frac{K_{s m} K_{r m}}{l}\left(h_{f}-h_{m}\right)
$$

There is a lack of datia on the fracture specific surface and the pseudo-length parameter. Specific surface is defined as surface area per unit volume. If a block with dimensions $\Delta x \Delta y \Delta z$ has f vertical fractures per unit length (e.g. fractures per meter), then the fracture specific surface becomes:

$$
A_{1}=\frac{2(f \Delta x) \Delta y \Delta z}{\Delta x \Delta y \Delta z}=2 f
$$


where

$\begin{array}{ll}\Delta x \Delta y \Delta z & =\text { the volume of the block } \\ \Delta y \Delta z & =\text { the area of one side of the fracture } \\ f \Delta x & =\text { the number of vertical fractures in the block. }\end{array}$

The number "2" enters into the equation because flow across 'moth sides of the fracture must be considered.

If it is assumed that fractures are equally spaced and that the centroid between two fractures is were the porous matrix pressure occurs, then

$$
l=\frac{1}{2 f}
$$

Therefore,

$$
\frac{A_{s}}{l}=4 f^{2}
$$

and has dimensions of length ${ }^{2}$. Finally, Equation 3-12 can be substituted into Equation 3-9 to yield:

$$
\Gamma=4 f^{2} K_{s m} K_{r m}\left(h_{f}-\dot{h}_{m}\right)
$$

The fracture frequency, $f$, is provided in Barnard and Dockery (1991). The term $A_{\mathrm{s}} K_{\mathrm{sm}} / l$, or $4 f^{2} K_{s m}^{\prime}$, is called the transfer factor and is tabulated in Table 3.1. The same result as Equation 3-12 can be obtained for horizontal fractures.

General. Flow in a vertical, one-dimensional column was modeled. Data are based on measurements of USW G-4 drill hole core from Yucca Mountain (see Barnard and Dockery, 1991). The modeled column extended from the water table (elevation $730.6 \mathrm{~m}$ above mean sea level) to the bottom of the repository (elevation $960.0 \mathrm{~m}$ ). The elevation difference between the water table and the repository bottom was $229.4 \mathrm{~m}$. In all the models, the downward direction was considered as the positive direction.

All conceptual models were run through a transient solution to go from an initially zero water-flux condition to steady-state. Steady-state was assumed when the total Darcy flux through the matrix and fractures was equal to the recharge rate of $0.1 \mathrm{~mm} / \mathrm{yr}$.

The same boundary conditions and initial conditions were used for all the conceptual model simulations. Water was injected at the repository boundary at a rate of ().1 $\mathrm{mm} / \mathrm{yr}$ to simulate recharge. The matrix and fracture pressure heads were set at ().() $\mathrm{m}$ at the water table; that is, saturated conditions in both the matrix and fractures 
at the water table. The initial pressure head in each grid block was set to the negative of the distance of the grid block center above the water table. This initial pressure head caused a zero water flux throughout the column at the beginning of the simulation.

For purposes of this study, fifteen distinct stratigraphic layers exist between the water table and the repository. These layers are distinct because of their matrix hydrologic properties rather than their fracture ones. Their names, elevations, and hydrologic properties are summarized in 'Table 3.1. The data were taken from the base case specification for this problem (see Barnard and Dockery, 1991).

Matrix-dominated flow model. Thirteen stratigraphic layers were used in the matrixdominated flow model. Layer 3, Layer 4, and Layer 5 were combined into one layer and assigned the matrix hydrological properties of Layer 4 . This was done to ease the computational burden of the problem.

The computational problems were caused by two factors. First, Layer 4 had such a high matrix saturated hydraulic conductivity compared to Layer 3 and Layer 5 . Second, because Layer 3's saturated hydraulic conductivity was less than the recharge rate, an inverted (perched) water table formed there. In order to move the water table, DCM3D used very small time steps and this required large amounts of computer time. In order to reduce the computer time, the three layers were combined. Combining the three layers into one eliminated the inverted water table problem. It was believed that assigning the hydrologic properties of Layer 4 to the combined layer would provide faster travel tirnes because the saturated hydraulic conductivity of Layer 4 is six orders of magnitude higher than that of Layer 3 or Layer 5. Thus, it was believed the this combined layer would provide a conservative estimate of the travel time.

The grid consisted of 278 grid blocks. The grid block assignments and thicknesses are shown in Table 3.2. The finer grid spacing in Layer 5 occurs at the bottom of the layer at its boundary with Layer 6 . The coarser grid spacing occurs at the top of the layer against the boundary of Layer 4.

Fracture-dominated flow model. Five stratigraphic layers were used in this model. The top two layers, Layer 1 and Layer 2, were combined into one layer. These two layers were combined because they had the same fracture hydrological properties. The bottom ten layers, Layer 6 through layer 15 were combined into another layer for the same reason. This combining of layers was done as a matter of convenience only. Layer 3 , Layer 4, and Layer 5 remained as distinct layers.

The grid consisted of 1000 grid blocks, which ranged in thickness from a minimum of $0.01 \mathrm{~m}$ to a maximum of $0.25 \mathrm{~m}$. The smaller grid block thickness were located at the bottoms of each of the five layers. The thicknesses of the grid blocks are shown in Table 3.3. 


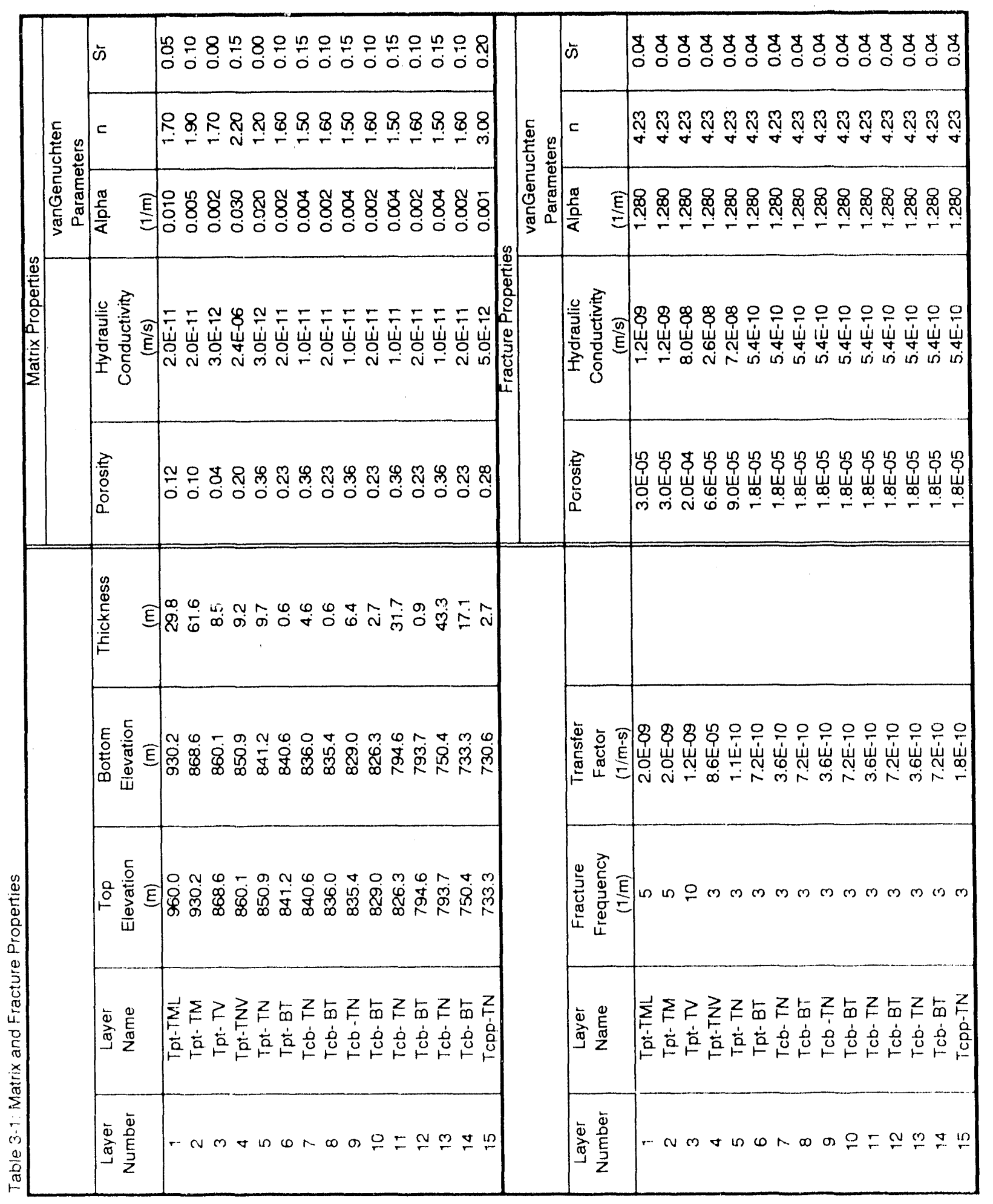


Table 3-2: Grid Block Thicknesses for Matrix Flow Problem

\begin{tabular}{|c|c|r|r|}
\hline Layer No. & $\begin{array}{c}\text { Number of } \\
\text { Grid Blocks }\end{array}$ & $\begin{array}{c}\text { Thickness of } \\
\text { Grid Block } \\
(\mathrm{m})\end{array}$ & $\begin{array}{c}\text { Thickness of } \\
\text { Layering } \\
(\mathrm{m})\end{array}$ \\
\hline 1 & 8 & 3.725000000 & 29.80000 \\
\hline 2 & 32 & 1.925000000 & 61.60000 \\
\hline 3 & 32 & 0.265625000 & 8.50000 \\
\hline 4 & 16 & 0.575000000 & 9.20000 \\
\hline 5 & 56 & 0.151562500 & 8.48750 \\
& 8 & 0.075781250 & 0.60625 \\
& 16 & 0.037890625 & 0.60625 \\
\hline 6 & 2 & 0.300000000 & 0.60000 \\
\hline 7 & 4 & 1.150000000 & 4.60000 \\
\hline 8 & 4 & 0.250000000 & 1.00000 \\
\hline 9 & 8 & 0.750000000 & 6.00000 \\
\hline 10 & 4 & 0.675000000 & 2.70000 \\
\hline 11 & 32 & 0.990625000 & 31.70000 \\
\hline 12 & 4 & 0.225000000 & 0.90000 \\
\hline 13 & 32 & 1.353125000 & 43.30000 \\
\hline 14 & 16 & 1.068750000 & 17.10000 \\
\hline 15 & 4 & 0.675000000 & 2.70000 \\
\hline \hline Totals & 278 & & 229.40000 \\
\hline
\end{tabular}




\begin{tabular}{|c|c|c|c|c|}
\hline & $0 \quad \pi$ & 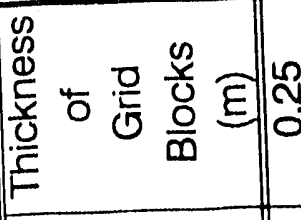 & 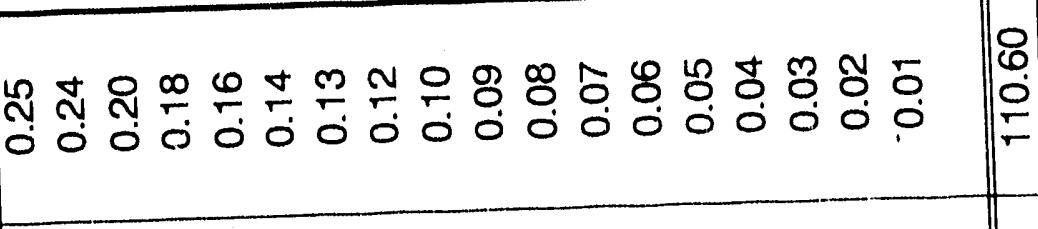 & $\left|\begin{array}{l}0 \\
0 \\
0 \\
\hdashline \\
0\end{array}\right|$ \\
\hline & गे & 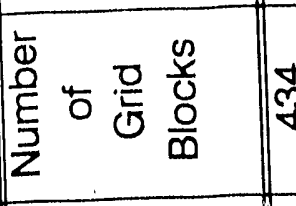 & 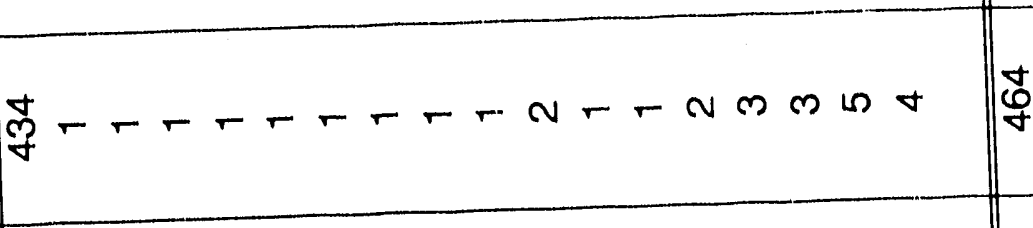 & $\mid \begin{array}{l}0 \\
0 \\
0 \\
\vdots\end{array}$ \\
\hline & ما & 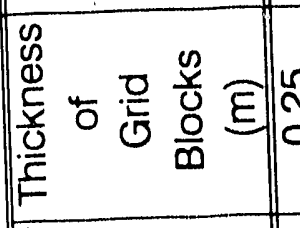 & 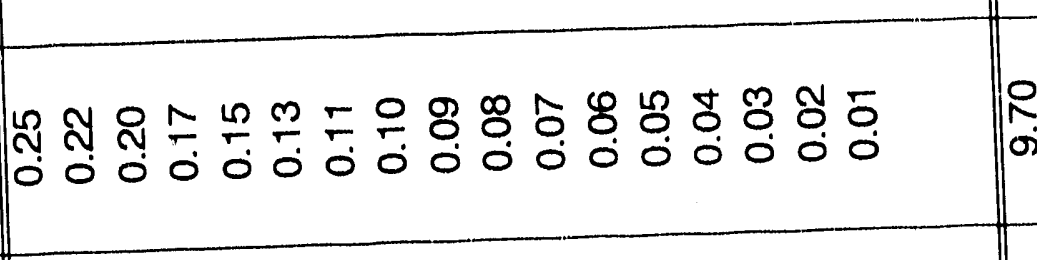 & $\left|\begin{array}{l}R \\
\sigma^{\prime}\end{array}\right|$ \\
\hline ל. & 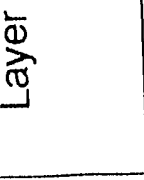 & 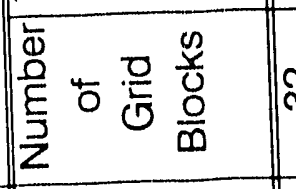 & $m-t-t-t-t-h m m \theta$ & $\left|\begin{array}{l}\infty \\
1\end{array}\right|$ \\
\hline 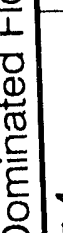 & $\theta$ & 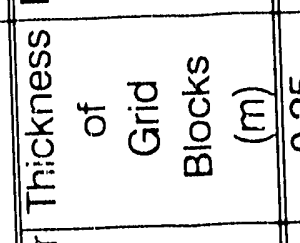 & 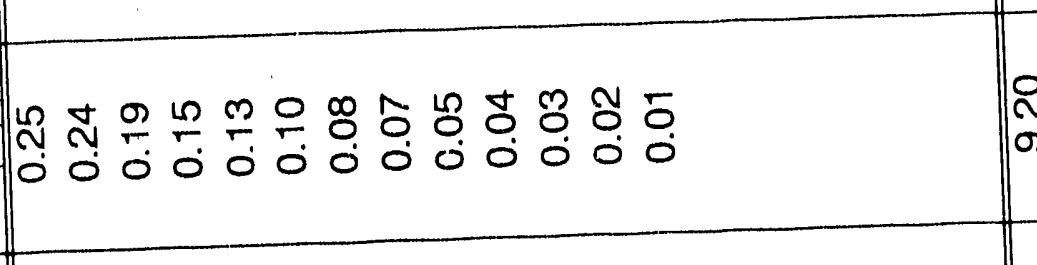 & 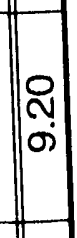 \\
\hline . & बे & 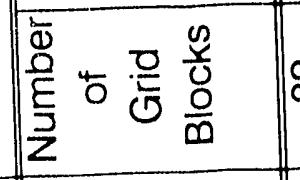 & $m-r-r-m-m n$ & $\mid \infty$ \\
\hline \begin{tabular}{l}
5 \\
\multicolumn{1}{c}{} \\
0 \\
0 \\
0 \\
0 \\
0 \\
0 \\
0 \\
0
\end{tabular} & & 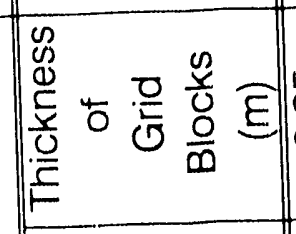 & 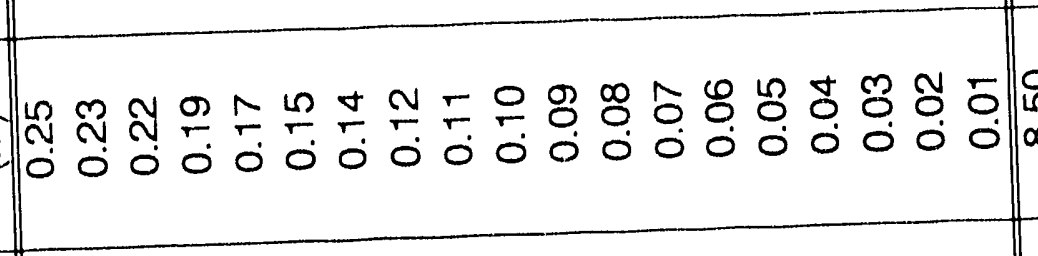 & 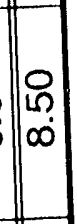 \\
\hline 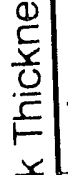 & 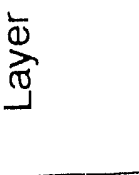 & 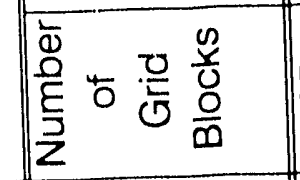 & 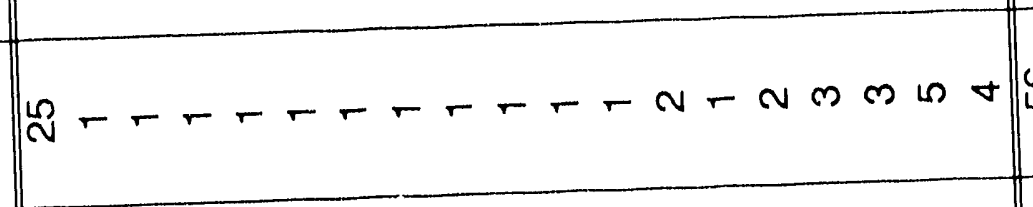 & 道 \\
\hline $\begin{array}{l}\overline{0} \\
\frac{0}{0} \\
0 \\
0 \\
0 \\
\dot{0} \\
\dot{m}\end{array}$ & $=2$ & 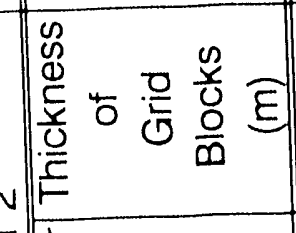 & 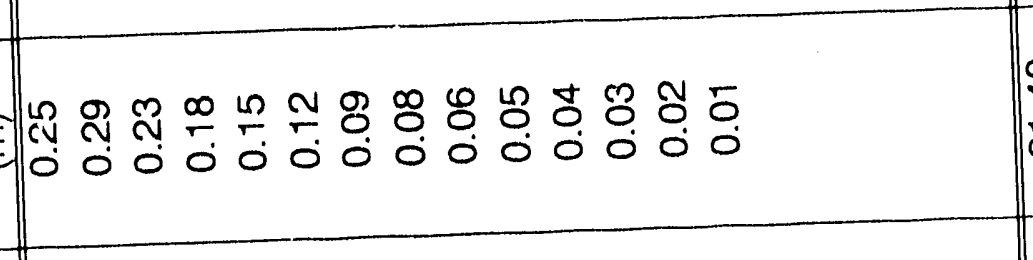 & $\mid \begin{array}{c}q \\
\dot{\sigma} \\
\dot{\sigma}\end{array}$ \\
\hline $\begin{array}{l}m \\
\dot{m} \\
\frac{0}{0} \\
\frac{0}{0} \\
\leftarrow\end{array}$ & 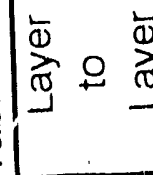 & 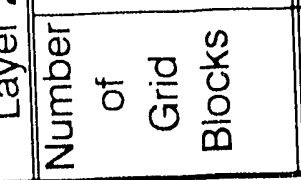 & 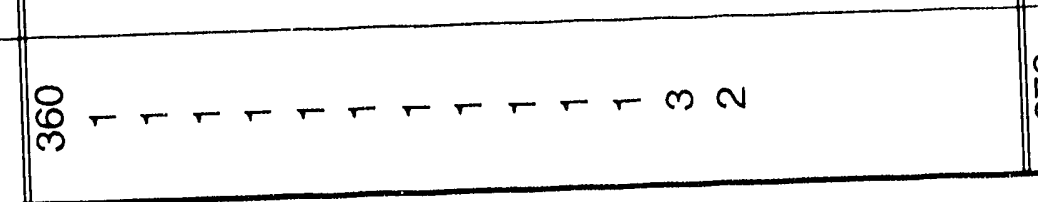 & $\mid \begin{array}{l}0 \\
\stackrel{0}{m}\end{array}$ \\
\hline
\end{tabular}


Simultaneous matrix and fracture flow model. Fifteen stratigraphic layers were used in this conceptual model. The layers and their hydrologic properties are shown in Table 3.1. Three cases were studied for this model. The first case, called the "large case" in this report, used the transfer factors that appear in Table 3.1. The second case, called the "medium calse", used transfer factors that were 1/10 those presented in Table 3.1. The third case, called the "small case", used transfer factors that were 1/100) those presented in Table 3.1. The transfer factors were reduced to simulate features, such as fracture surface coatings, which may reduce water transfer between the fractures and the porous matrix. The grid spacing was the same as for the matrix-dominated flow model (Table 3.2).

The recharge into the top of the grid block was divided between the matrix and the fractures based on the unsaturated hydraulic conductivity of the matrix and the fractures. The amounts going into the matrix and the fractures are:

$$
r_{m}=\frac{r K_{m}\left(h_{m}\right)}{K_{m}\left(h_{m}\right)+K_{f}\left(h_{f}\right)}
$$

and

$$
r_{f}=\frac{r K_{f}\left(h_{f}\right)}{K_{m}^{\prime}\left(h_{m}\right)+K_{f}\left(h_{f}\right)}
$$

respectively, where $r$ is the total recharge, $r_{\mathrm{f}}$ is the recharge into the fractures, $r_{\mathrm{m}}$ is the recharge into the matrix, $K_{f}$ is the unsaturated hydraulic conductivity of the fractures, and $K_{\mathrm{m}}$ is the unsaturated hydraulic conductivity of the matrix. At the repository horizon, the infiltration into the matrix was much larger than that into the fractures. In fact, more than $99.99 \%$ of the recharge goes into the matrix because the matrix and fracture pressures at the repository are nearly the same and the relative hydraulic conductivity characteristic curves are much steeper for the fractures than for the matrix. Hence, at the repository horizon, the unsaturated hydraulic conductivity for the matrix is much higher than that for the fractures.

Alternative stratigraphic layering model. Four layers were used in the alternative stratigraphic layering model. In this model layer 1 and layer 2 were combined to form the first layer; Layer 3 through Layer 5 were combined to form the second layer; Layer 6 through Layer 14 were combined to form the third layer; and Layer 15 formed the fourth layer. The effective hydrologic properties of a given combined layer were estimated from the properties of the actual layers comprising the combined one. Arithmetic average properties were calculated after weighting the properties of the actual layers by their respective thickness. The grid spacing used for this model is presented in Table 3.4. The recharge into the matrix and fractures were determined from the unsaturated hydraulic conductivities of the matrix and the fractures as given by Equation 3-5 and Equation 3-6. The large transfer coefficient was used for this model. 
Table 3.4. Grid Block Properties for fiour-l alyer Stratigraphy flow Morlel

\begin{tabular}{|c|c|c|c|}
\hline Layer Number & $\begin{array}{c}\text { Number of Cirid } \\
\text { Blocks }\end{array}$ & $\begin{array}{c}\text { Thickness of Cirid } \\
\text { Block (m) }\end{array}$ & $\begin{array}{c}\text { 'Ihickness of } \\
\text { I alyer (m) }\end{array}$ \\
\hline 1 and 2 & 4() & $2.28 .50(1)(1)$ & (9) 1.4 \\
\hline 3 thru 5 & 128 & 0.2140625 & 27.4 \\
\hline 6) thru 14 & 112 & 0.9633929 & 107.9 \\
\hline 15 & 4 & $0.6750(0) 00$ & 2.7 \\
\hline Totals & 284 & & 229.4 \\
\hline
\end{tabular}

\subsubsection{Radionuclide Transport Analysis}

NEFTRAN II (NEtwork Flow and 'I'RANsport II) is a performance assessment code designed to conduct computationally efficient simulations of transport of multiple, nmembered (where $n \geq 1$ ) radionuclide chains through fractured, saturated and unsaturated media, across large distances, and over long simulation times.

The NEFIRAN II code uses the Distributed Velocity Method (DVM) (Campledl et al., $1981)$ to simulate convective-dispersive transport of radionuclides through a series of one-dimensional legs or stream tubes. For unsaturated zone transport, NLIFTRAN II was designed so that the transport migration path, mean pore velocities for each leg along the path, and satturations for each leg along the path would each be determined from an external flow calculation. For salurated zone transport, NISF"RAN II can internally calculate a flow network based on preseribed pressure head datat and determine a transport migration path through the network. However, NIER"TRAN II is intended to rely on sophisticated flow calculations external to the code to provide the neessiary ground water flow information, and on assumplions aboul solute transport to justify the use of the NISFTRAN II mathematical model.

To simulate transport, the DVM partitions the radionuclides within eatch leg into diserete packets, and decemines a distribution of packet velocities about the mean velocity, based on the mean retarded particle velocily and a dispersivily for each leg. Mean retarded particte velocity within a leg is the mean pore velocity divided by the particle retardation factor. Iegs along the migralion path can be designalled ats either single-

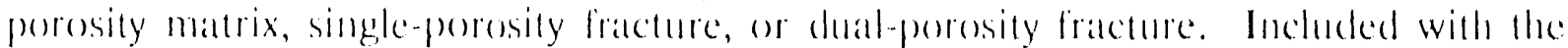
dual-porosity fratemre legs is an immobile mallix volume, into and oul of which mallix diffusion can be simulated. The equation geverming exchange by matrix diffusion for any 
given cell along the path is

$$
C_{m}^{\prime}(t+\Delta t) \quad \cdots \frac{\beta \Delta t}{n_{m} R_{m}}\left[C_{j}^{\prime}(t) \cdots C_{m}^{\prime}(t)\right]+C_{m}(t)
$$

where

$$
\begin{aligned}
& C=\text { radionuclide concentration, } \\
& \beta=\text { an exchange coefficient, } \\
& n=\text { porosity, } \\
& t=\text { time and, } \\
& R=\text { retardation factor. }
\end{aligned}
$$

The subscripts $m$ and $f$ denote matrix and fracture. Matrix diffusion is important because, in theory, the matrix can essentially act as a storage volume and enhance retardation of the radionuclides (Bonano et al., 1989).

Becaluse the spatial orientation of the transport legs in NEFTRAN II is neither specified by the user nor implied within the code, the orientation of the legs can be arbitrary. As a result, if a dominant, mon-branching, migration path (or paths) can be defined in two or three dimensions by a flow calculation external to NEFTRAN II, the program can simulate quasi multi-dimensional transport through this path. The models in this study did not utilize this capability as they were all one-dimensional and vertical.

Additional discussion of the mathematical, and numerical models used in NEFTRAN II can be found in I ongsine et al. (1987) and Olague et al. (1991).

Specifically, the transport analysis was based on the nominal system geometry described in Figure 2.2. The conceptualized system consisted of 15 hydrogeological units from the base of the proposed repository to the water table. The number and nature (i.e., fracture or matrix) of transport legs varied from model to model depending on the flow field. The transport migration path for NEFTRAN II was determined using a DCM3D post-processor (described in Section 3.2). A summary of the flow and transport conceptualized systems will be provided in Section 4.2 .

As was mentioned in Section 2.3, three fission products $\left({ }^{(x)} \mathrm{Tc},{ }^{121} \mathrm{I},{ }^{135} \mathrm{Cs}\right)$ and one actinide $\left({ }^{237} \mathrm{~N} p\right)$ were included in the transport simulations. The selection of these four radionuclides was made for several reasons. No short-lived nuclides (e.g., ${ }^{17} \mathrm{Sr},{ }^{1.37} \mathrm{Cs}$ ) were comsidered becallse of the expected long travel times. The half-lives for the selected radionuclides range from $2.15 \times 10^{5}$ years ("1) $\left.\mathrm{Tc}\right)$ to $1.6 \times 10^{7}$ years( ${ }^{129} \mathrm{I}$ ). Radionuclides with solubility-limited $\left({ }^{237} \mathrm{~Np}\right)$ and reaction-rate-limited $\left({ }^{(9)} \mathrm{Te},{ }^{129} \mathrm{I}\right.$, and 135 (s) dissolution mechanismos are included. Furthermore, ${ }^{125} \mathrm{Ic},{ }^{129} \mathrm{I}$ and ${ }^{13.5} \mathrm{Cs}$ have rapidrelease fractions, as well ats alteration-rate-controlled releases. Finally, these raddionuclides represent a range of sorption properties, ranging from non-sorbing ${ }^{221} \mathrm{I}, \mathrm{to}$ weikly sorbing "1" le and ${ }^{23 /} \mathrm{Np}, 10$ strongly sorbing ${ }^{135}$ ('s. These sorption properties are for mallix rock; because of uncertanty in fracture surface characteristics, all of the

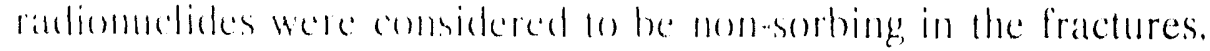


'The source term used was based on a continuous, 'wet-drip' watste-water contact process for mobilization of the radionuclides from the waste form (Apted et al, 1991). 'This mechanism considers the possibility that the flow field of water percolating through the tuff surrounding a waste container is such that the water is diverted into fractures which intersed the emplacement hole. Further, water soust then drip from the rock to the container, eventually causing perforations, through which water can enter the container. Alter the bottom of the container has also been breached, release from the waste form begins. Release curves for the four isotopes considered are shown in Figure 3.1. "\%r, ${ }^{129} 1$ and ${ }^{13.5} \mathrm{Cs}$ all have essentially the same source term except with different amplitudes. 'This source term was used for all of the conceptual models.

\subsection{Flow and Transport Coupling}

The DCMBD and NEFTRAN II codes are not directly linked to one another. Therefore, some post-processing of the DCM3D-generated flow field is required to produce a useable transport migration path for NEFI'IRAN II. This is described below.

The post-processor is an enhanced particle-tracking routine that takes the Darcy flow velocities, moisture contents and material porosities produced or used by DCM.D and designates a single, nonbranching transport migralion path for NEFTRAN II. As described above, attributes of the transport migration path include number of transport leg.s, transport leg lengths, mean degree of saturation for each transport leg, and mean pure velocity (Darcy velocity divided by moisture content) of each transport leg. For single-continuum, one-dimensional models, the particle tracker simply calculates the pore velocities along the flow path. However, NEFTRAN II can only handle transport in cither a fracture or matrix continuum but not both simultaneously. For dual-continuum models the particle tracker must look at the velocities in both the fracture continuum and the matrix continum and decide which is the dominant path. The particle tracker designates the one with the higher pore velocity to be the dominant transport path. As a result, the transport path does not allow for simultaneous fracture and matrix mamsport. An alternative approach to transport modeling would be to treat the fracture and matrix continua together as an equivalent porous medium (Erickson et al., 1986; 1)udley et al., 1988). This was the approated taken in the fifth ennecptual model, described in section 2.3.

Ihe particle tracker defines a new transport leg whenever a change in malerial propertics occurs along the transport path. A change in either the hydrological or the genchemical properties warrants the definition of a new leg. A new leg is also defined wherever the dominant transport path chathes from fracture to matrix or vice versal. A mean prove velocity and a mean degree of sallurallow are calculated based on the pore velocities and saturations in each of the grid blocks (from D( M.3D) that matke up that lo $\}^{\prime}$. 


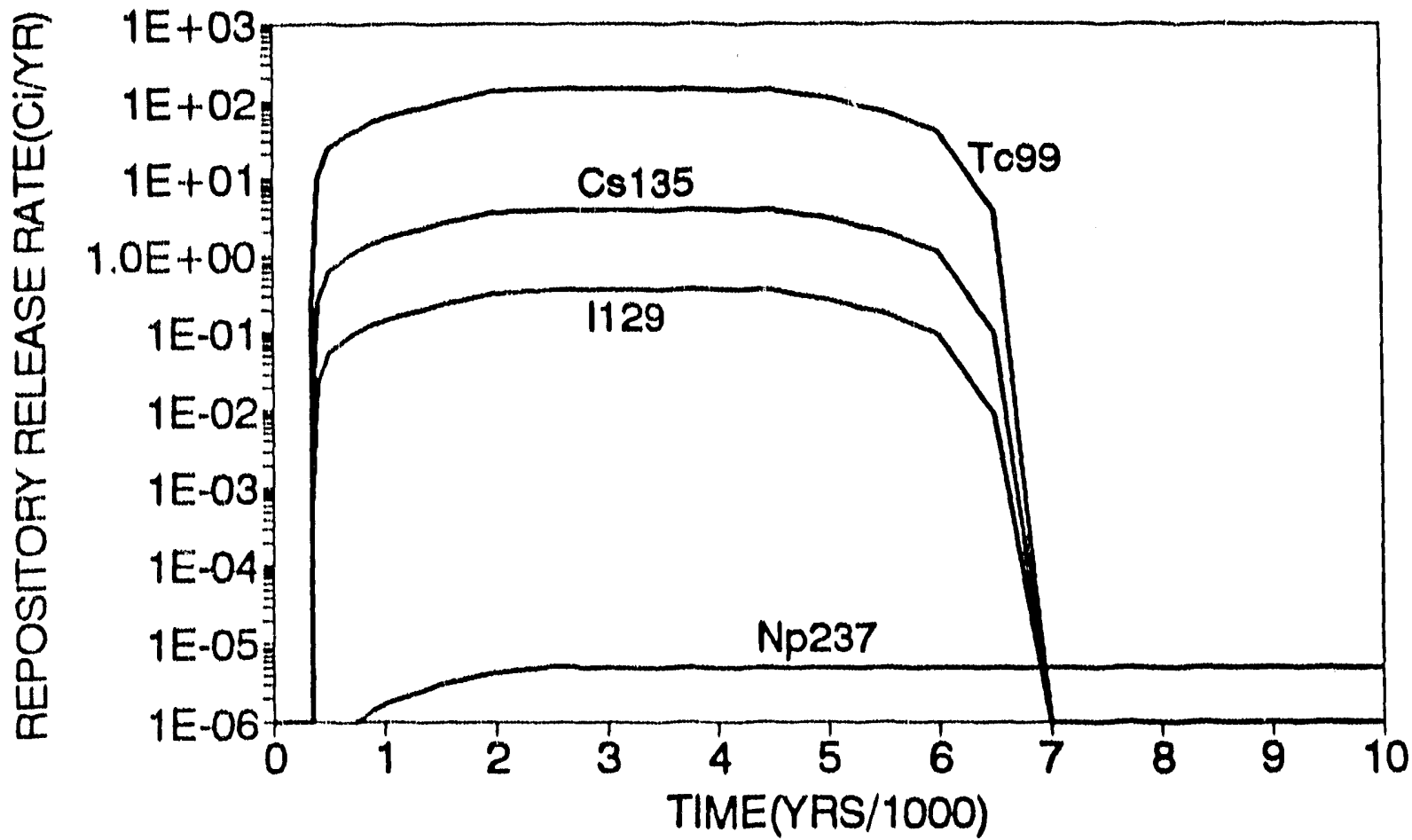

figure 3.1. Sunree 'Term Release Raltes for Isotopes Considered

\section{3 ('CDF Generation}

Ihe primary performance criterion chosen as a measure of comparison between the alternative conceptual models is total integrated release of radionuclides to the water lable helow the repository, expressed in terms of a CCDF. This performance measure is, in principle, consistent with the proposed EPA Containment Requirements, 40 CFR 19) (I:PA, 1985). Simulating release of radionuclides beyond the water table to the accessible enviromment could result in a proportionately larger number of zero-release realizations for certain conceptual models. The larger number of zero-release realizations would likely make any type of uncertainty analysis and sensitivity analysis less meaningful.

I'o generate the (CDPF, data and parameter uncertainty was treated primarily for the ladionuclide transport parameters. The parameters that were assumed to have some uncertanty associatled with them include matrix retardation factors, longitudinal dispersivity, path length, and mean pore velocity. The distributions and ranges for these are summantized in lable 3.5 . The range given in lable 3.5 is the range of values by which the batse values were multiplied. For example, for a leg length of $100 \mathrm{~m}$, the base vallue lor longiludinal dispersivily would be $10 \mathrm{~m}$. Therelore, the range of dispersivities for that lege would be $2 \mathrm{~m} 10.50 \mathrm{~m}$. This range contains $99.8 \%$ of the normal probability density function and was chesen arbitrarily. 'The 'mominal' base retardation factors were 
calculated using distribution coefficients $\left(K_{0}\right)$ from 'Thomas (lox"7). 'These are presented in Table 3.6. The path lengths and mean pore velocities were determined asing lace

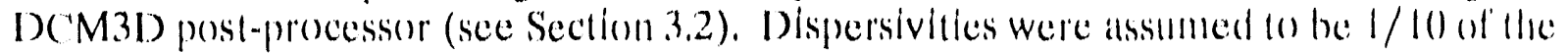

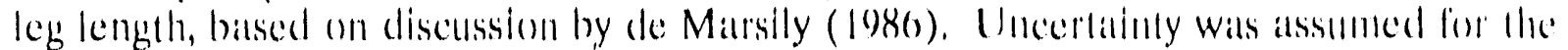
fracture/matrix transfer coefficient in the fracture/mallix flow simmlations; lowwever, only the largest transfer coeffleient run was used to provide a flow fleld for the transpont

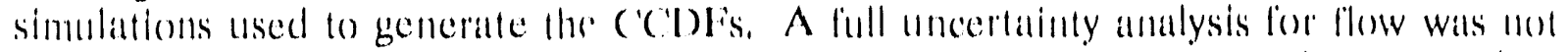

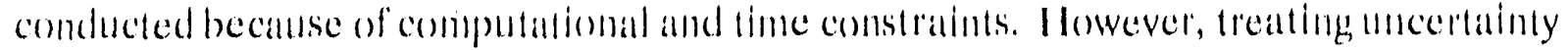
in only the transport paramelers was considered suffictent for the porpose of this investigation, which is to cualitatively evaluate conceptual model ancertantly. Note that a sensitivity analysis based on parameter values is not presented as part of his investigation. Only the sensitivity of results lo conceptual mokeling assumplions was it. sessed.

Table 3.5. Paramelers Varied in 'Transpont Analysis

\begin{tabular}{|c|c|c|c|}
\hline PARAMEIILR VARILD & RANCil: & DISIIRIBIITION & $\begin{array}{l}\text { BASE: } \\
\text { VAIUUS }\end{array}$ \\
\hline Matrix Retardation Factor & (). .1 & Normal & Nominail \\
\hline Iongitudinal Dispersivity & $0.2 \cdot 5$ & Normal & (0.1* Pall 1 enghth \\
\hline Path Length & $0.5-2$ & Normal & Nominal \\
\hline Mean Pore Velocity & $0.2 \cdot 5$ & N(trimal & $\begin{array}{l}\mathrm{D}(\mathrm{M} 3 \mathrm{I}) \\
\text { Results }\end{array}$ \\
\hline
\end{tabular}

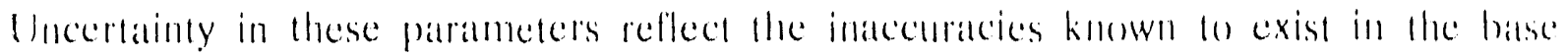

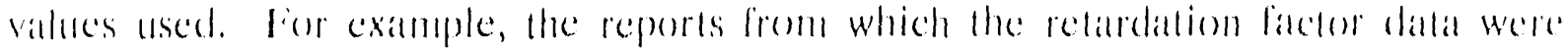

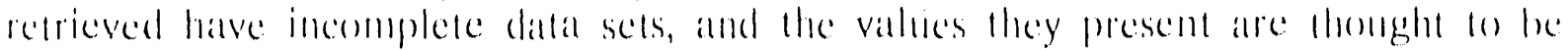

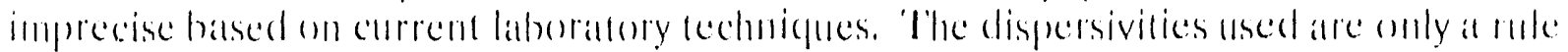

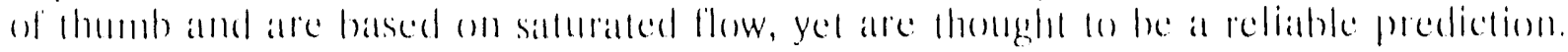

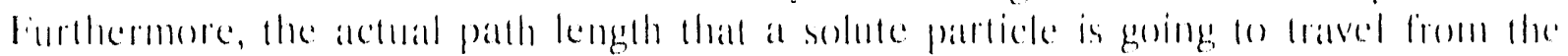

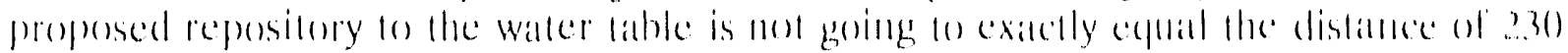

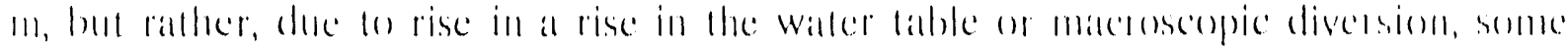

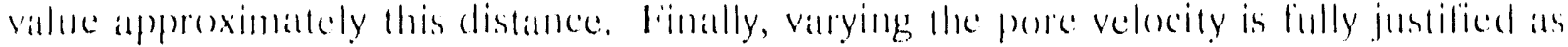

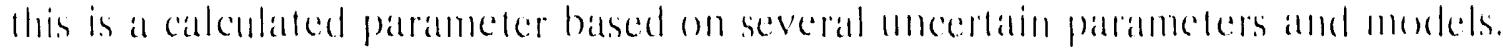

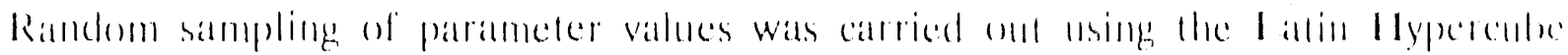

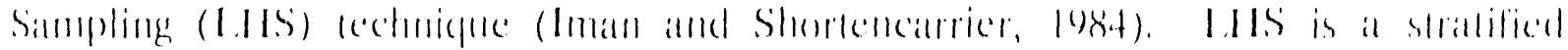


I'illik 3.6. Retardation finctors Used in Transport Analyses

\begin{tabular}{|c|c|c|c|c|}
\hline leg \# & ${ }^{\prime \prime \prime} \mathrm{I}^{\prime} \mathrm{C}$ & $|2 y|$ & $13.5 \mathrm{Cs}$ & ${ }^{2.37} \mathrm{~Np}$ \\
\hline 1 & 18.7 & 1.0 & 17,600 & 884 \\
\hline 2 & 18.7 & 1.11 & $17,660)$ & 884 \\
\hline 3 & 24.4 & $1.1)$ & 23,360 & 1,160 \\
\hline 4 & 71.4 & 1.0 & 140,700 & $7(0.5$ \\
\hline 5 & 1.0 & 1.0 & 1.0 & 1.0 \\
\hline 0 & 1.0 & $1 .(1)$ & 1.0) & 1.0 \\
\hline 7 & 1.0 & 1.0 & $7.2 \times 10^{12}$ & $7.5 \times 10^{10}$ \\
\hline 8 & 1.0 & 1.11 & $36,78()$ & 38 \\
\hline 9 & 1.11 & 1.0 & 101,700 & 10.3 \\
\hline 10 & 1.0 & 1.0 & $35,89()$ & 37 \\
\hline 11 & 1.0 & $1 .()$ & $1(01,7()()$ & 10.3 \\
\hline 12 & 1.0 & 1.0 & 35,840 & 37 \\
\hline 1.3 & $1 .()$ & 1.0 & $101,60(0)$ & 103 \\
\hline 14 & 1.1 & 1.0 & $3.5,7.30$ & 37 \\
\hline 1.5 & $1.1)$ & 1.0 & $1.9 \times 100^{14}$ & $1.9 \times 100^{11}$ \\
\hline
\end{tabular}


sampling technicue in which the range of values for each variable is divided into intervals of equal probability so that a value is sampled from each interval. Sampling In such a way ensures that values for each parameter are obtained covering the entle range of values. 'The base paranneter values, listed in Table 3.5, were multiplied by the 1.ISS samples, which were from the ranges given. Using this set of parameter values, the release to the water table was calculated using NEFTRAN II. fillty siamples requiled (1) distinguish between certain groups of alternalve conceptual model. For example, differences between the all fracture and fracture with matrix diffusion models, and the models with matrix transport, were quite apparent with only $5($ ) realizations. On the other hand, 5()() samples were used to clarify some of the differences among the models containing matrix transport.

\subsection{Comparison Criteria}

As mentioned in Section 3.3, the CCDF of total radionuclide release to the water table is the regulatory-related performance measure used to compare conceptual models with calch other in this investigation. However, intermediate calculations, such as saturation proliles, pressure profiles, and mean isolope travel times, can provide a great deal of insight as to the effect fundamental assumptions can have on results. These intermediate sleps were taken in calculating the CCDFs and the results will be presented in Section 4.

Becallse the CCDF, in general, incorporates all sources of uncertainty (including comceptual, mathematical, and numerical model uncertainty, data and parameter mocertainty, and uncertainty about future states of the system), it can be difficult to (liscern which source(s) of uncertainty contributes most to changes in the CCDF. For this study, however, the same mathematical and numerical models and data and parrancter values were used for each of the conceptual models. Also, uncertainty about llic fulure state of the system was not included in the modeting. Consequently, relative changes in the CCDF could be attributed primarily to differences in the fundamental assumptions used in developing the conceptual models.

The ('C 'D F's generated for each of the alternative conceptual models will be qualitatively and graphically compared to one another using a sensitivity analysis type approach. 'That is, the comparison should assist in icientifying those fundamental assumptions, if any, that have the greatest impact on the performance measure. 


\subsection{RESUL'TS}

The calculations curried out by DCM3D and NEFTRAN II, and outlined in Section 3, cventually resulted in integrated releases for each isotope ancl realization. The multiple realizations for each conceptual model were then summed and plotted as a CCDF curve. 'The results of these calculations are described below.

\subsection{Ground Water Flow Simulations}

Results from the DCM3D simulation consisted of pressure heads, moisture contents, and Darcy velocities for both the matrix and fractures. Legrees of saturation were calculated from the moisture contents and the porosittes for each geologic unit. The total heads were calculated from the elevation of a grid block center and the corresponding pressure head al that grid block center.

\subsubsection{Matrix-1)ominated Flow Model}

In general, the matrix pressure head is always negative and has an average negative gradient between the water table and the repository bottom (Figure 4.1). However, in layer 1, the matrix pressure head has a positive gradient. This may be due to this layer

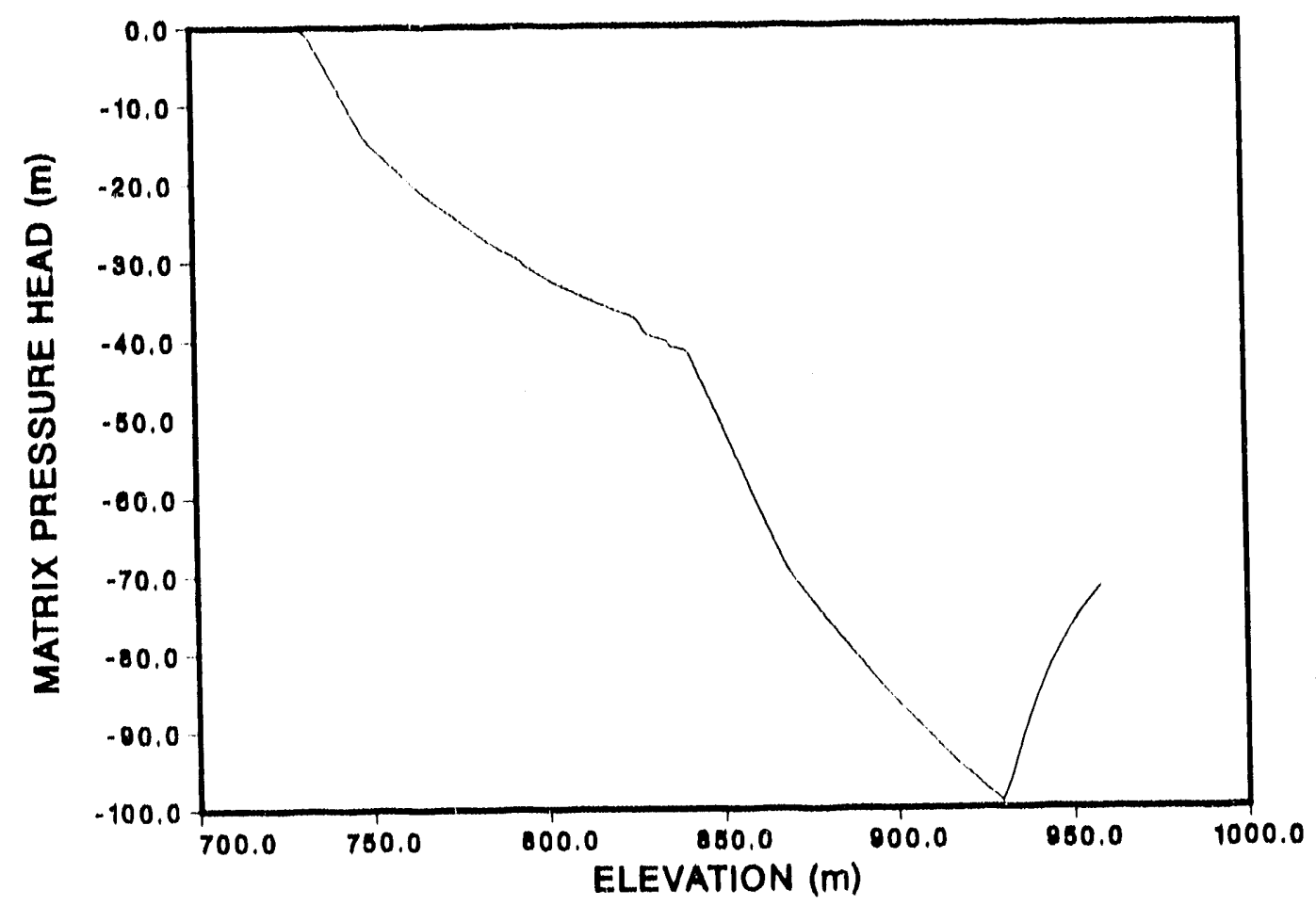

Figure 4.1. All Matrix Flow Model-Pressure Lead 
having a steeper characteristic curve than many of the other layers. The positive gradient in this layer indicates a downward movement of water doe to suction. Between $841 \mathrm{~m}$ and $808 \mathrm{~m}$, in the combined layer, the pressure gradient is almost $-1 .($ ) which counteracts the gravitational component of flow so that the total head gradient in this layer is almost zero (see Figure 4.2). This unit was assigned a saturated hydraulic conductivity several orders of magnitude larger than the recharge rate, which accounts for this phenomenon. Throughout the remainder of the column, the pressure gradient is negative.

The total head gradient is positive everywhere in the column (see Figure 4.2). This indicates a downward flux of water from the repository to the water table. Between $841 \mathrm{~m}$ and $868 \mathrm{~m}$, the gradient is extremely that but it is still possitive. 'The matrix siturated hydraulic conductivity in this layer is very large and only a small gradlent is required to let water flow through it.

The moisture contents are cuite variable below 841 mo (ligure 4.3 ). In this region the layers have alternating hydrologic properties and the moisture contents reflect this. The moisture contents vary rapidly between $(0.36$ and $(0.23$. However, in the layers with similar hydrologic properties, the moisture contents decrease slightly with increasing elevation. This indicates a general downward movement of water.

Below $841 \mathrm{~m}$, the layers with the lower moisture contents have a higher degree of

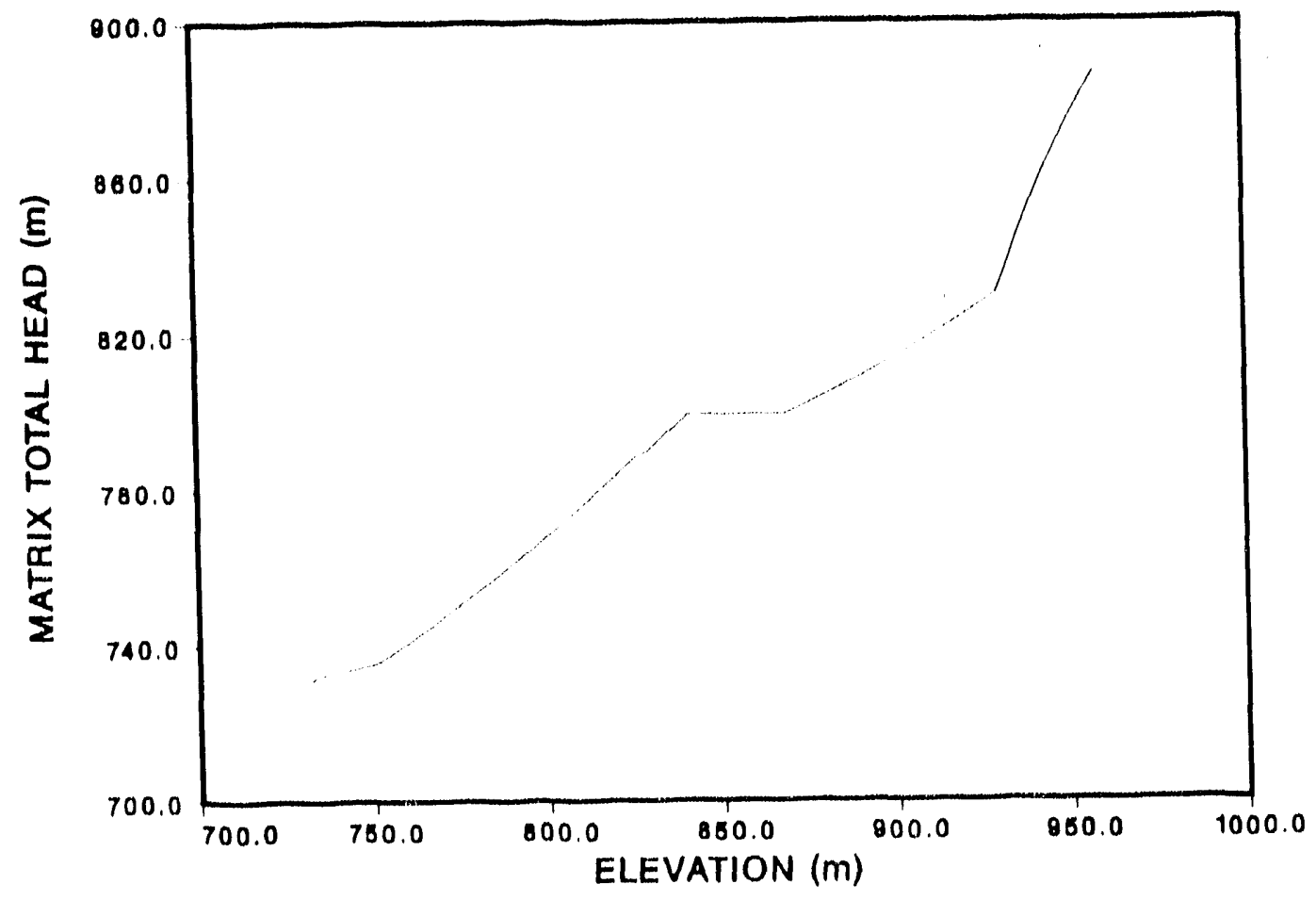

Figure 4.2. All Matrix filow Model - 'loutal Head 


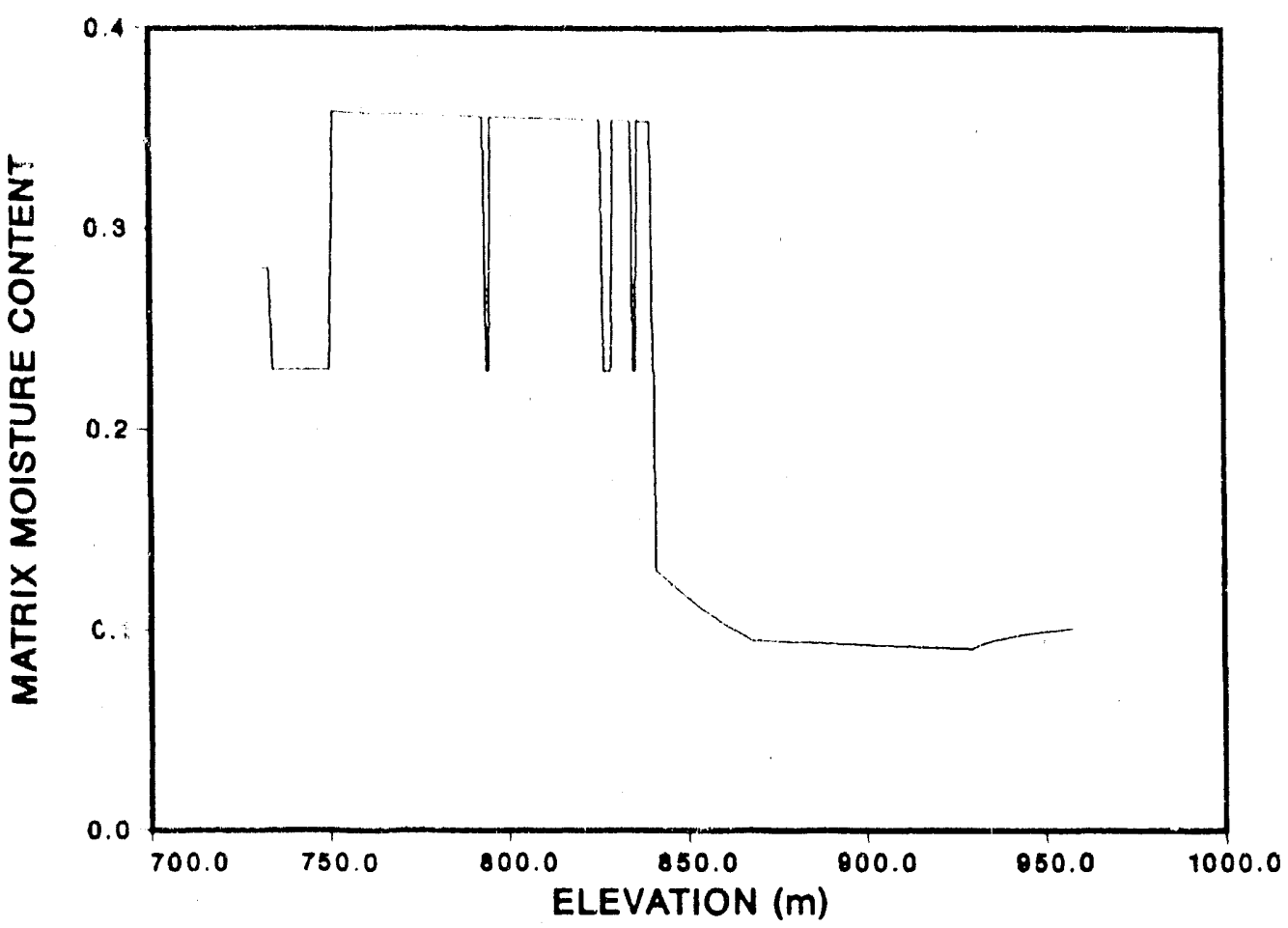

Fïgure 4.3. All Matrix Flow Model - Moisture Content

saturation (Figure 4.4). This is a reflection of the properties of the characteristic curves; the layers with the higher porosities tend to have steeper characteristic curves. At elevations between $841 \mathrm{~m}$ and $868 \mathrm{~m}$, the saturation decreases relatively rapidly. This phenomenon occurs in the combined layer with the very high saturated hydraulic cors ductivity.

\subsubsection{Fracture-Dominated Flow Model}

The pressure head gradients in each of the five layers of the fracture-dominated flow model are (0.) except at the bottom of the layers, where they become steep (Figure 4.5). Because the van Genuchten parameters are the same for each layer, the pressure heads between layers change solely (1) differences in the fracture saturated hydraulic conductivity of the layers. In general, layers with the higher fracture saturated hydraulic conductivities have the lower pressure heads and vice versal. The rapid change in the pressure heads at the bottom of the layers is due to the steep fracture characteristic curves. Small changes in the pressure heads can cause rapid changes in the relative hydatulic conductivities.

The zero pressure heid gradient behavior indicates that flow is mostly dorminated by gravity everywhere except at the bottom of the layers. At 730 $\mathrm{m}$ and $841 \mathrm{~m}$, the gravity 


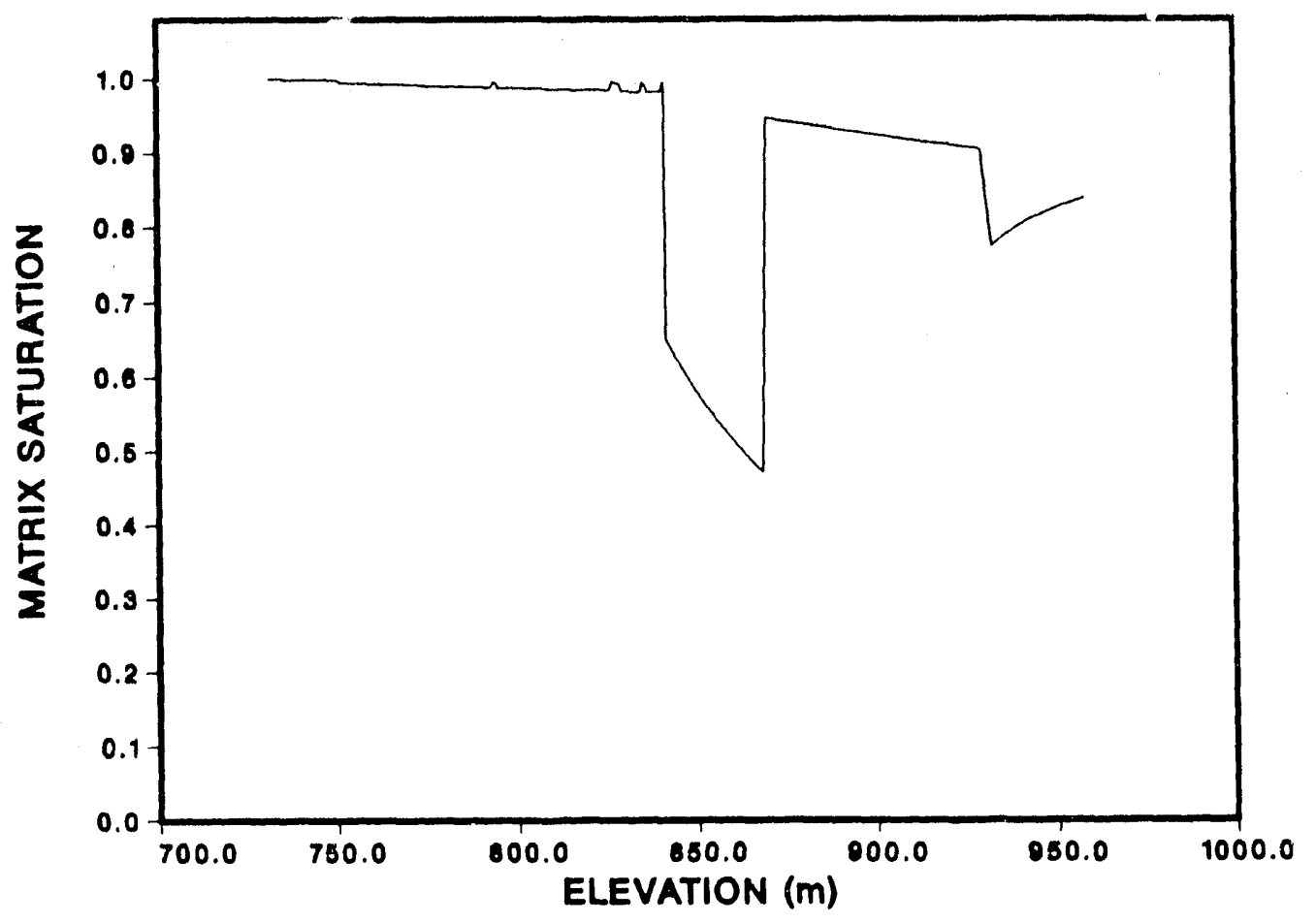

Figure 4.4. All Matrix Flow Model - Saturation

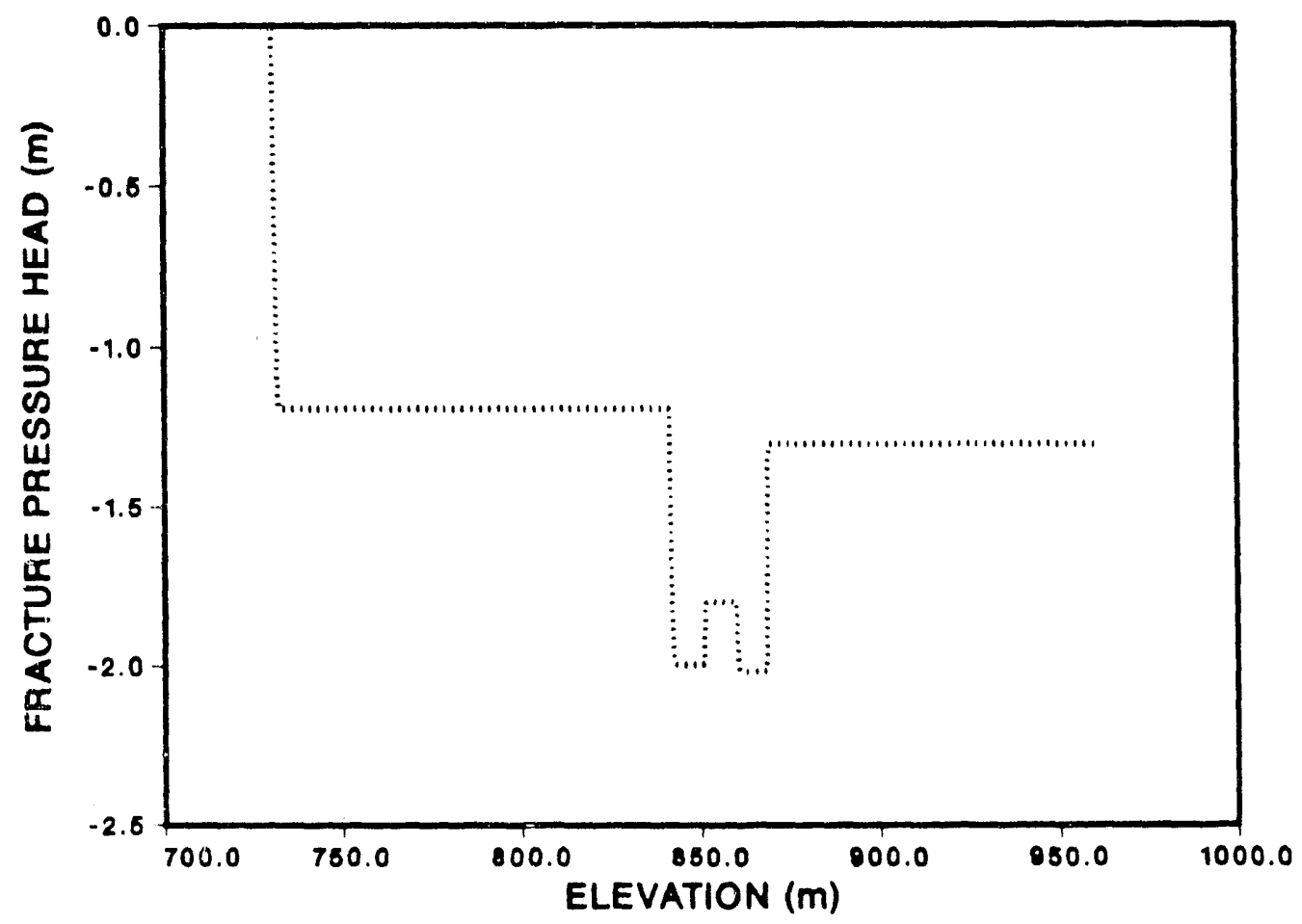

Figure 4.5. All Fracture Flow Model - Pressure Heäd 
effects and suction effects almost counteract each other so that the total head gradient is almost 0.0 . At $868 \mathrm{~m}$, the pressure head and total head gradients counteract each other somewhat. The total head gradient there is 0.33 . At $851 \mathrm{~m}$ and $860 \mathrm{~m}$, the pressure head and total head gradients are both positive, resulting in strong positive total head gradients at these locations.

The total head gradient averages 1.0 throughout the column (Figure 4.6). This gradient indicates that gravity dominates the downward flow of the water. The scale of this figure is too large to show the total head gradient at the layer bottoms. However, the total head gradients are nearly zero at the layer bottoms at $730 \mathrm{~m}$ and $841 \mathrm{~m}$. The gradients are positive at $851 \mathrm{~m}, 860 \mathrm{~m}$, and $868 \mathrm{~m}$.

Throughout the column the saturations do not change within a layer except rapid saturation changes at the bottom of the layers (Figure 4.7). The saturations reflect the pressure heads, which do not change within at the bottom. The saturations are higher than the residual saturations everywhere throughout the column.

In addition, the moisture contents do not change within a layer except at the bottom of the layer (see Figure 4.8). The moisture contents change rapidly at the bottom of each layer which reflects the porosity and saturation changes between the layers.

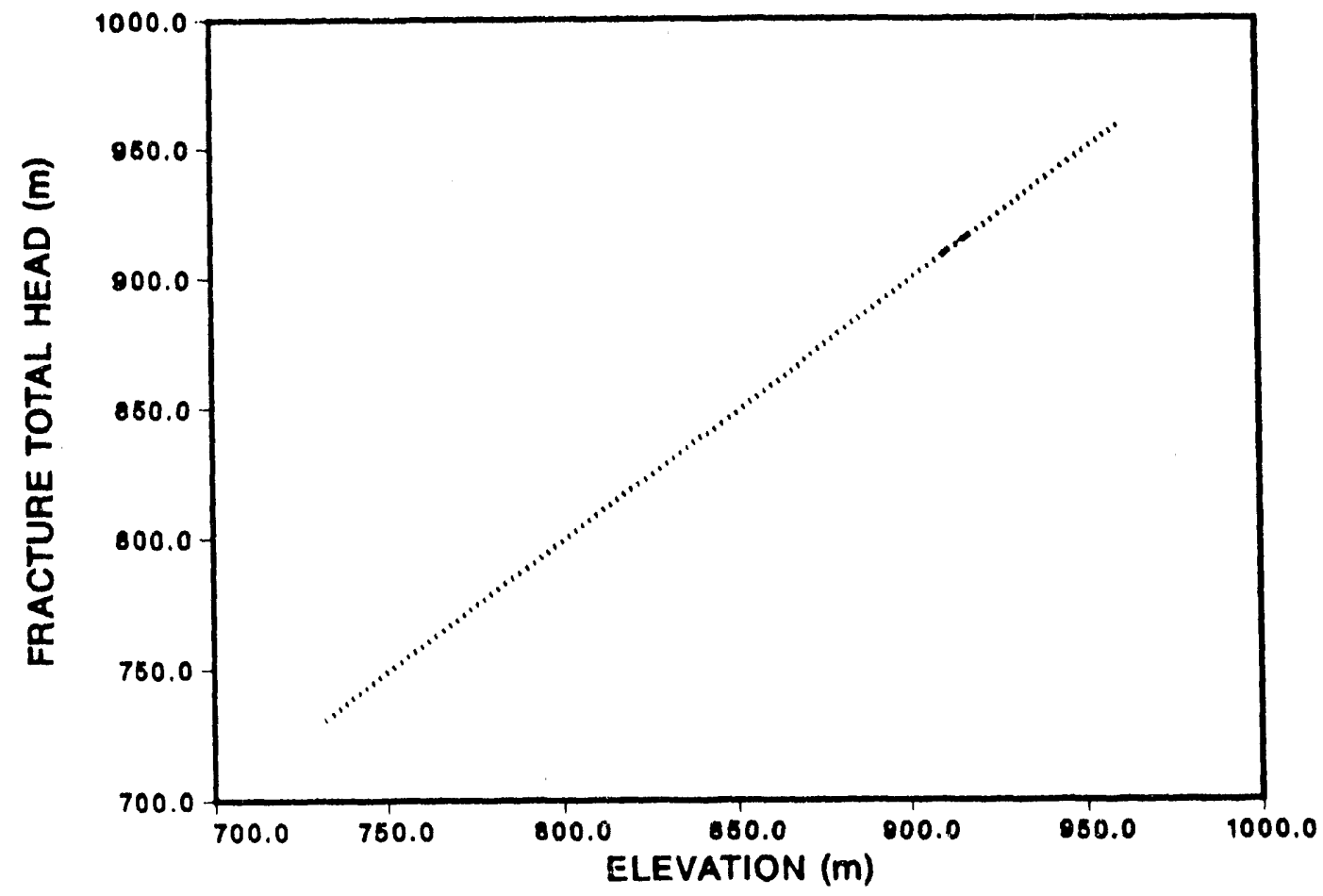

Figure 4.6. All Fracture Flow Model - Total Head 


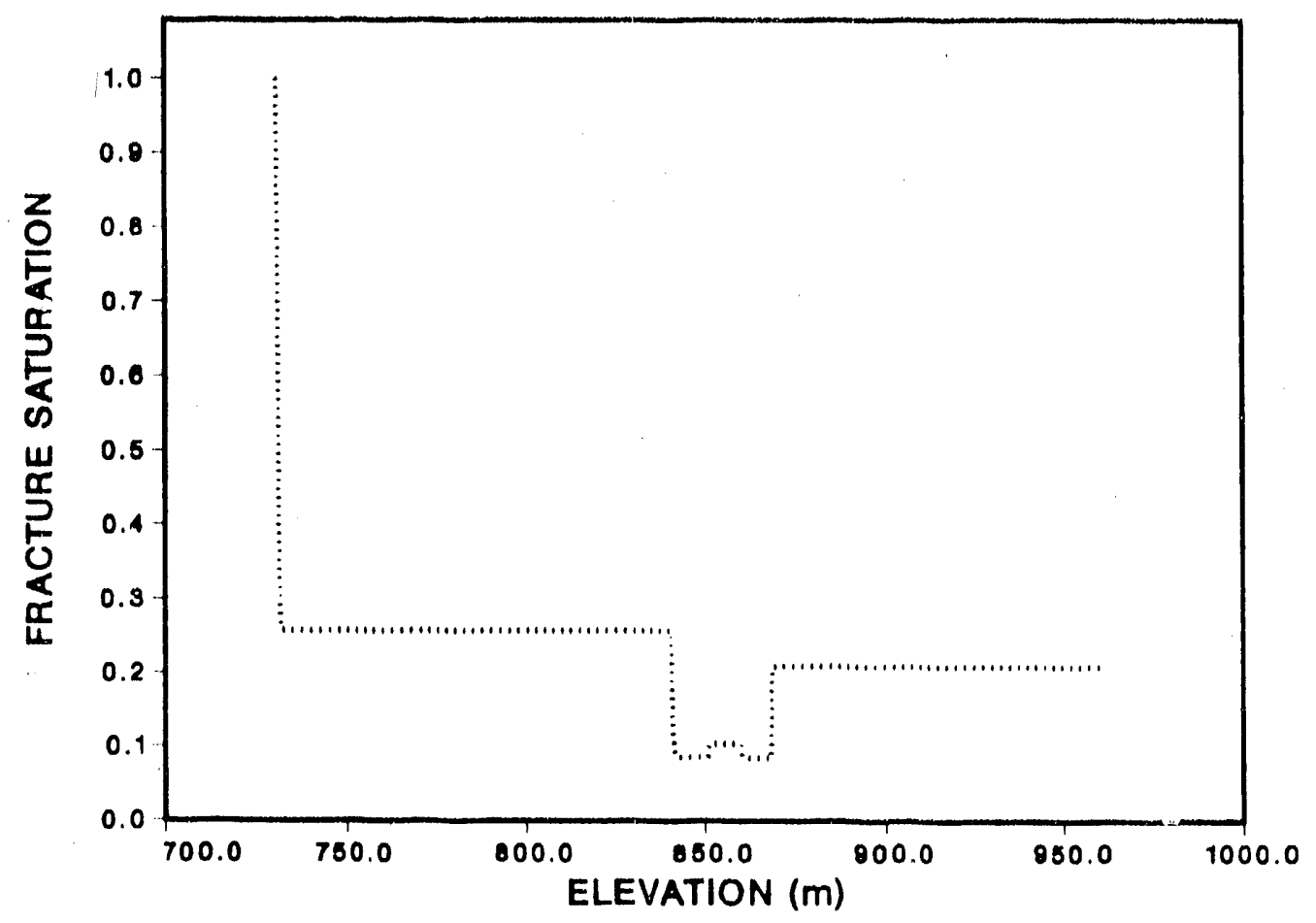

Figure 4.7. All Fracture Flow Model - Saturation

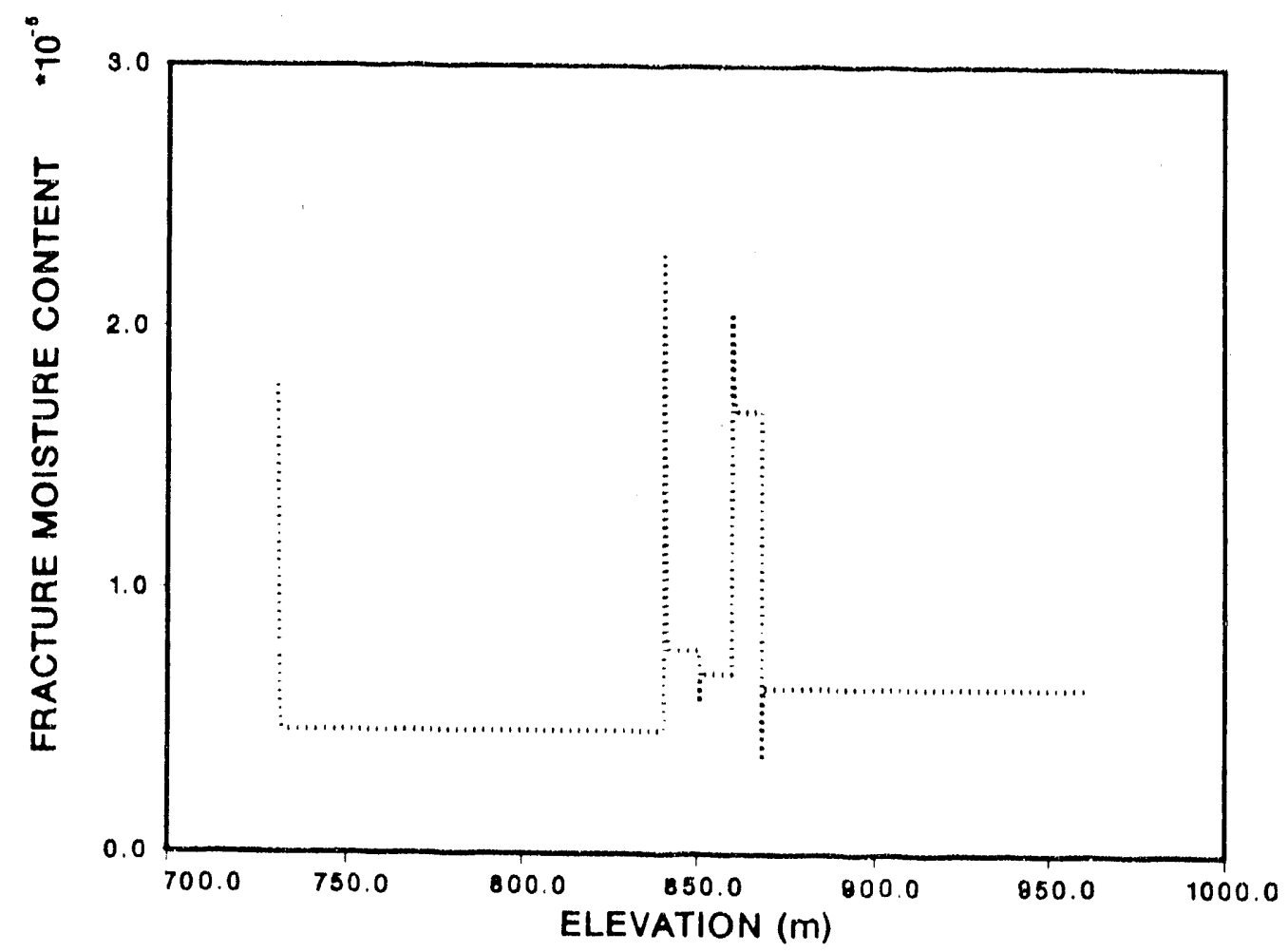

ligure 4.8. All Fracture Flow Model - Moisture cintent 


\subsubsection{Simultaneous Fracture and Matrix Flow Model}

Large transfer coefficient case. The pressure heald for the large transfer coefficient case shows an average negative gradient throughout the column (see Figure 4.9). However, in some layers the gradient is positive and in others it is negative. The matrix and fracture pressure heads are equal everywhere except at the water table $(730 \mathrm{~m}), 843 \mathrm{~m}$, and $850 \mathrm{~m}$ (see figure 4.10). A positive difference indicates transfer of water into the fractures from the matrix. A negative difference indicates transfer into the matrix from the fractures. Thus, at the water table and $850 \mathrm{~m}$, water is transferred into the fractures, and at $843 \mathrm{~m}$ water is transferred into the matrix. The water transfers at $843 \mathrm{~m}$ and $850 \mathrm{~m}$ both occur in 1 ayer 5.

Between $840 \mathrm{~m}$ and $868 \mathrm{~m}$, the pressure head changes rapidly (see Figure 4.9). In Layer 3 , between $800 \mathrm{~m}$ and $868 \mathrm{~m}$, there is a positive pressure head gradient. Because the matrix salturated hydraulic conductivity of this layer is less than the recharge rate, the gradient must be greater than 0.0 in order for the recharge to flow through it. After flowing through Layer 3 , the water must flow through layer 4 between $8.51 \mathrm{~m}$ and $860 \mathrm{~m}$. Layer 4 has an extremely high matrix saturated hydraulic conductivity. As a result, the total head gradient in this unit is very small (see Figure 4.11) and the pressure head gradient approaches -1.(). At the top of the underlying unit, Layer 5, water starts to transfer into the fractures. This is caused by the small matrix saturated hydraulic conductivity (less than the recharge rate) of Layer 5 , between $841 \mathrm{~m}$ and $851 \mathrm{~m}$. Except

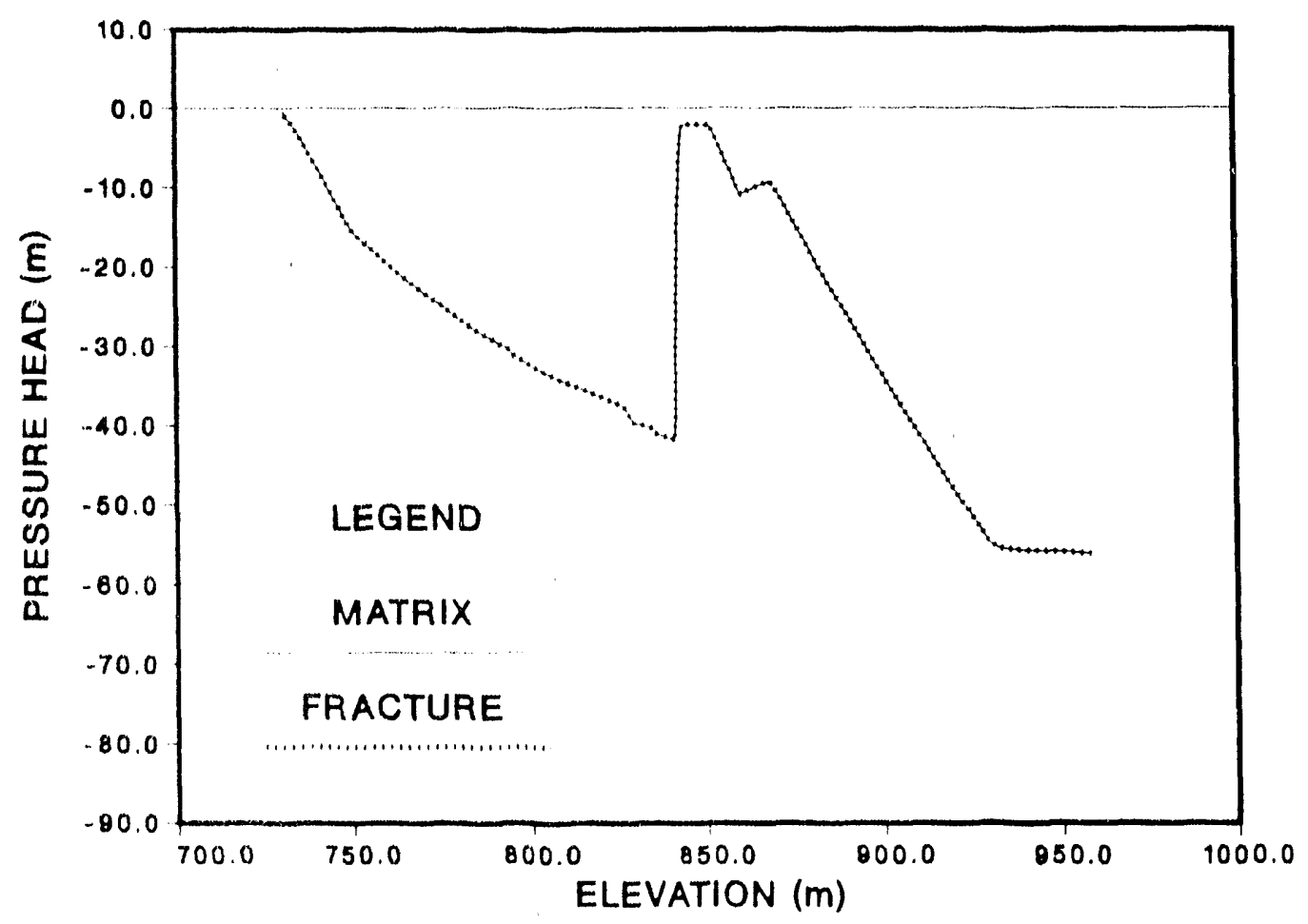

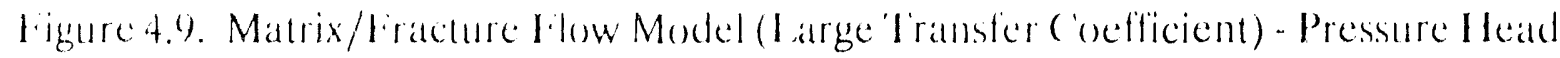




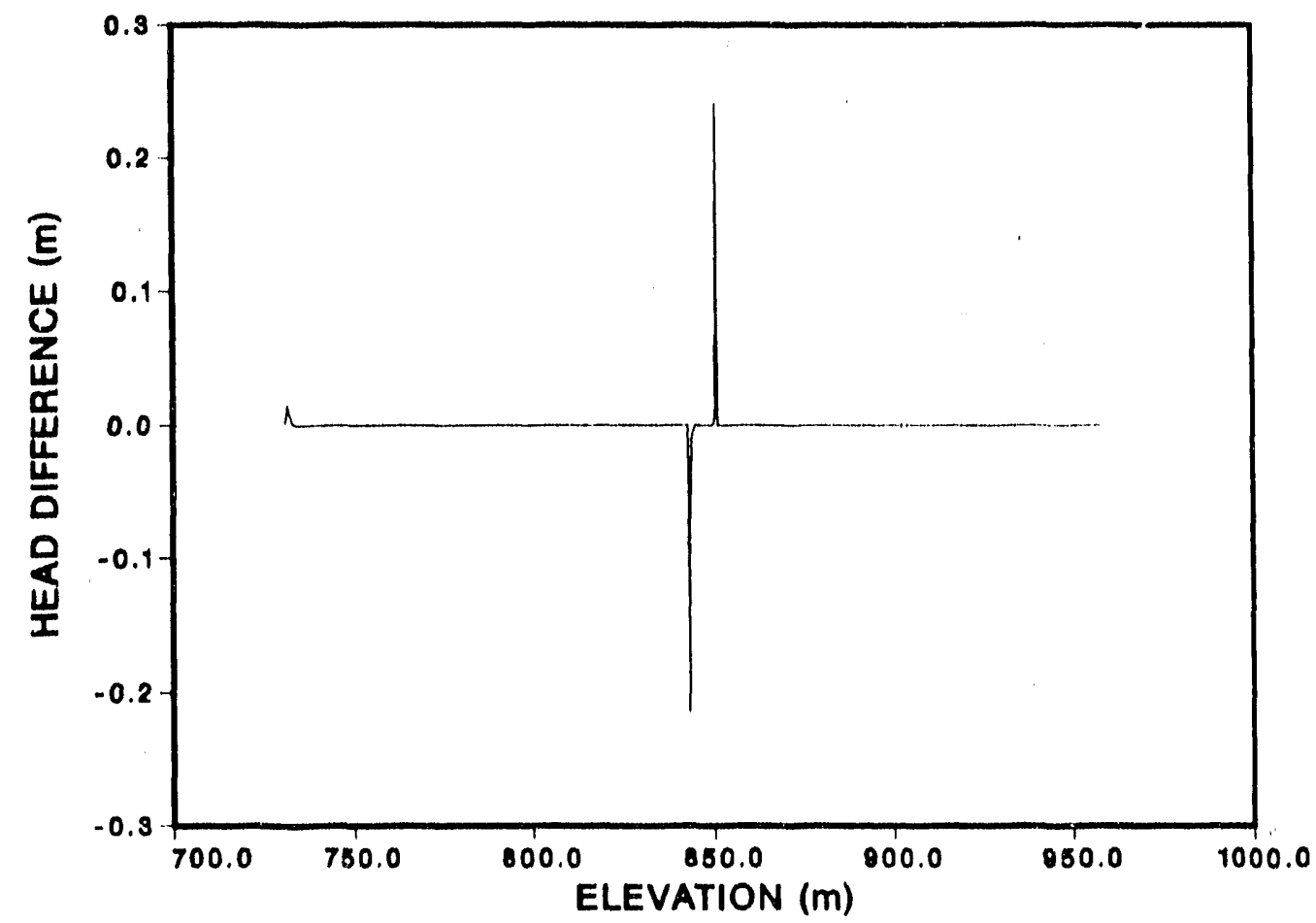

IF̈gure 4.10. Matrix Fracture Flow Model (Large Transfer Coefficient) - Head Difference

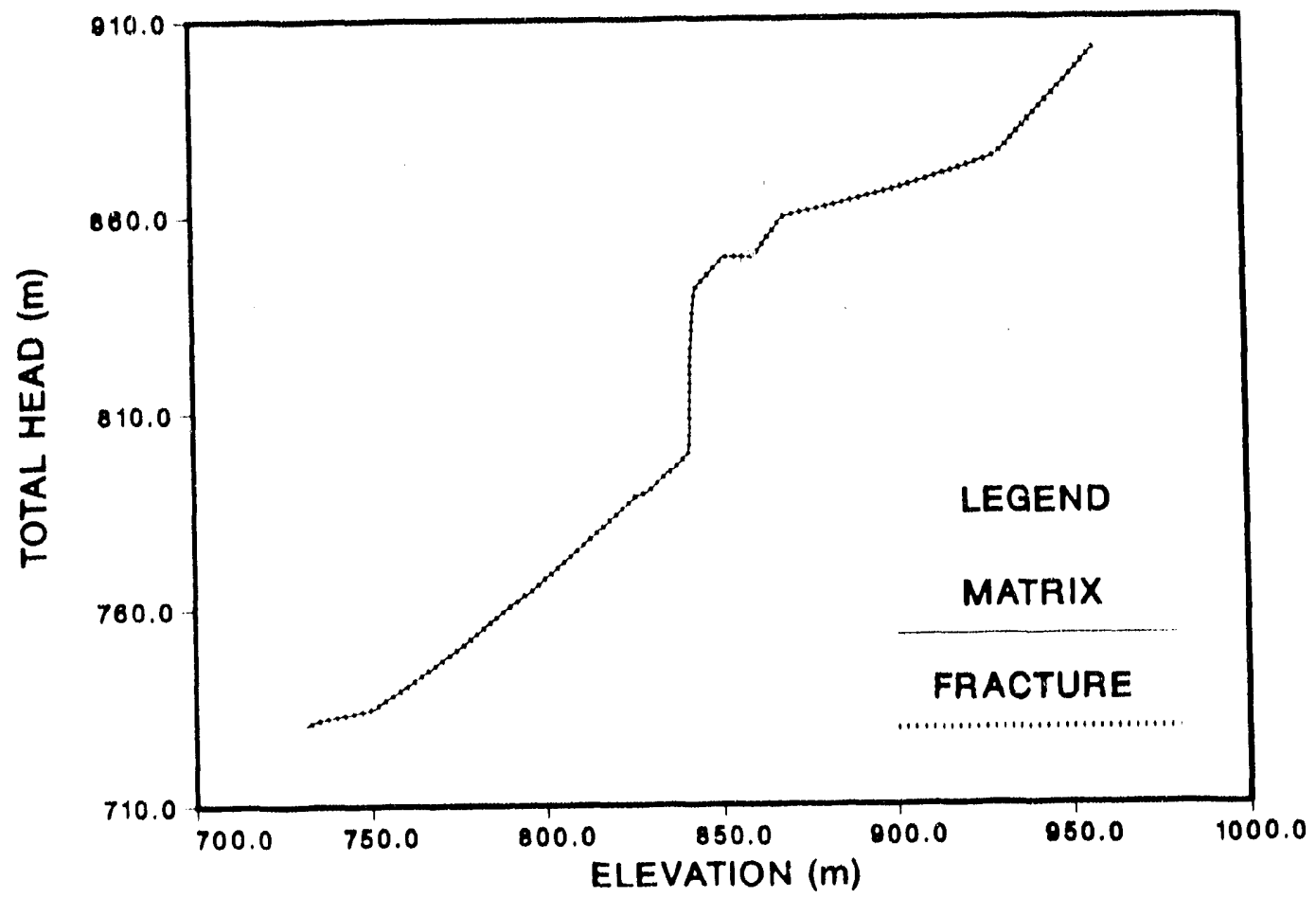

Figure 4.11. Matrix/Fracture Flow Model (I arge Transfer Coefficient) - Total Head 
at the bottom, flow through layer 5 is driven by gravity in both the matrix and the fractures. This is indicated by the flat pressure head gradient in this unit. $78.7 \%$ of the water flow through I ayer 5 occurs in the fractures (see figure 4.12). Near the bottom of Layer 5, a transfer of water from the fractures into the matrix begins. At the very bottom of Layer 5 and underneath the region of water transfer from the fractures into the matrix, a very steep pressure head gradient forms. Because almost all the water has transferred back into the matrix, a steep gradient must form in order for water to move through this low matrix saturated hydraulic conductivity unit. The underlying unit, Iayer 6, has such shallow characteristic curves (resulting from small alpha values) that even large pressure head changes affect the matrix unsaturated hydraulic conductivity only slightly. As a result, in the thin Layer 6, between $840 \mathrm{~m}$ and $841 \mathrm{~m}$, the pressure head changes only slightly. From $840 \mathrm{~m}$ to the water table, the pressure head gradually increases toward a totally saturated condition in both the matrix and the fractures.

Near the water table there is another transfer of water from the matrix to the fractures. At this point the fractures are nearly saturated as a result of being close to the water table. Because the fractures have both a large saturated hydraulic conductivity and a relative hydraulic conductivity near 1.0 from being closer to the water table, the fractures provide a less resistant conduit for flow than the matrix. Therefore, water is transferred from the matrix into the fracturs. At the walter table, the flow in the fractures nearly equals the recharge rate (see rigure 4.12).

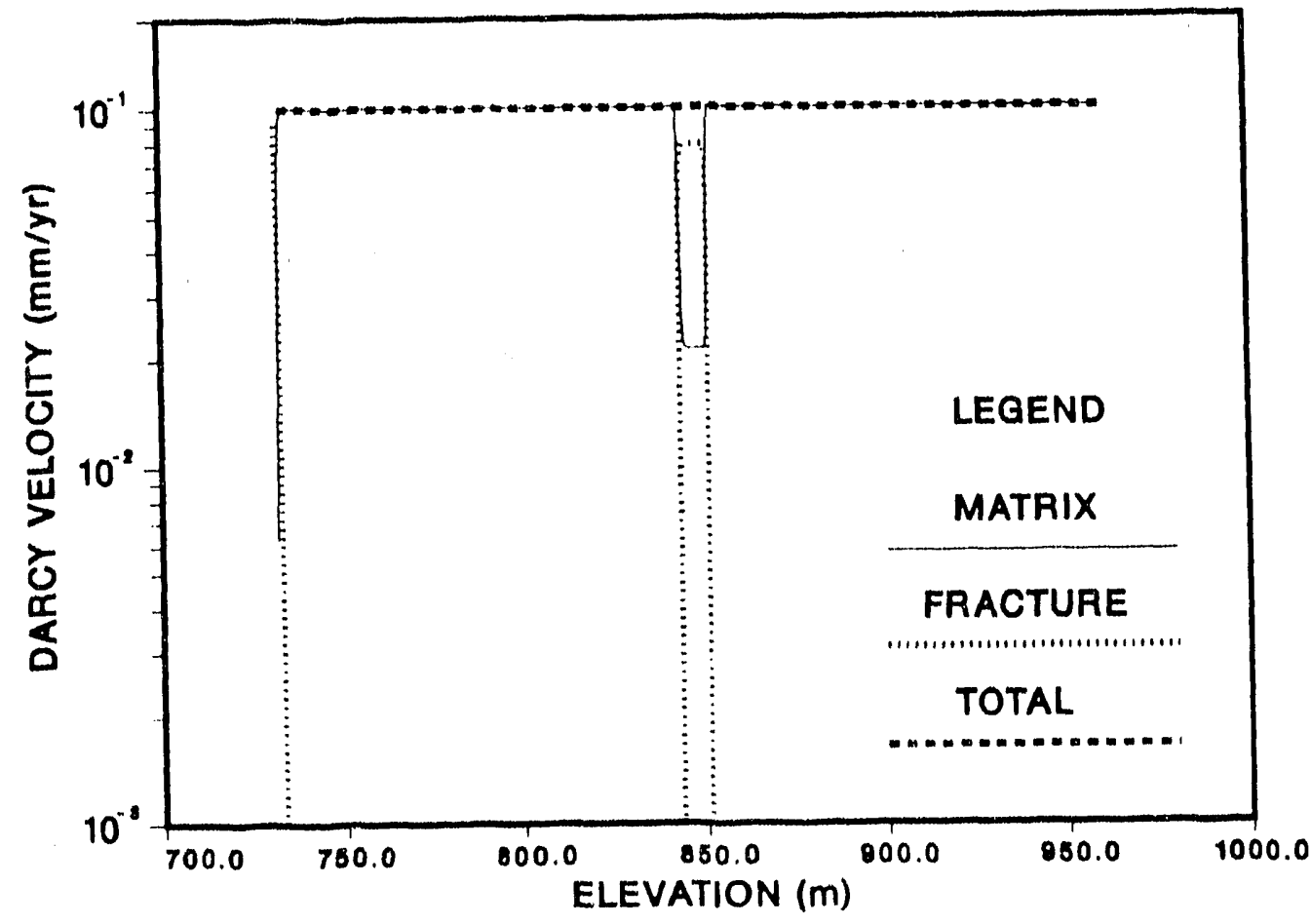

Figure 4.12. Matrix/Fracture Flow Model (large Transfer Coefficient) - Darcy Velocity 
The matrix saturations indicate a gradual drying as distance up the colmmon incereases (sce Figure 4.13). The matrix saturations are near l.() between the water table and 9.3() m, indicating nearly saturated onditions. Above 9.30) m the matrix saturation drops raphilly (1) 0.88 . The fracture salturations hover neall the fracture residual salluration (0.().t) throughout most of the column except at two places. At the water lable, the fratedre saturation approaches $1 .()$ due to the water lable boundary condition. Between $841 \mathrm{~m}$ and $851 \mathrm{~m}$, the fracture saturation approaches (0.08. This higher fracture sallaraliom occurs in the low matrix hydraulic conductivity unit where there is a significant amomnt of flow in the fractures (Latyer 5).

The moisture contents reflect the saturations and the porosities in the varions layers (see ligure 4.14). The thin layers below $841 \mathrm{~m}$ are easily visible here. Even though lhose layers have high matrix saturations, their porosities cause a wide variation in the moisture contents.

The matrix Darcy fluxes equal the recharge ralle everywhere exeept in layer 5 and nean the water table (see Figure 4.12). As a result, the fracture Darcy lluxes are negligible everywhere except in 1 alyer 5 and near the waller lable. In I ayer 5 the matrix l)arcy flux reduces to $21.3 \%$ of the recharge rate and the fracture Darcy flux is $78.7 \%$ of the recharge rate. At the water lable, the malrix Darcy flux decreases $101.5 \%$ of the recharge rate. $98.5 \%$ of the recharge at the water table flows in the fractures as indicated by the fracture Darcy flux approaching the recharge rate.

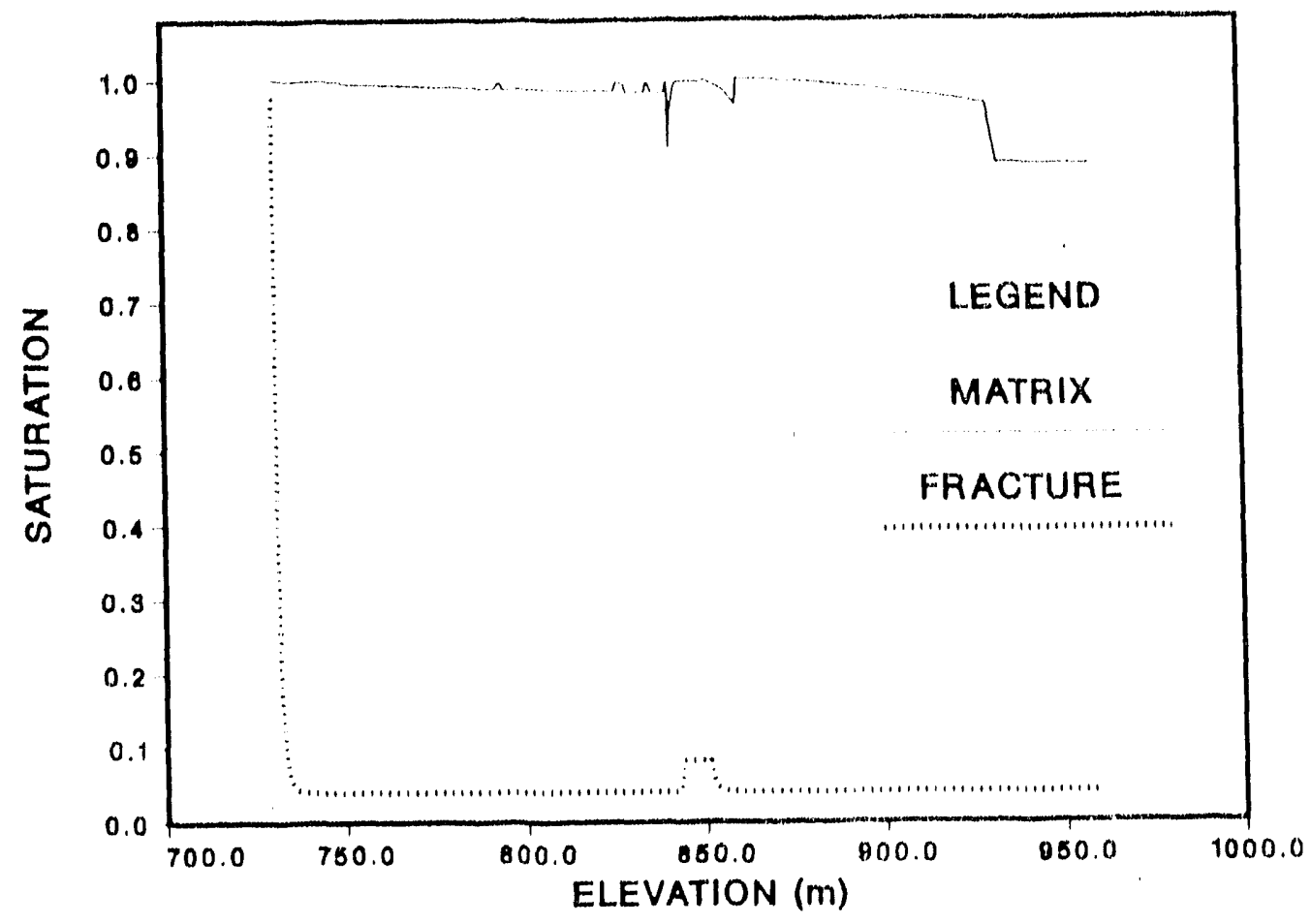

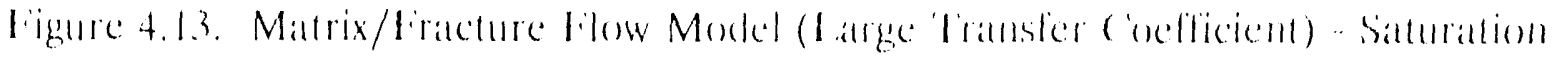




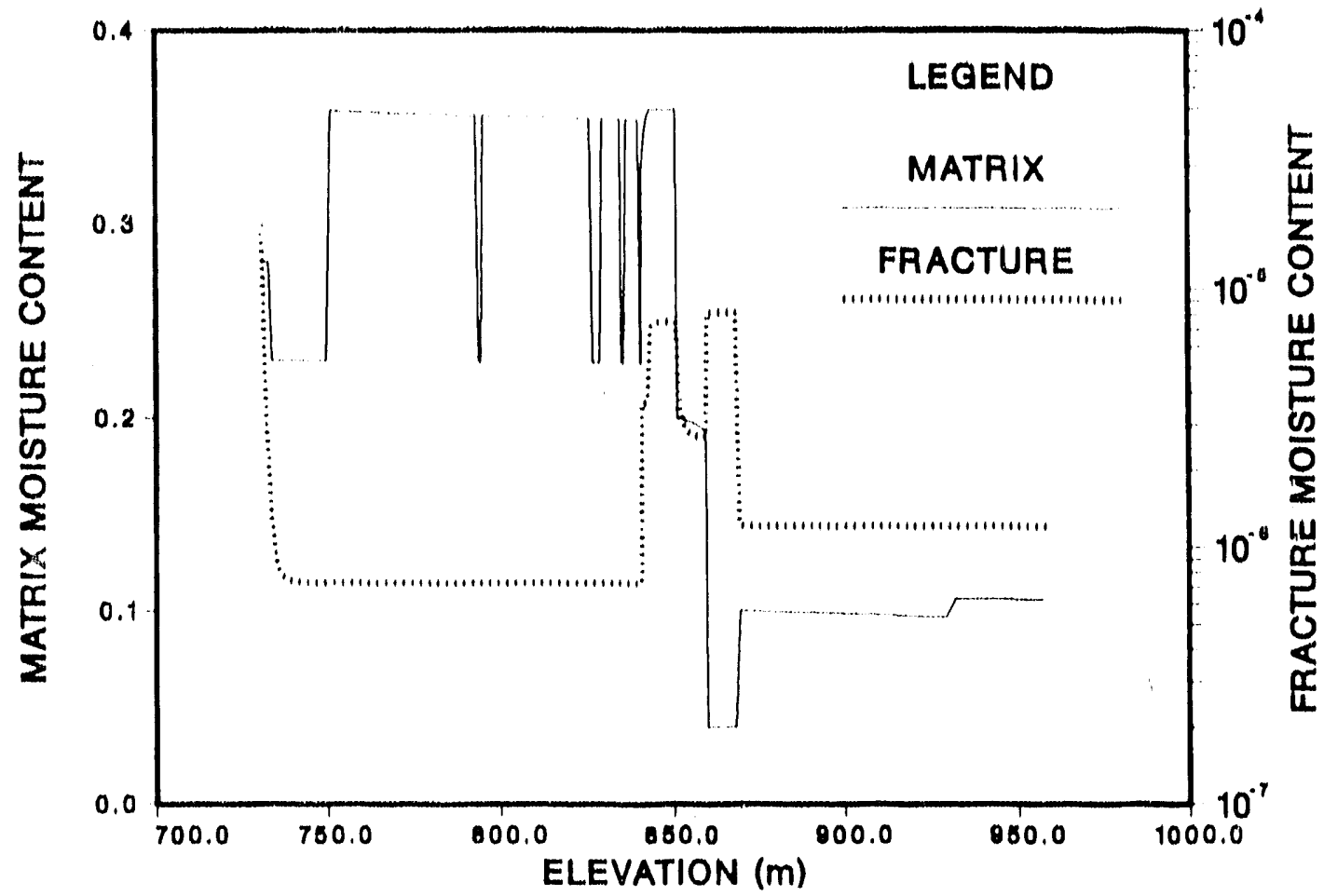

Figure 4.14. Matrix/liacture Flow Model (Large Transfer Coefficient) - Moisture ('ontent

Medium transfer coeficiont case. 'The medium transfor coefficient case produces results that are very similar o those for the lange transfer case. However, there are some minor differences. These differences are cansed manly by the reduced transfer coefficient. Most of the statements made for the large transfer coefficient apply to this case also.

The matrix and fracture pressure and total heads for the medium transfer coefficient catse (Figure 4.15 and ligure 4.16) are very similar to those for the large transfer coeflicient case (see Figure 4.9 and rigure 4.11, respectively). The major contrast ocents in the pressure head differences (see liggure 4.17). Both the positive and negative pressure differences for the medium transter coefficient catse are larger than for ihe large transfer coefficient case (see fighre $4.1(0)$ by almost an order of magnitude. Since the transfer coefficient for the medium case is smaller than for the large case, a large pressure difference is reguired in order to transfer water 0 and from the fractures.

The salturations and moismore contents are relatively malfected by this larger pressure difference (ligure 4.18 and Figure 4.19). Ilowever, at the bottom of latyer 4, there is a shatp peak in the fracture saturation. 'This is due to the large difference in the matrix sallurated hydraulic conductivities between laber 4 and I alyer 5.

lixcept all the water table, Darcy fluxes in the matrix and the fractures for the medium transfer coefficient case are the same those for the large transfer conefficient case (see 


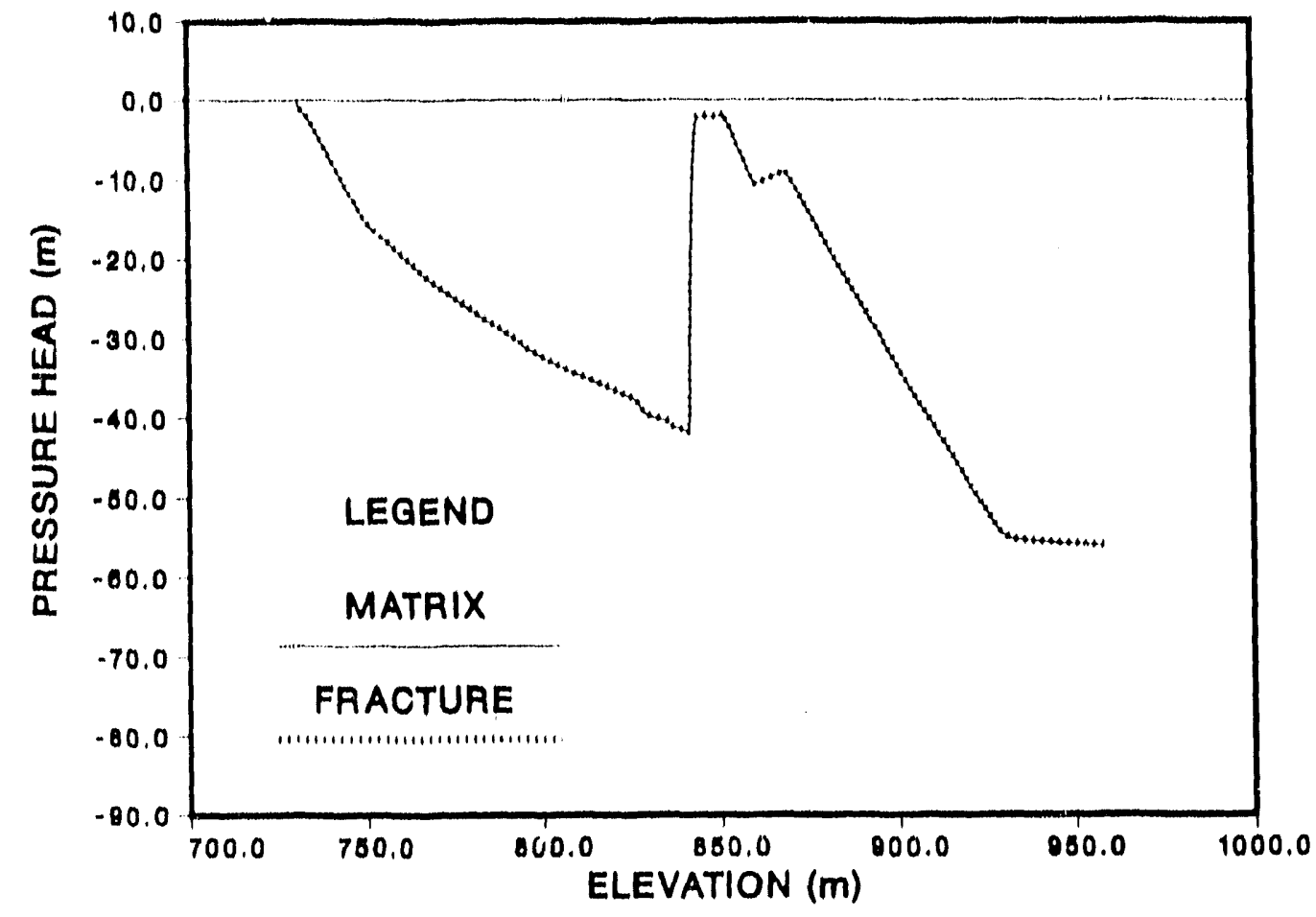

Fignure 4.15. Matrix/Fracture Flow Model (Medium Transfer Coefficient) - Pressure Heal

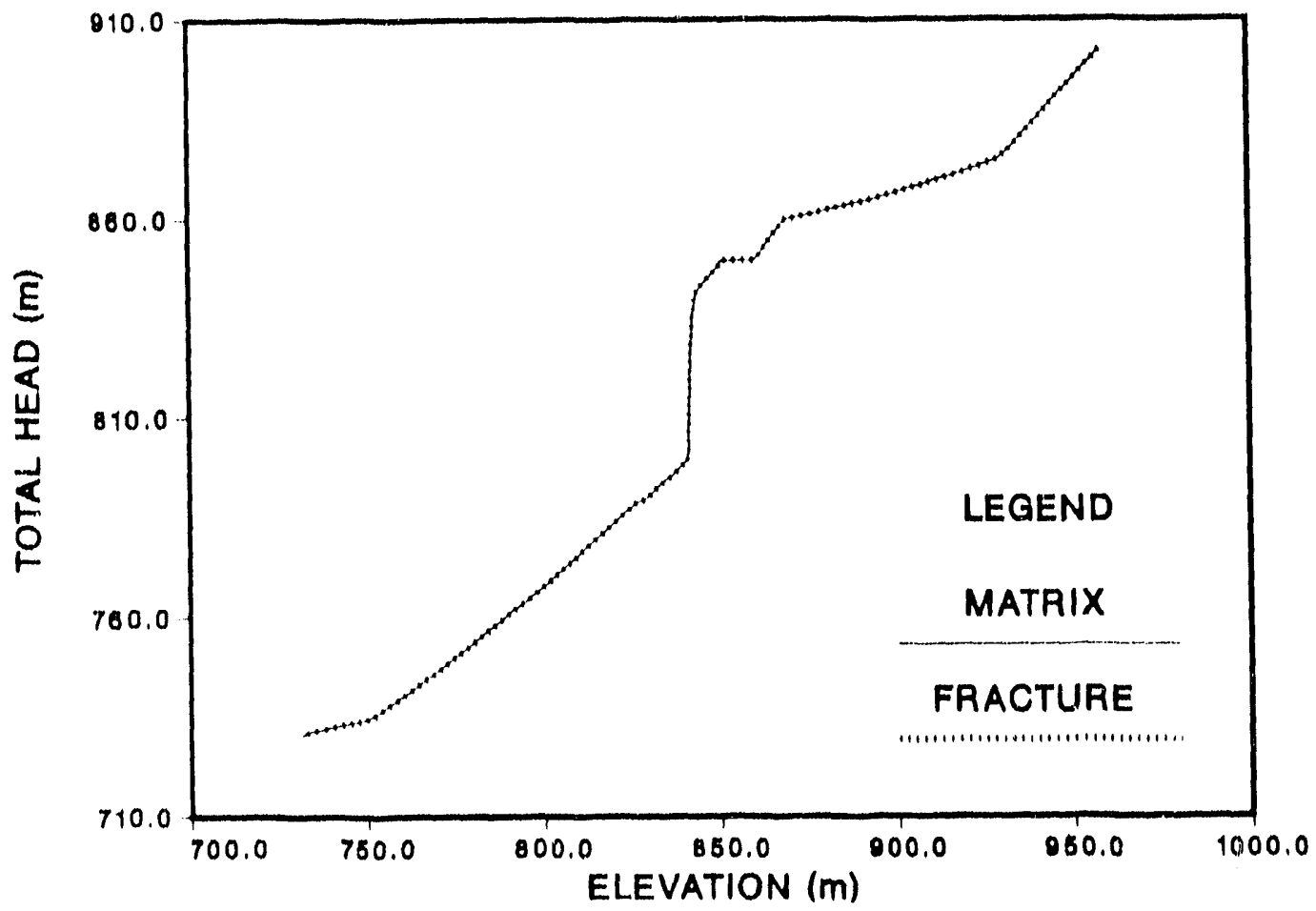

I'gunre 4.16. Matrix/Fracture Flow Model (Medium Transfer Coefficient) - Total lleids 


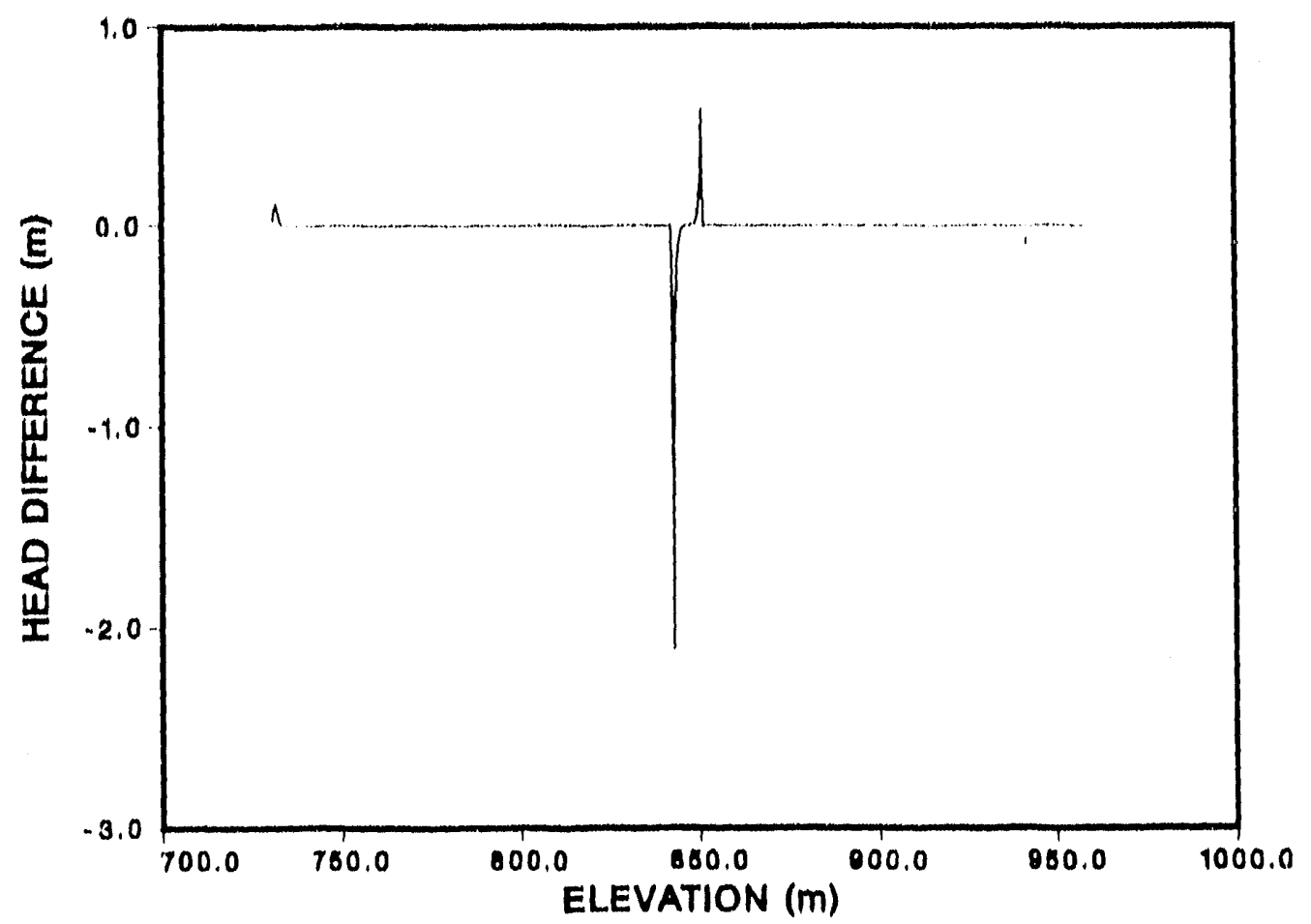

ligure 4.17. Matrix/Fracture Flow Model (Medium Transfer Coefficient) - Head Difference

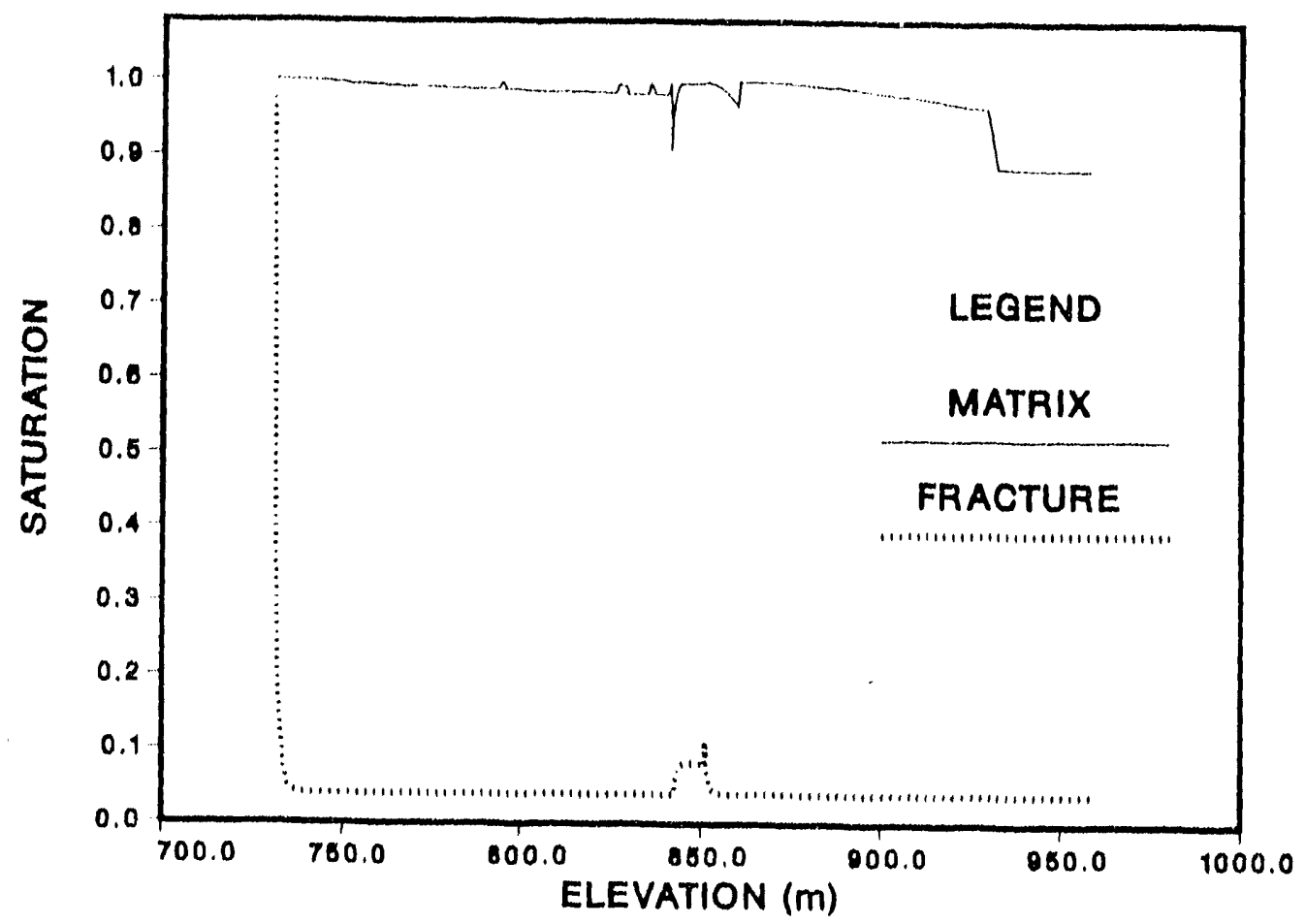

Figure 4.18. Matrix/Fracture Flow Model (Medium Transfer Coefficient) - Saturation 


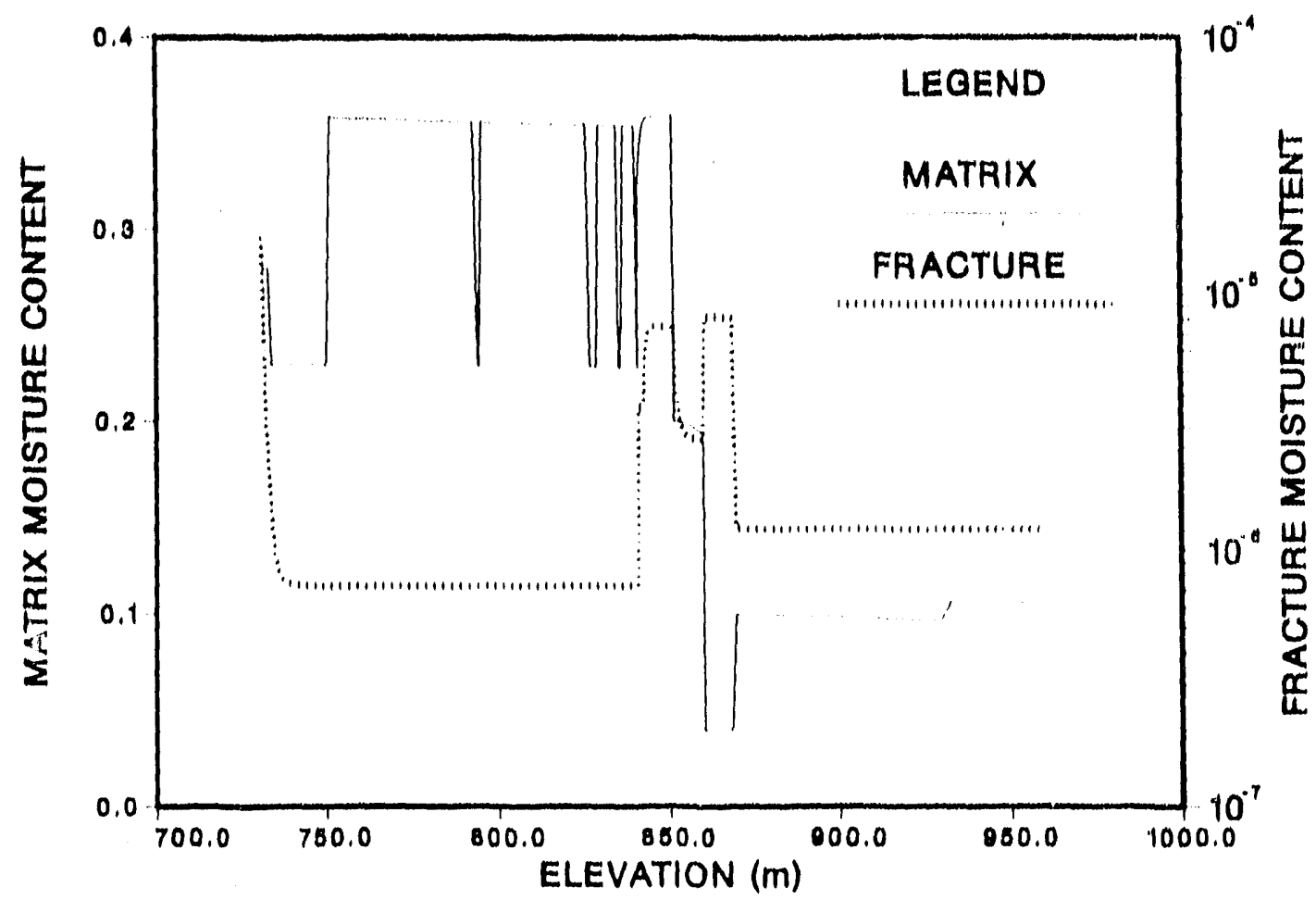

Figure 4.19. Matrix/Fracture Flow Model (Medium 'Transfer cofficient) - Moisture Content

figure 4.2()). Flow in the matrix and fractures all the waller lable is significantly different. At the water table, the flux in the matrix increases $1021.1 \%$ of the recharge rate and the flux in the fractures decreases $1078.9 \%$

Small transfer coefficient case. The small hanster coefficient case produces similat hehavior as the large transfer coefficient case. However, their are some differences worth noting.

The matrix pressure head for the small mansfer conefficient case (see fighne 4.21) is similar to the matrix pressure head for the large and medium cases. The fracture pressure heads are similar everywhere except at $843 \mathrm{~m}$ in layer 5 . Here here is a lange difference in the matrix and fracture heads (see figure 4.22), which is due to the smaller transfer coefficient. In fact, the fracture pressure alctually geses positive. 'Ithis indicates thatt the fractures satturate at this elevation. Apparently the pressure head difference becomes so strong due to small transfer coefficient thall the fractures must salluralle in order for waller to flow through this unit. The lotal head for the matrix and fractures reflects the head difference at $84.3 \mathrm{~m}$; otherwise, the lotal head is the same as for the large and medium calses (see lighre 4.23).

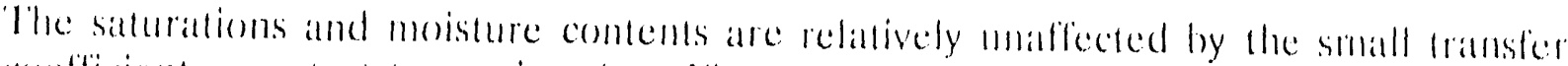
cocflicient except all two points (see liggure 4.24 and lïgure 4.25 ). At the boltom of 


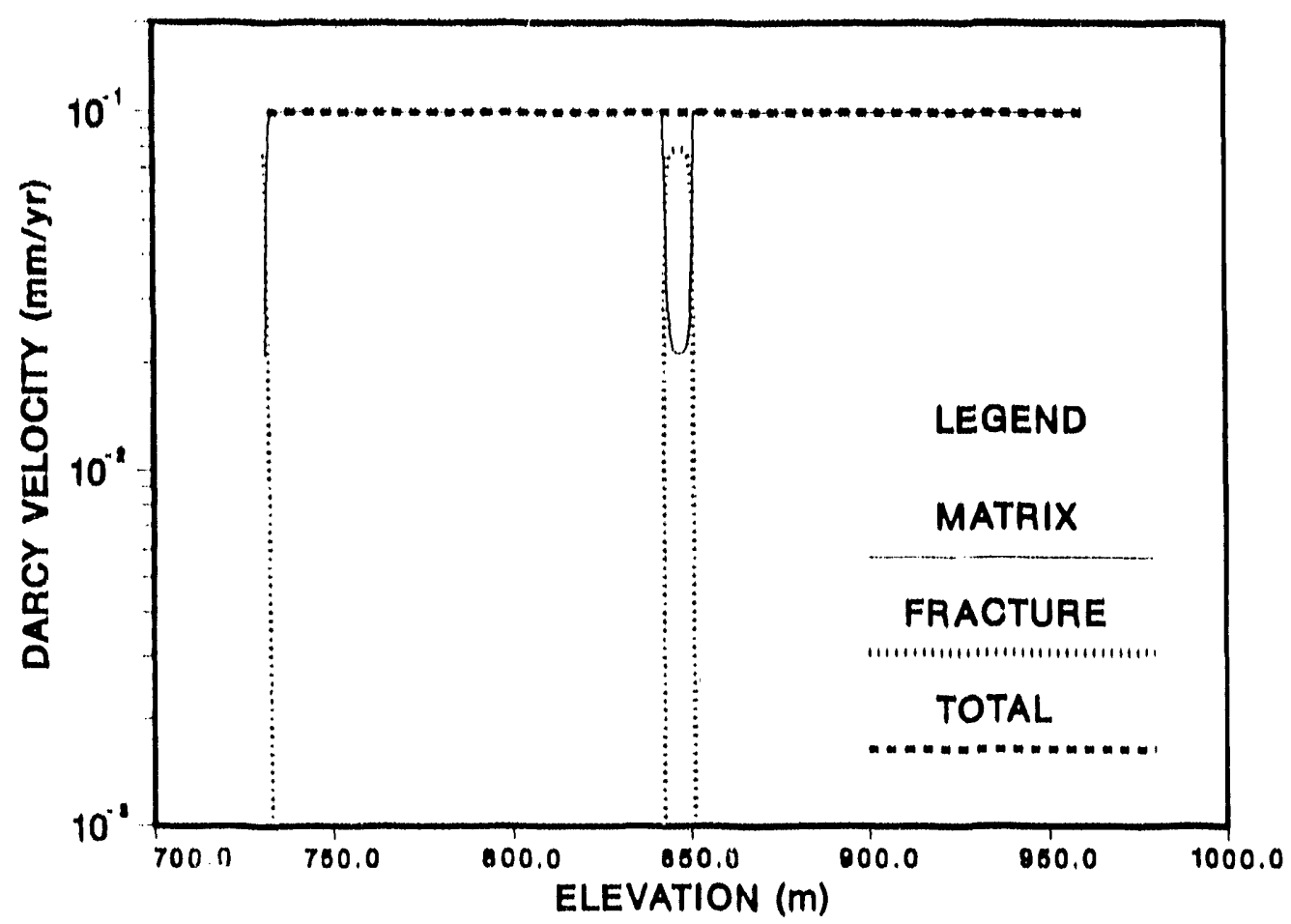

Figure 4.20. Matrix/Fracture Flow Model (Medium Transfer Coefficient) - Darcy Velocity

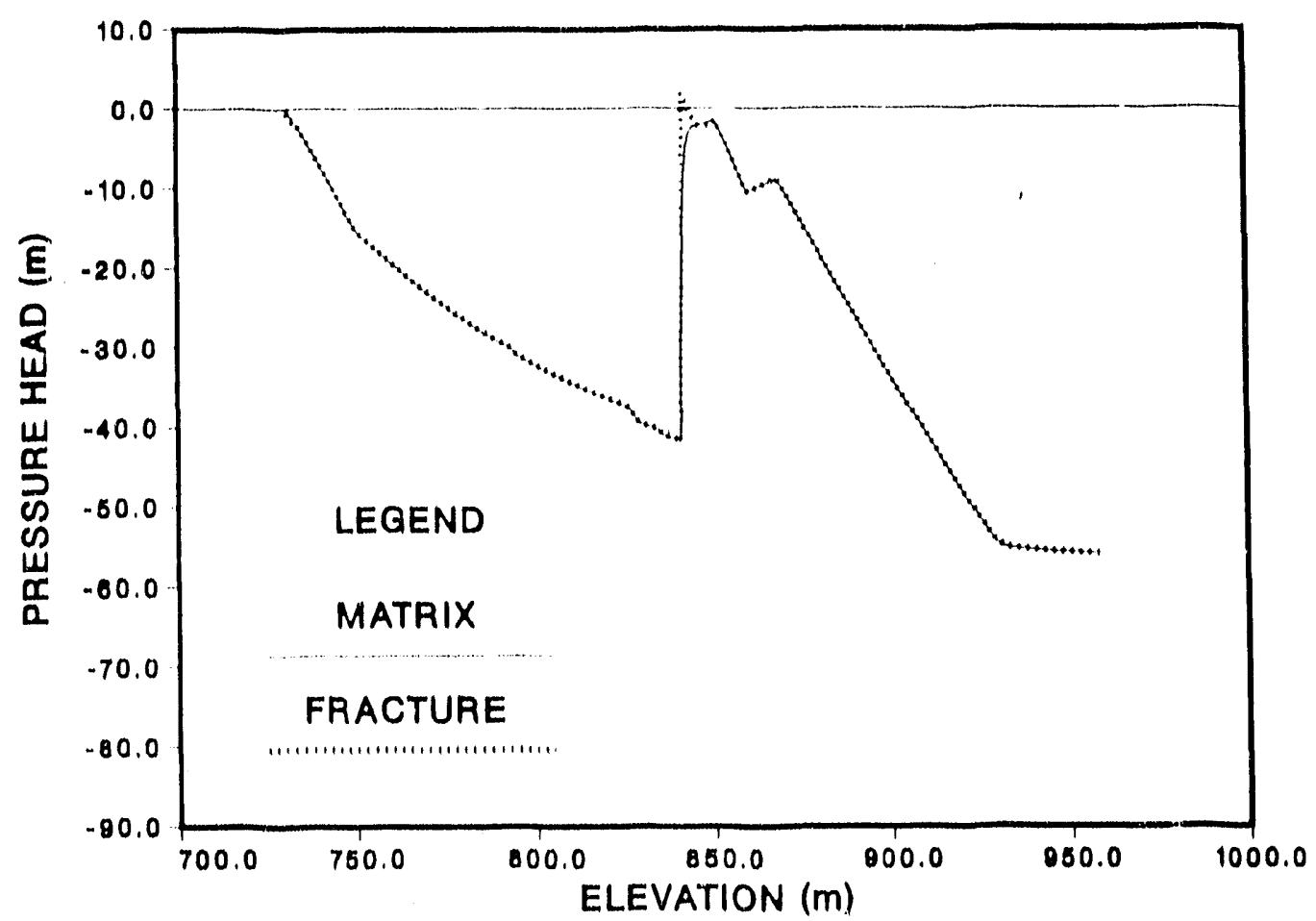

Fïgure 4.21. Matrix/fratcure lilow Model (Small Iransfer Coefficient) - Pressure Heall 


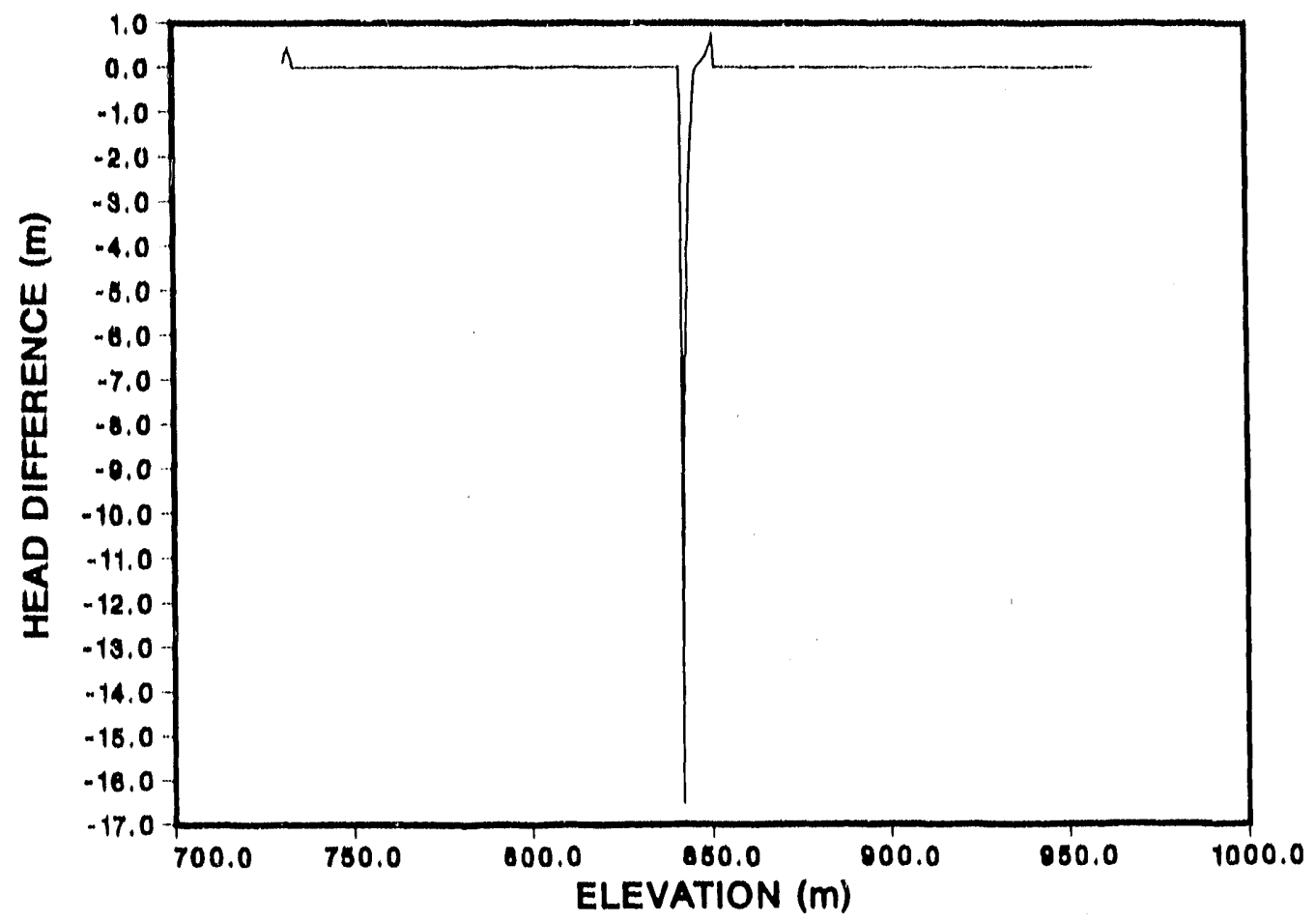

Figure 4.22. Matrix/Fracture Flow Model (Small Transfer Coefficient) - Head Difference

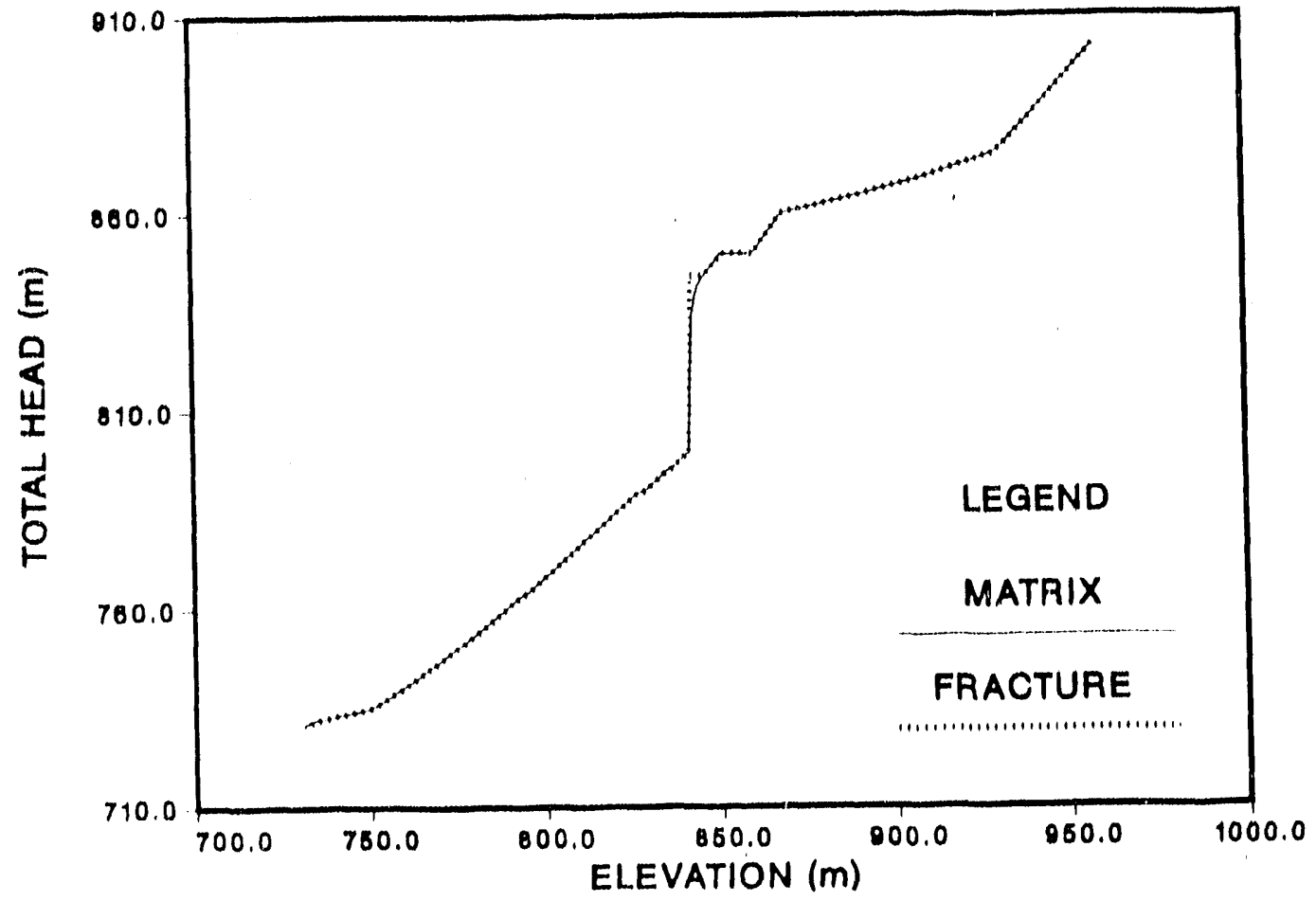

Iigure 4.23. Matrix/Fracture Flow Model (Small Transfer Coefficient) - T'otal Head 


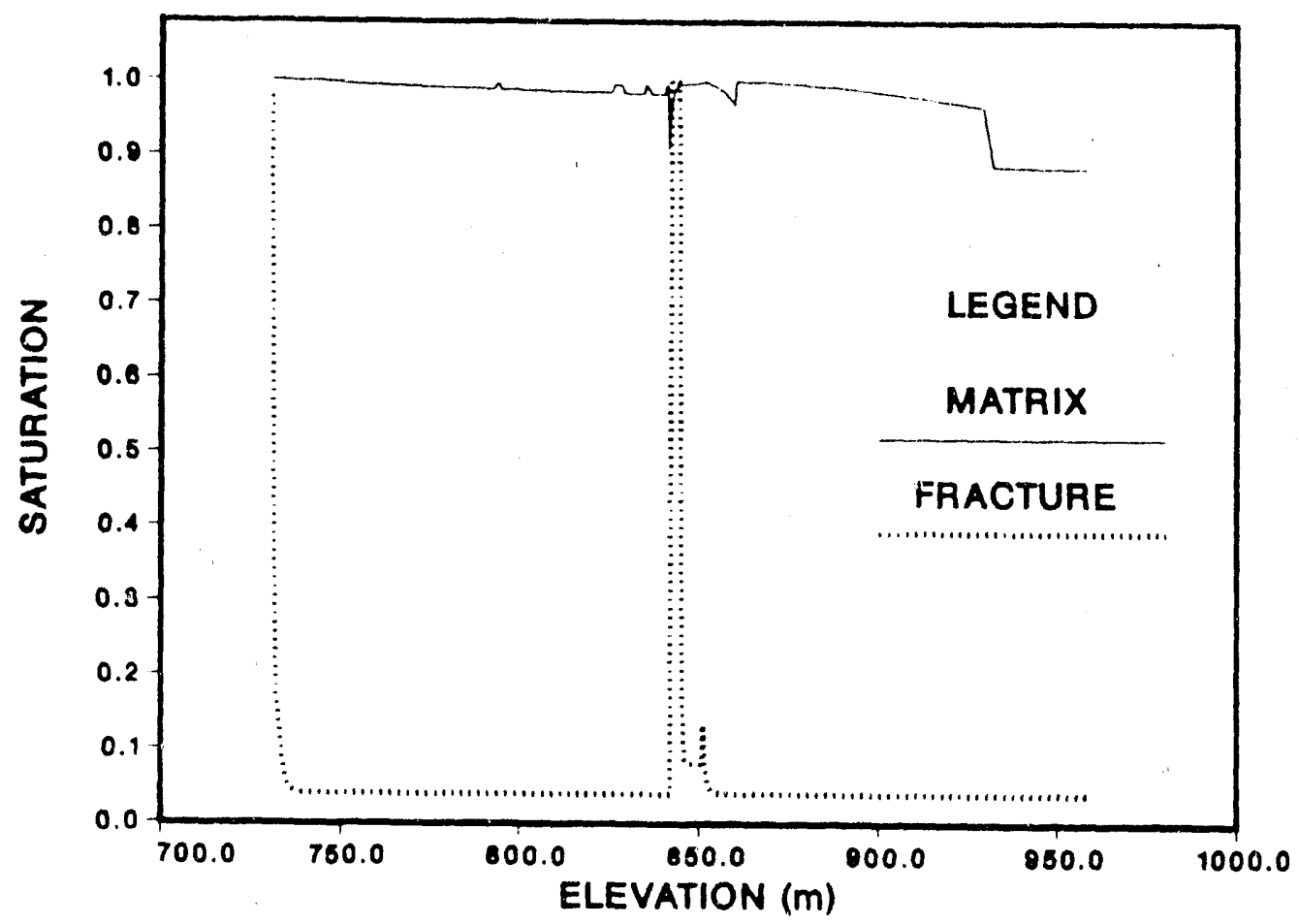

Figure 4.24. Matrix/Fracture Flow Model (Small Transfer Coefficient) - Saturation

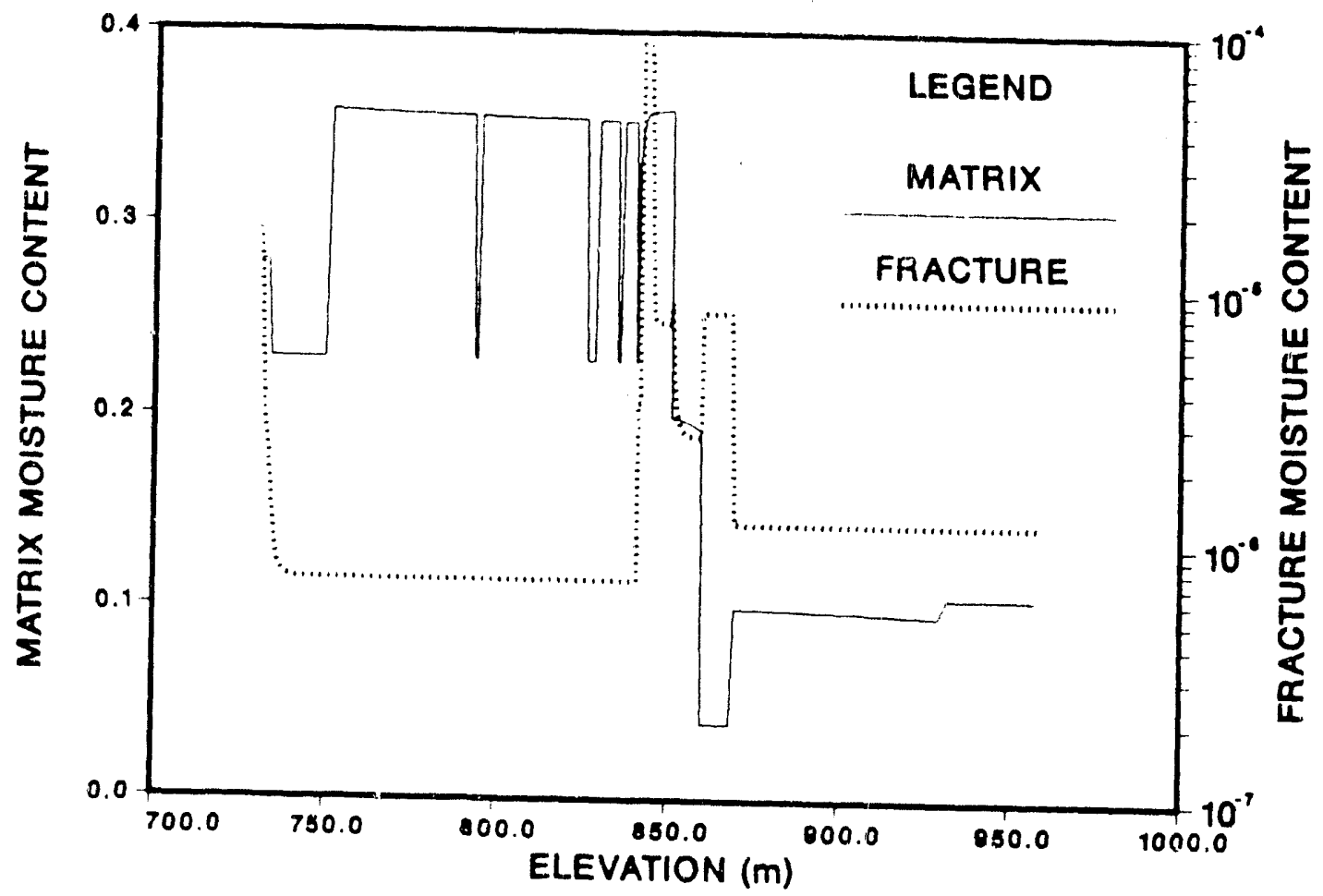

Figure 4.25. Matrix/Fracture Flow Model (Small Transfer Coefficient) - Moisture Content 
Layer 4 , there is a sharp peak in the fracture saturation. This is due to the large difference in the matrix saturated hydraulic conductivities between Layer 4 and Layer 5 . Near the bottom of Layer 5, the fracture saturation becomes 1.0, which reflects the positive fracture pressure head at that point.

Flow in the matrix and the fractures for the small transfer coefficient case are the same as in the large case (see Figure 4.26) except in Layer 5 and at the water table. Matrix flux in Layer 5 increases slightly to $23.3 \%$ of total recharge and fracture flux reduces slightly to $76.7 \%$. At the water table fluxes in the matrix and fractures are significantly different. The flux in the matrix increases to $54.1 \%$ of the recharge rate and the flux in the fractures decreases to $45.9 \%$.

\subsubsection{Alternative Stratigraphic Layering Flow Model}

Matrix and fracture pressure heads are equal and the pressure head gradient is negative throughout the entire column (see Figure 4.27). The pressure gradient in the region between the water table and $841 \mathrm{~m}$ averages $-(0.45$. The region between $841 \mathrm{~m}$ and $868 \mathrm{~m}$ shows a pressure head gradient of -1.0 . The pressure head gradient in this region is almost identical to the negative of the gravitational gradient because the matrix saturated hydraulic conductivity is very large compared to the recharge rate. Thus, only an extremely small gradient is necessary to cause water to flow through this region.

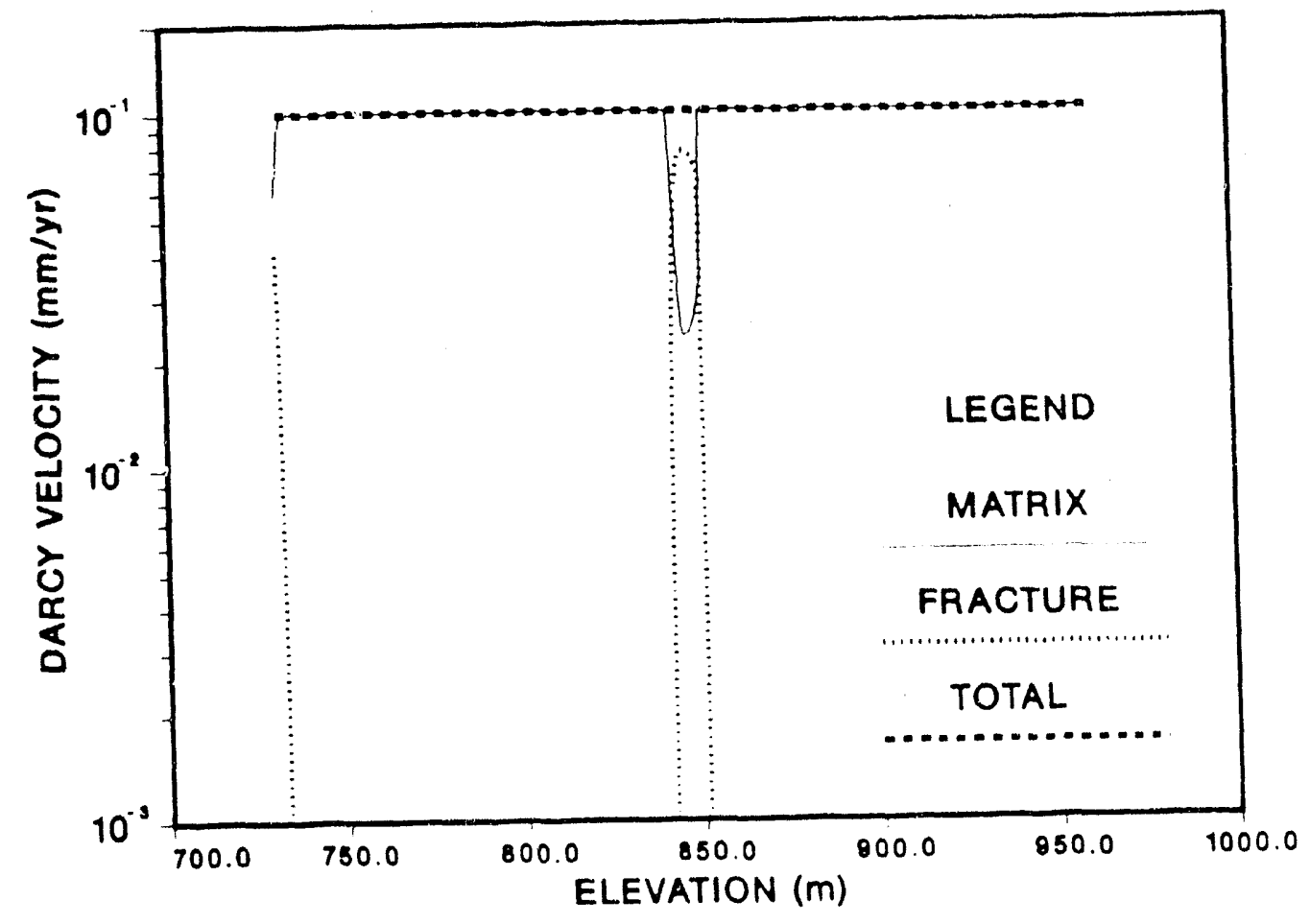

Figure 4.26. Matrix/Fracture Flow Model (Small Transter ('oefticient) - Darcy Velocity 


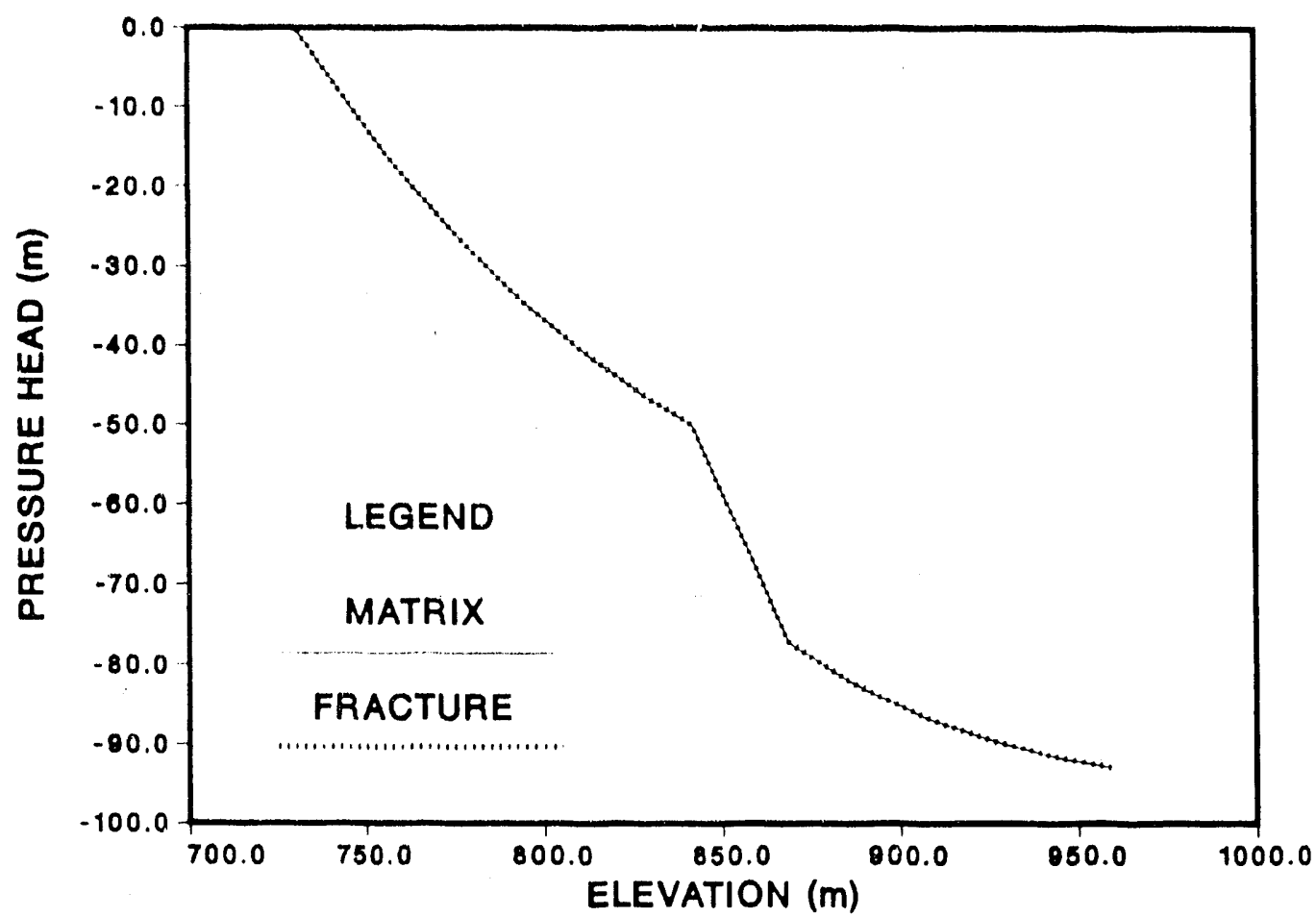

Figure 4.27. Four-Layer Stratigraphy Flow Model - Pressure Head

Above $868 \mathrm{~m}$, the pressure gradient averages $-(0.17$, which reflects a higher matrix hydraulic conductivity being assigned to this region than to the lowest region ( $731 \mathrm{~m} \mathrm{to}$ $841 \mathrm{~m})$.

Matrix and fracture total heads are equal also (see Figure 4.28). The total head gradient is positive everywhere and reflects the downward movement of water. In the region between $841 \mathrm{~m}$ and $868 \mathrm{~m}$, the pressure gradient is almost 0.0 . The matrix saturated hydraulic conductivity is very large compared to the recharge rate; therefore, only a small hydraulic gradient is necessary for flow to occur.

For the region between $841 \mathrm{~m}$ and $868 \mathrm{~m}$, in the simultaneous matrix and fracture flow conceptual models, the pressure and total heads were quite variable. The averaging of the hydrologic parameters in the alternative stratigraphy model removes this variability and smooths the heads in this region.

The matrix saturations are nearly $1 .()$ between the water table and $868 \mathrm{~m}$ (see Figure 4.29). Above this elevation the matrix saturations drop to 0.83 . The fracture saturations hover near the fracture residual saturation of 0.04 except near the water table. At the water table the fractures saturate as a result of the water table boundary condition. The moisture contents reflect the saturations and porosities of the various regions above the water table. 


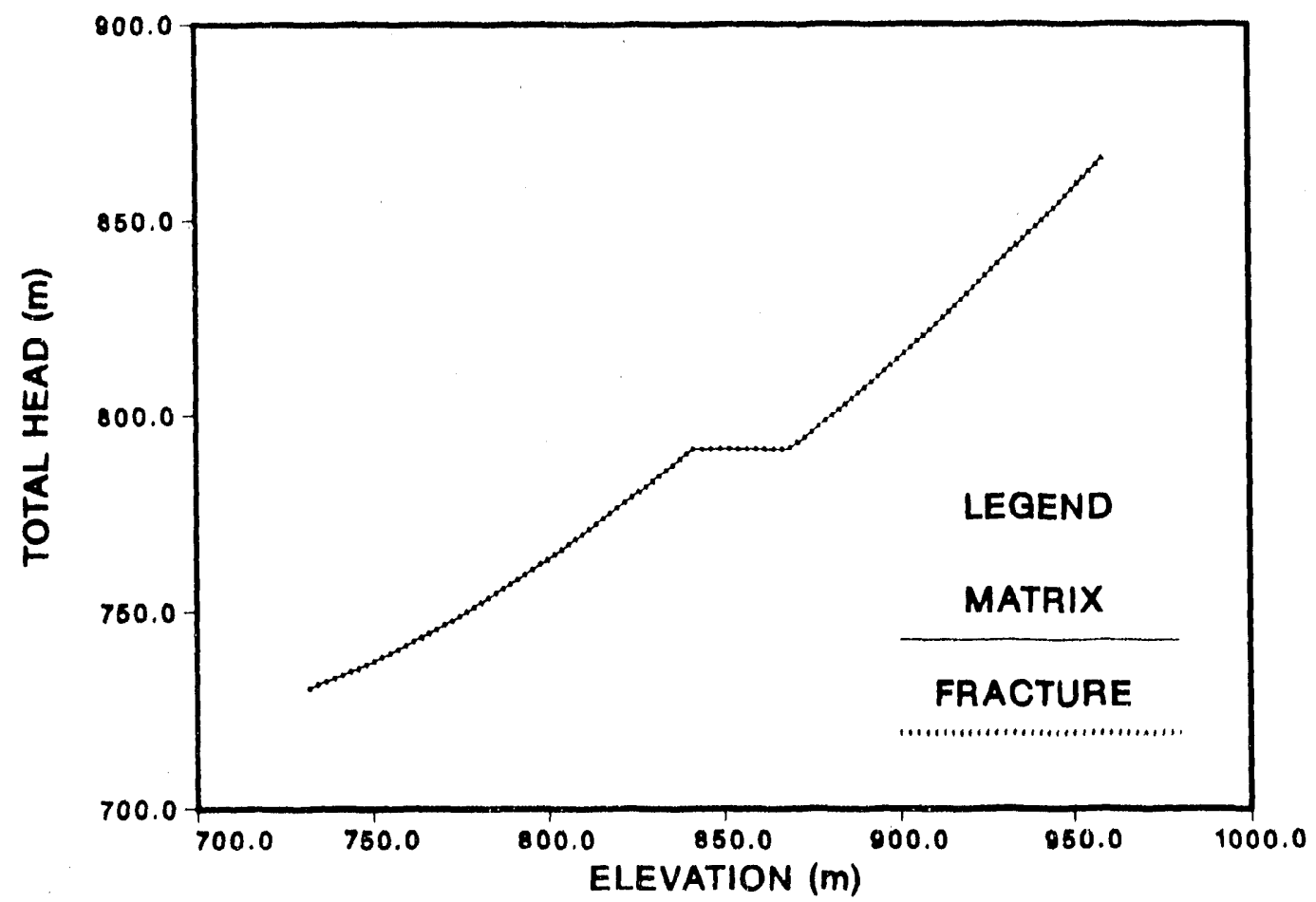

Figure 4.28. Four-Layer Stratigraphy Flow Model - Total Head

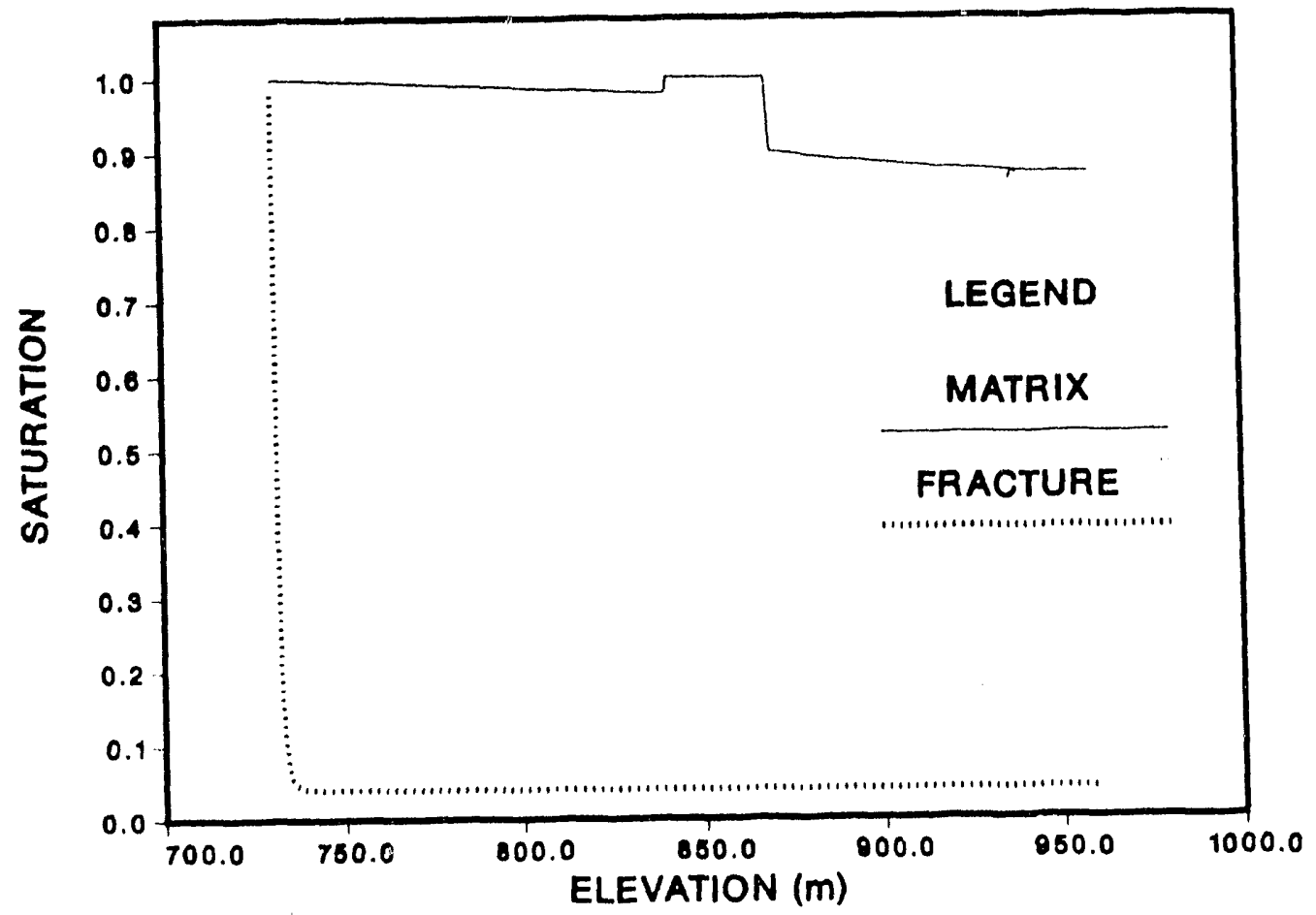

Figure 4.29. Four-Layer Stratigraphy Flow Model - Saturation 
The changes in moisture content are due almost entirely to porosity changes between the water table and $868 \mathrm{~m}$ (see Figure 4.30). Above $868 \mathrm{~m}$ the matrix moisture contents are determined mostly by the matrix saturation because it is lower in this region than in the region below $868 \mathrm{~m}$.

Throughout the entire column, except near the water table, recharge is carried entirely by the matrix (see Figure 4.31). This indicates that there is no exchange between the matrix and the fracture anywhere except at the water table. Near the water table the fractures begin to saturate and provide an easier conduit for flow than the matrix. Because the fractures have a much higher hydraulic conductivity than the matrix, they are capable of maintaining more flow than the matrix. At the water table the fractures carry $98.5 \%$ of the recharge and the matrix carries $1.5 \%$.

\subsection{Radionuclide Transport Simulations}

A summary of the alternative conceptual models is given in Table 4.1 . In terms of comparative results, it is obvious, and expected, that the all-fracture model resulted in shortest travel time, and that the all-matrix model resulted in the longest travel time. The travel time for the fracture-with-matrix-diffusion model is the same as the all fracture model because the travel times are based on the mean pore velocity of an

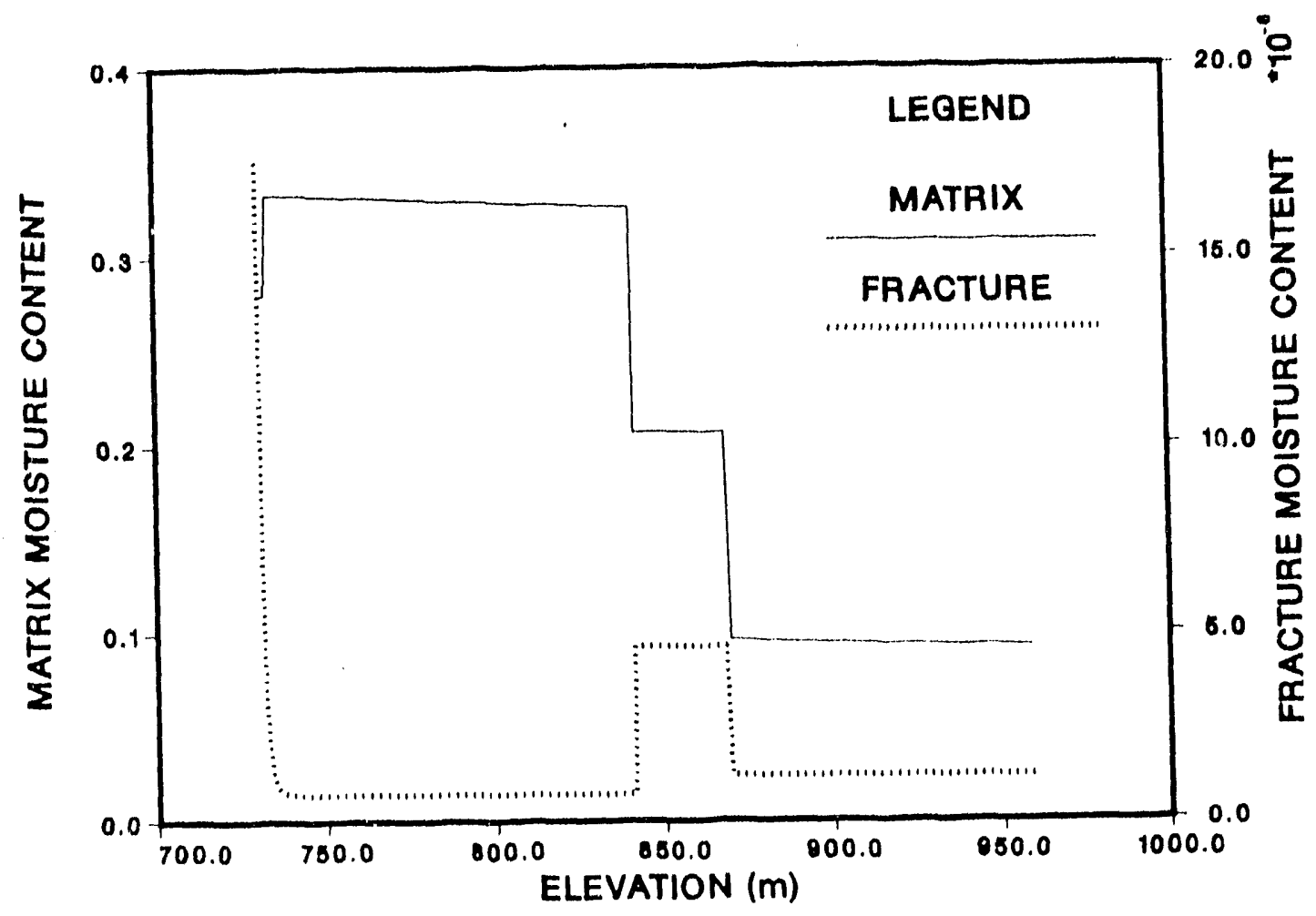

Figure 4.30. Four-Layer Stratigraphy Flow Model - Moisture Content 


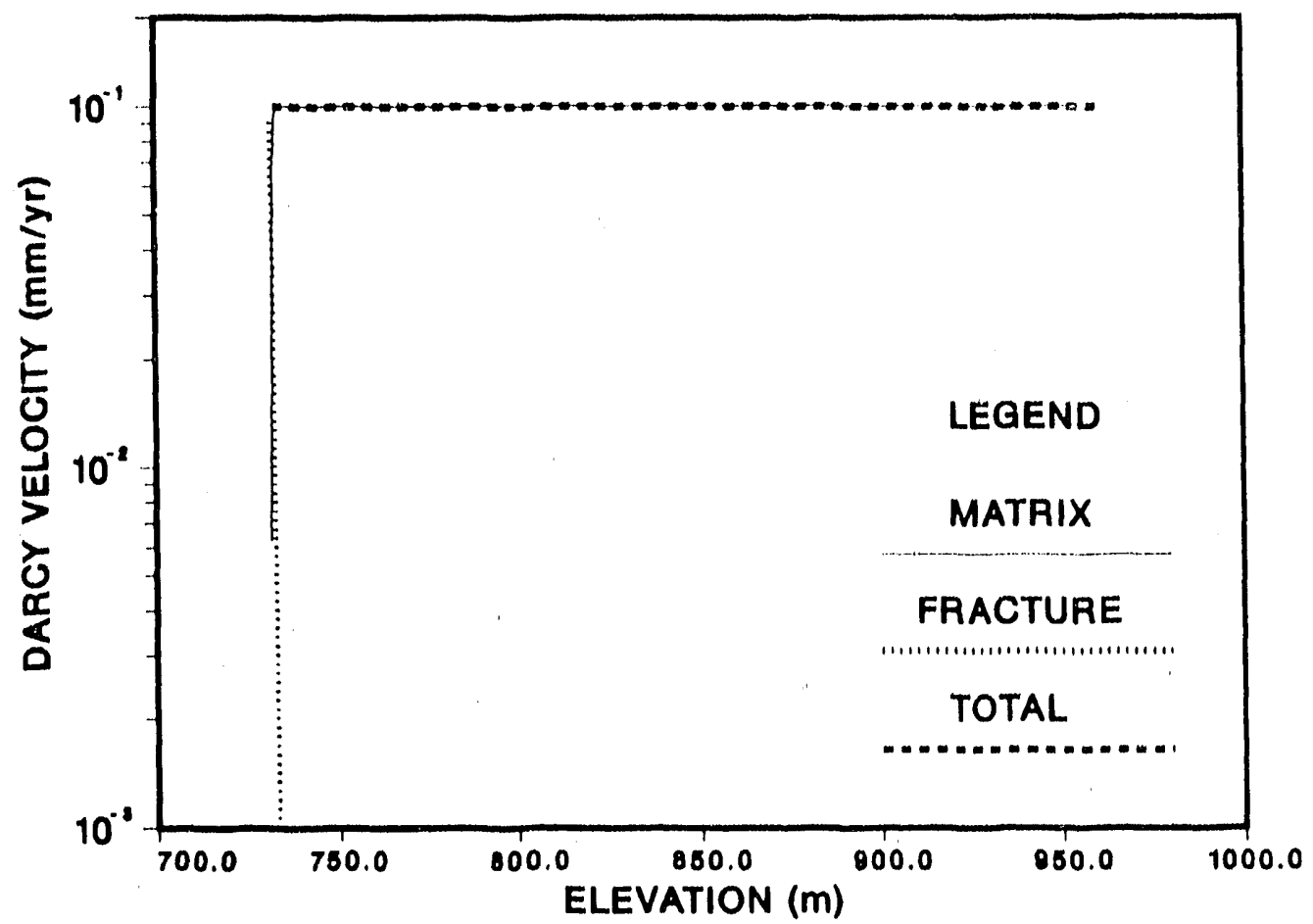

Figure 4.31. Four-Layer Stratigraphy Flow Model - Darcy Velocity

isotope that is not retarded. The contrast in pore velocities is clearly demonstrated in Figure 4.32. Shown in this figure are the mean pore velocities for the all-fracture, allmatrix, and fracture/matrix (i.e., dual-continuum) models as calculated by the D(M.3I) post-processor. Note that the curves are not smooth because the mean pore velocity in each leg in the transport path has been assumed to be constant across the entire leg. Large jumps in the velocity curve from relatively low velocities to relatively high velocities for the fracture/matrix model are indicative of a switch from matrix to fracture flow.

The remaining information provided in Table 4.1 is either prescribed data or is datat that are calculated by the DCM3D post-processor and are needed for the transport simulations. Although the first five conceptual models contained 1.5 hydrogeologic units except for the all-matrix model which contained 13, none but the all-matrix case contained the same number of transport legs as hydrogeologic units. As discussed in Section 3.2, the number of fracture legs and matrix legs is a function of the material properties and whether the dominant transport path switches from fracture to matrix or vice versa. For the all-fracture models (No, 2 and $N($ o. 3), several groups of adjacent hydrogeologic units had the same material properties and could therefore be grouped into a fewer number of equivalent legs. In the dual-continum models, however, the dominant transport path switched, within certain hydrogecologic units, from matrix to fracture and from fracture to matrix; therefore, the number of transport legs exceeded 
'lable 4.1. Summaly of Conceptual Model Properties

\begin{tabular}{|c|c|c|c|c|c|c|c|}
\hline & & $\begin{array}{c}\text { 1) } \\
\text { All } \\
\text { Malrix }\end{array}$ & $\begin{array}{c}\text { 2) } \\
\text { All } \\
\text { Fracture } \\
\end{array}$ & $\begin{array}{c}\text { 3) } \\
\text { Fracture } \\
\text { w/ Diff }\end{array}$ & $\begin{array}{c}\text { 4) } \\
\text { Dual } \\
\text { Comtinuum }\end{array}$ & $\begin{array}{c}\text { 5) } \\
\text { Equiv. } \\
\text { Porous } \\
\end{array}$ & $\begin{array}{c}\text { ()) } \\
4 \text { Laycr } \\
\text { Stratig. }\end{array}$ \\
\hline \multirow{4}{*}{ 'Transport } & $\begin{array}{c}\text { Fracture } \\
\text { Legs }\end{array}$ & . & 6 & 6 & 4 & 1.5 & 2 \\
\hline & $\begin{array}{l}\text { Mallix } \\
\text { Legs }\end{array}$ & 1.3 & - & . & 15 & 15 & 4 \\
\hline & $\begin{array}{l}\text { Simulation } \\
\text { Time (yrs) }\end{array}$ & $101^{4}$ & $10)^{4}$ & $10^{4}$ & $10)^{5}$ & $101^{5}$ & $10^{5}$ \\
\hline & $\begin{array}{l}\text { Exchinnge } \\
\text { cinclfi. }\end{array}$ & - & . & $0 .(5)() 1$ & . & - & - \\
\hline \multirow{3}{*}{ Flow } & Continumm & single & single & single & dual & dual & dual \\
\hline & $\begin{array}{l}\text { Coupling } \\
\text { Torm }\end{array}$ & - & . & - & 1 & 1 & 1 \\
\hline & $\begin{array}{l}\text { Travel } \\
\text { Time (yrs) }\end{array}$ & $1.3 \times 10^{\prime \prime}$ & 14 & 14 & $5 .(1) \times 10^{5}$ & $4.8 \times 10^{5}$ & $5.4 \times 10^{5}$ \\
\hline
\end{tabular}

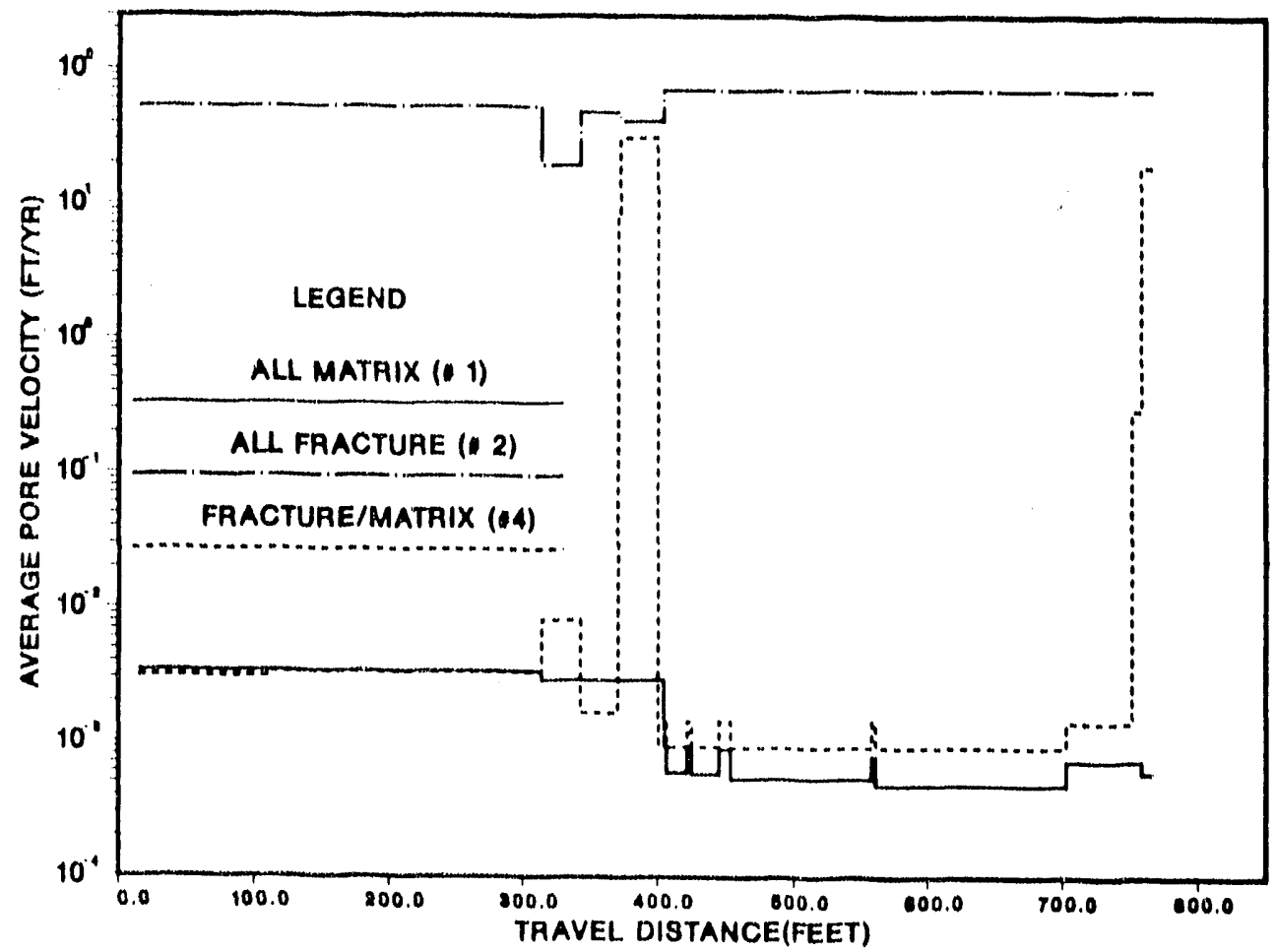

Fïgure 4.32. Pore Velocities for All-Fracture, All-Matrix and Fracture/Matrix (onceptual Models. 
the mumber of hydrogeologic units.

The fracture/matrix coupling term used in the flow calculations (which were in turn used 10 gencrate transport migration paths) was the largest of the three. The transport fracture/matrix mass exchange coffeicient was relatively high compared to the values used in the study by Bonano et al. (1989); however, they were using values for a sallurated system. Appropriate values for the transfer or coupling terms (for both flow and transport), and what those values imply has yet to be properly addressed and, therefore, is still not clear.

Because the desired transport result is total integrated release, expressed in terms of a. ('DFF, the radionuclide transport simulations were conducted in a manner such that mulliple data sets were accessed and run without user intervention between runs. The multiple data sets were the result of the random sampling described in Section 3.3. Because of the nature of this procedure, intermediate results from individual runs, such ats isotope-specific cumulative release and release rates, were not reported. In spite of this, one set of sampled data was used to illustrate the impact of different conceptual models on intermediate results. An example of cumulative releases over the simulation tinke for the individual radionuclide species transported is shown in Table 4.2. These

lable 4.2. Cumulative Isotope Release to Water Table using NEFTRAN II

\begin{tabular}{|c|c|c|c|c|}
\hline \multirow{2}{*}{ cinceptual Model } & \multicolumn{4}{|c|}{ Cumulative Release lo Watce Tahle (ci) } \\
\hline & "re & $\left|x x^{\prime}\right|$ & 1.5. & ${ }^{231} \mathrm{~Np}$ \\
\hline 1) All Malrix. & 197 & 7.1 .5 & (1).0) & $(0,0)$ \\
\hline$\therefore$ All friacture t. & $0.26 \times 10)^{4}$ & 1510 & $1.68 \times 10^{4}$ & $(1) .(4.43$ \\
\hline 3) Iraclure w/ Malrix Diffusion ** & $5.8 \times 10^{-4}$ & $8.5 \times 10^{7}$ & $4.5 \times 10^{12}$ & $4.3 \times 10^{-1.5}$ \\
\hline 1) |xial (imlinumm* & $5.29 \times 10^{4}$ & 515 & 0.0 & (1).1) \\
\hline i) I:yuivalene Porous Medium * & $5.52 \times 10^{4}$ & 416 & $(1) .0$ & 0.0 \\
\hline (1) Pour-laber Stratigraphy * & $3.41 \times 10^{4}$ & 53.5 & (1).11 & 0.0 \\
\hline
\end{tabular}

111 year simulation

- $111^{\prime}$ y'atr simulation

values were gencrated using the random sample that resulted in the fargest LPA sum. The IPA sum is the sum of the individual isotope's cumulative release normalized by He wripinal inventory and the EPA contamment requirements for that isotope. Agan, tone that the simulation times for the all-fracture and fracture-with-matrix-diffusion models were 10$)^{4}$ years while that for the other models is $10^{5}$ years. Also note that the 
cumulative releases given in lable 4.2 have not been normalized by the quantity of waste and the EPA release limits provided in 40 CFR Part 191 (Appendix A, Table 1; LPA, 1985), as they would be when generating the CCDFr.

The cumulative release to the water table for the all-fracture conceptual model and for all the radionuclides is, for all practical purposses, equal to the cumulative release from the source. This is because of the relatively short travel time for this case, which results from the relatively high fracture velocities and lack of radionuclide retardation in the fracture continumm. Also, because of the very short travel time, a negligible amount of the inventory is lost to radioactive decay. Obvious from Table 4.1 is that adding any matrix transport and/or matrix retardation significantly decreases the cumulative release. In fact, for ${ }^{135} \mathrm{Cs}$ and ${ }^{237} \mathrm{~Np}$, any of the models that contain matrix transport result in zero release to the water table, primarily because of the high matrix retardation factors for these two isotopes. Note that, even for the long simulation times, little of the initial inventory is lost as a result radioactive decay, because of the long half-lives of the radionuclides. For example, over 10$)^{5}$ years, $28 \%$ of ${ }^{1 \%} l^{2}\left(100.4 \%\right.$ of ${ }^{221} 1$ is lost to decaly.

Similar information aboul transpont calculalions is conveyed in fighne 4.3.3, where the release rate as a function of time is plotted for ${ }^{129}$. These are the release rate curves that were used 10 calculate the cumblative releases for ${ }^{12} \mathrm{I}$ in lable 4.2 . The four conceptuat models that include matrix transport have heathlorough times for release greater than $10^{4}$ years; therefore, 10 produce comparative results, a $10^{5}$ year simulation

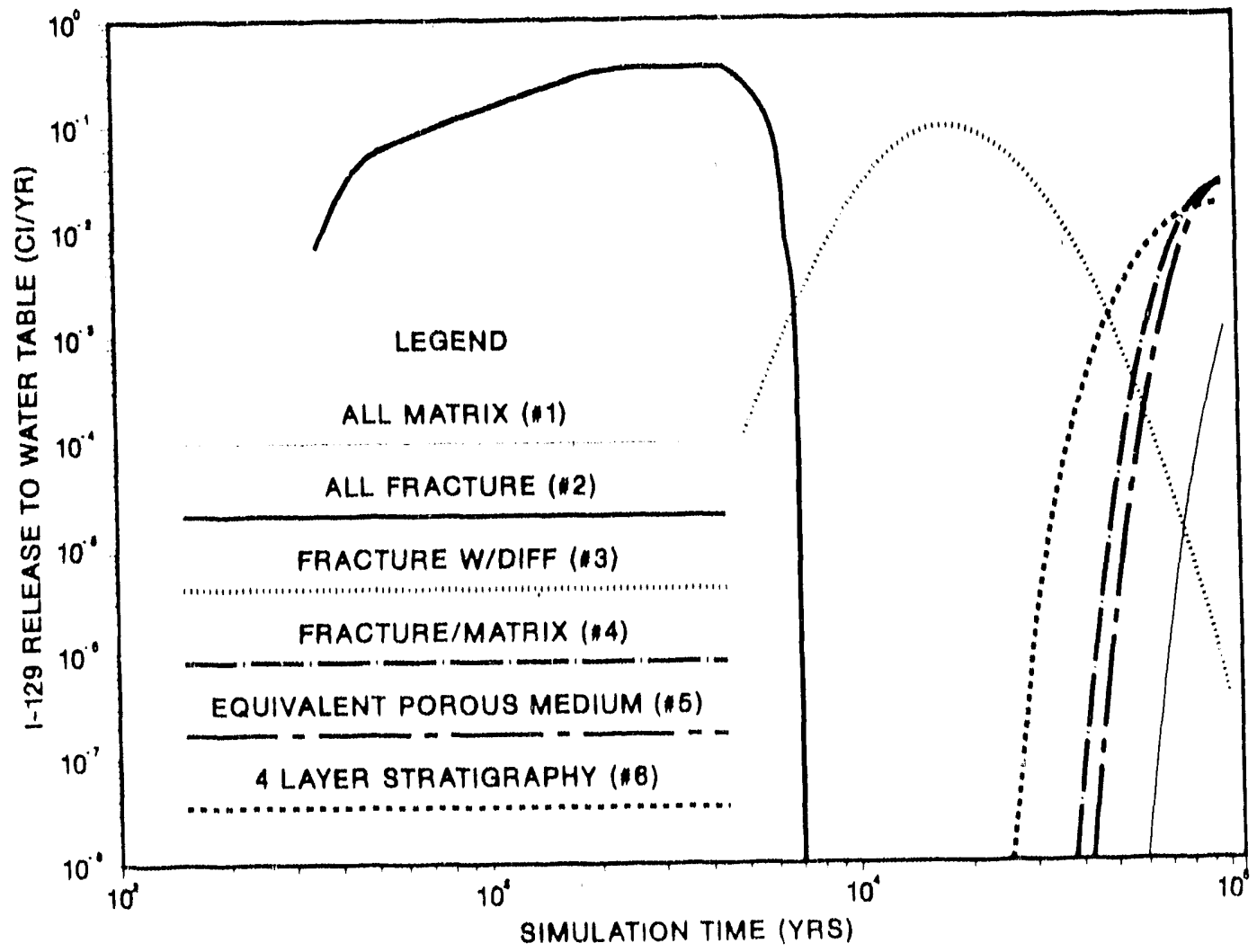

ligure 4.33. Relealse Rates to Water Table for I" I 
time was needed for these models. Note that the release rate for the all-fracture model, on the other hand, is virtually identical to the release rate from source (see figure 3.1 ), both in breakthrough the and magnitude of release. The delay of 14 years (mean travel time for the all-fracture model) is not discernible in ligure 4.33 . The inclusion of malrix diffusion significantly delayed the time of release although this model had the salme mean travel time as the all-fracture model.

\subsection{Assessment of Alternative Conceptual Models}

The CCDFs for the four alternative conceptual models that include any matrix transport are shown in Figure 4.34. 'The simulation time for each of these conceptual models was $10^{5}$ years. The EPA Containment Requirement $(\$ 191.13)$ is shown in the figure only (o) illustrate where the regulation lies on the plot. The containment requirement is in no way included to assess the site's ability to show compliance. Fifty realizations were used to generate each of the CCDFs shown in the figure. For the most part, the results are not surprising, except for possibly the all-matrix catse (No, 1). Only a f'ew parameter combinations for the all-matrix conceptual model resulted in realizations with summed normalized release greater than $10^{-2}$, and $n$ on combinations resulted in realizations with release greater than 1 . The other three matrix-transport conceptual models (No, 4, No. 5 , and $\mathrm{N}($ ), 6), on the other hand, had several realizations with summed normalized release greater than $10^{-2}$ and a few realizations with releatse greater than 1 . Although

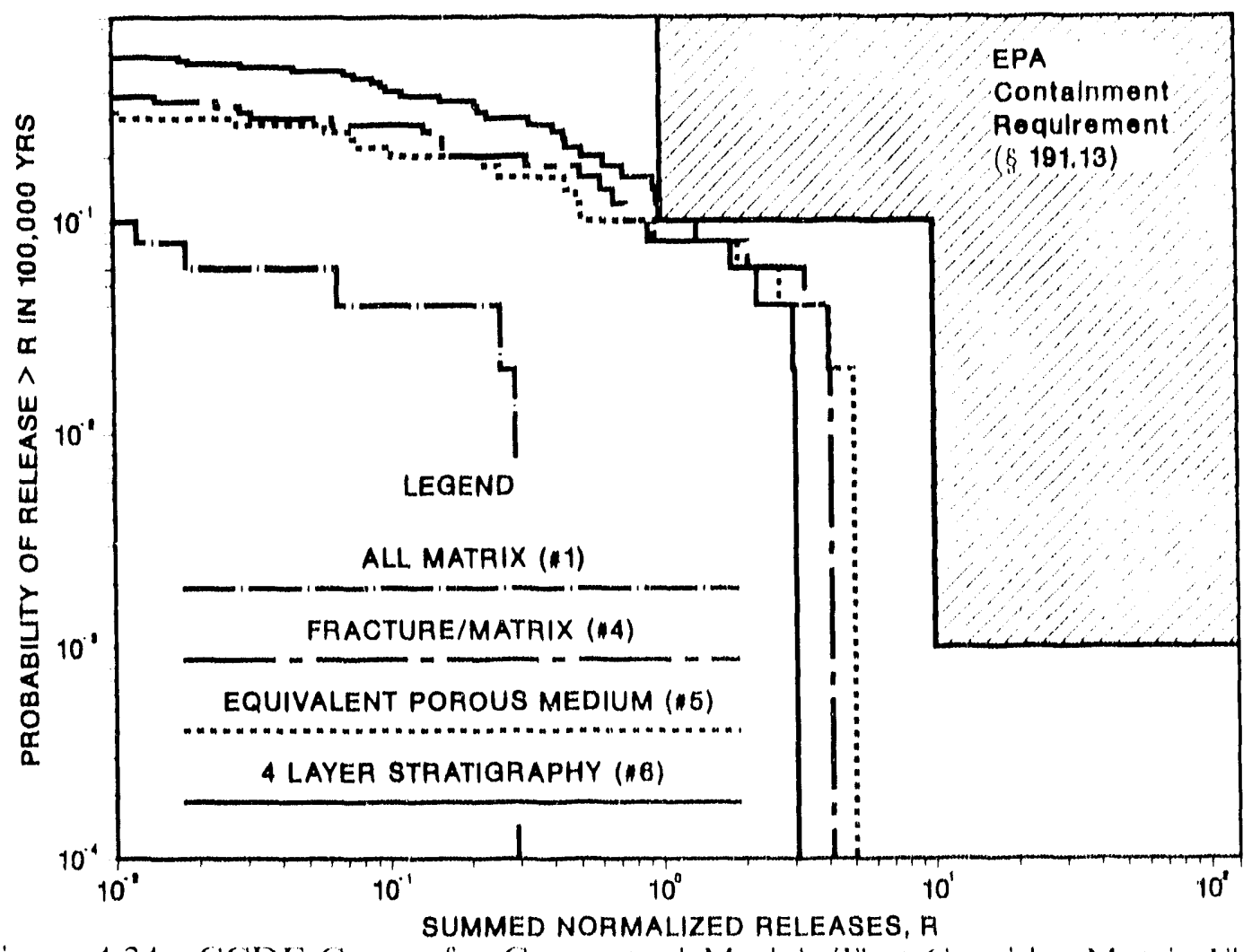

Figure 4.34. CCDP Curves for Conceptual Models 'l'hall ('omsider Mallix lilow and Transport 
It is ang shown in the ligune, all of the models had a number of zero-release realizations. Becallse the probability of release being greater than the summed normallaed release (y-axis value) must be 1 when the smmmed mormallzed release ( $x$-axis value) is zero, there may be a latge jump) ha the ('I)fi y-value at this polnt. One would expect that becaluse the majority of the flow and therefore, the transport, would occur h the matrix continumm, the four models would be yulte similar. However, remember that the latter three conceptual models, because liney were not restricted to matrix flow only, contained some fracture legs in the transport migration path. These fracture legs can, by the way the conceptual models are defined, act as hypasses to their matrix counterparts in the matrix-only model. Because the pore velocities in the matrix legs are so much lower Han in the fracture legs, the transpont in the matrix legs dominates the total release curve. Iherefure, having only a few matrix legs that would otherwise be fracture legs, can decrease the releatse of radionuclides significantly. This seems to be the case with the conceptual models shown.

()) the three fiftedn-latyer conceptual models containing matrix transport, the equivalentporous-medium tra'msport model (No. 5), conceptually, should result in the greatest release becaluse it moludes dransport in both fracture and matrix simultaneously. This is not very obvious from fïgure 4.34, however. In fact, for the high-probability, lowconseyuence realizations, the equivalent-porous-medium model consistently resulted in a greater number of lower releases than the fracture/matrix model (No. 4). This is a conseyuence of the manner in which the transport pore velocities and retardation factors were varied. In the fracture/matrix model, the pore velocities and the retardation fiachers were varied independently (i.e., they were uncorrelated). Therefore, for a given pore velocity, both high and low retardation factors may be realized, resulting in a variety of effective transport velocities. In the equivalent-porous-medium model, on the oller hand, an equivalent velocily wats defined in terns of the velocities and retardation factors in the fracture and in the matrix. Only this equivalent velocity was varied (over the same range as the pore velocity for the fracture/matrix model), and the retardation factors were comstant. In a sense, the velocity and retardation are completely correlated. Therefore, relardation factors were not allowed to affect the effective transport velocity as they were in the fracture/matrix model. As a result, the equivalent-porous-medium model results in a greater mumber of low reteases, and also a greater number of high releases than the fracture/matrix model. If the velocitiss and the retardation factors were valled in the same way in each model, the equivalent-porous-medium model would comsistently have fower low-release realizalions and more high-release realizations.

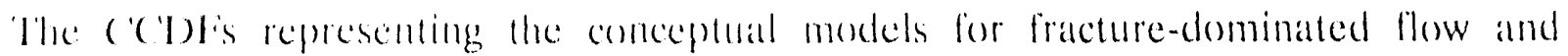

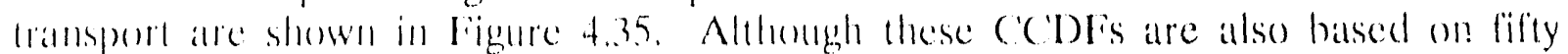
realizations, lhe simmlation lime is only lot years. From Figures 4.34 and 4.35 , it is obvions that given the assmmptions of the conceptual models in this investigatlon, the

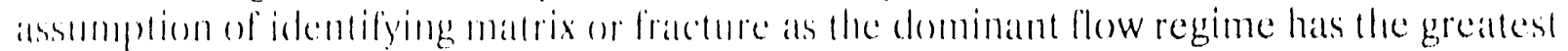
impate on the performance measmere. Although not shown in these figures, whenever a mallix bleck on leg is included in series with fracture legs, the releatse is reduced

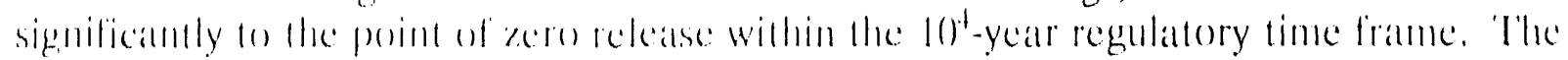




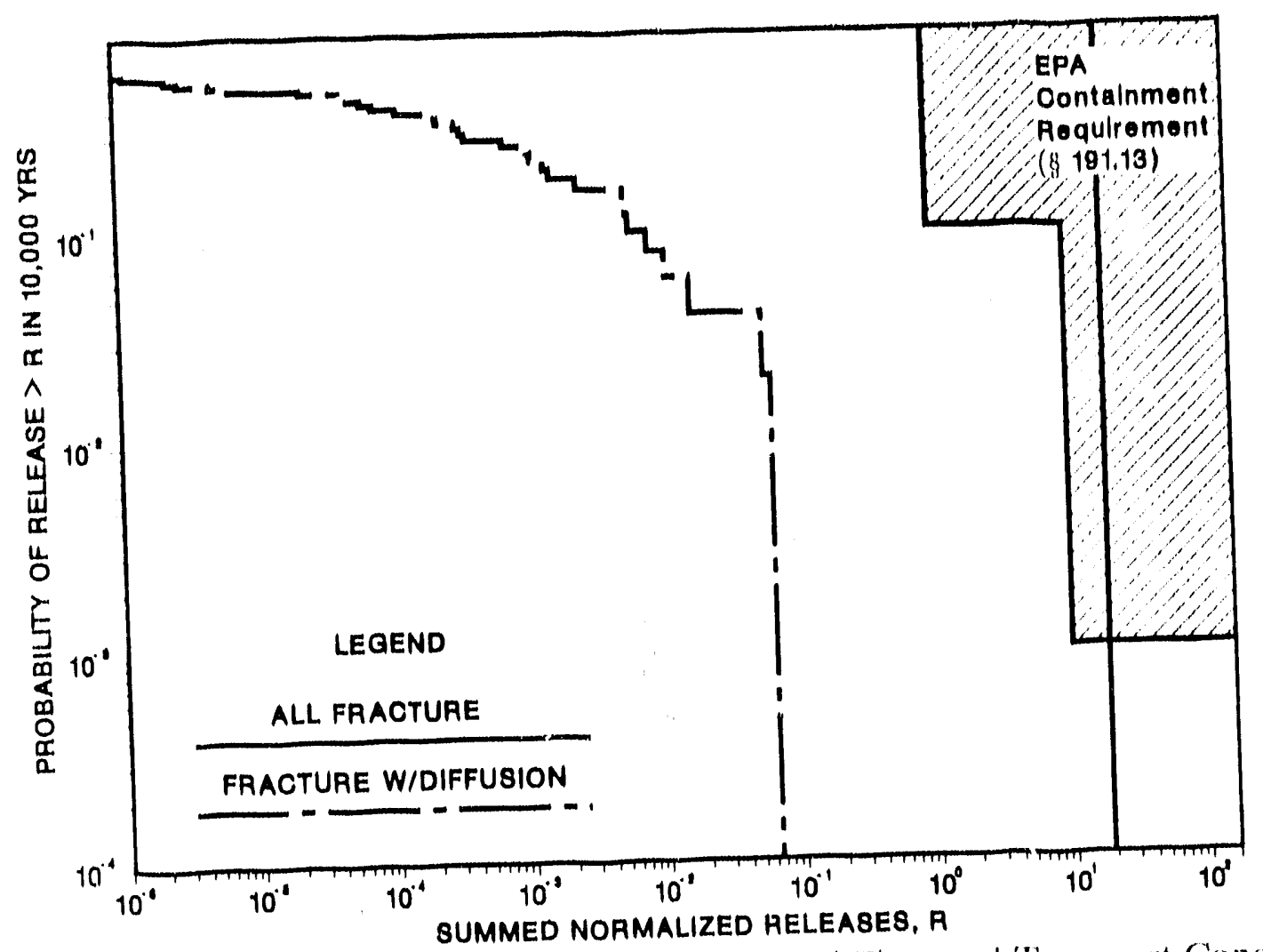

Figure 4.35. CCDF Curves for Fracture Dominated Flow and Transport Conceptual Models

vertical CCDF curve for the all-fracture case indicates that the entire inventory of radionuclides is released to the water table for all realizations. This is not very surprising in that fracture retardation faciors were assumed constant and equal to 1 for all radionuclides, and that the fracture velocities were relatively high. Matrix diffusion (n)viously has a significant impact on integrated release. This is not only because the matrix acts as an immobile storage volume, but also because the radtonuclides that diffuse into the matrix are assumed to be able to adsorb to the matrix surface. Given the ansumptions of these conceptual models, matrix diffusion can result in decrease in stlmmed normalized releases over several orders of magnitude.

Also of particular interest in this investigation was the number of samples or realizations hlat were used to generate the CCDFs. The CCDFs of the four models which include millix Iransport were presented in Figure 4.34. These were generated using 5() random bimples, giving each realization of the summed normalized releatse a probability of $1 / 50$ if eccurring. In Figure 4.36, however, 5)() samples were used to generate the (CD) giving cach realization a probability of $1 / 5(0)$ of occurring. This result of a larger mumber of samples is characterized by a greater number of extreme results. 'That is, will at larger sample size, and therefore more parameter combinations, one would expect it langer number of high releases, as well ats a larger number of low releases. In actuality, there is a larger number of realizations at all levels, but with more samples higher and lower releases will he realized. This is quite evident in the figures. Moss 


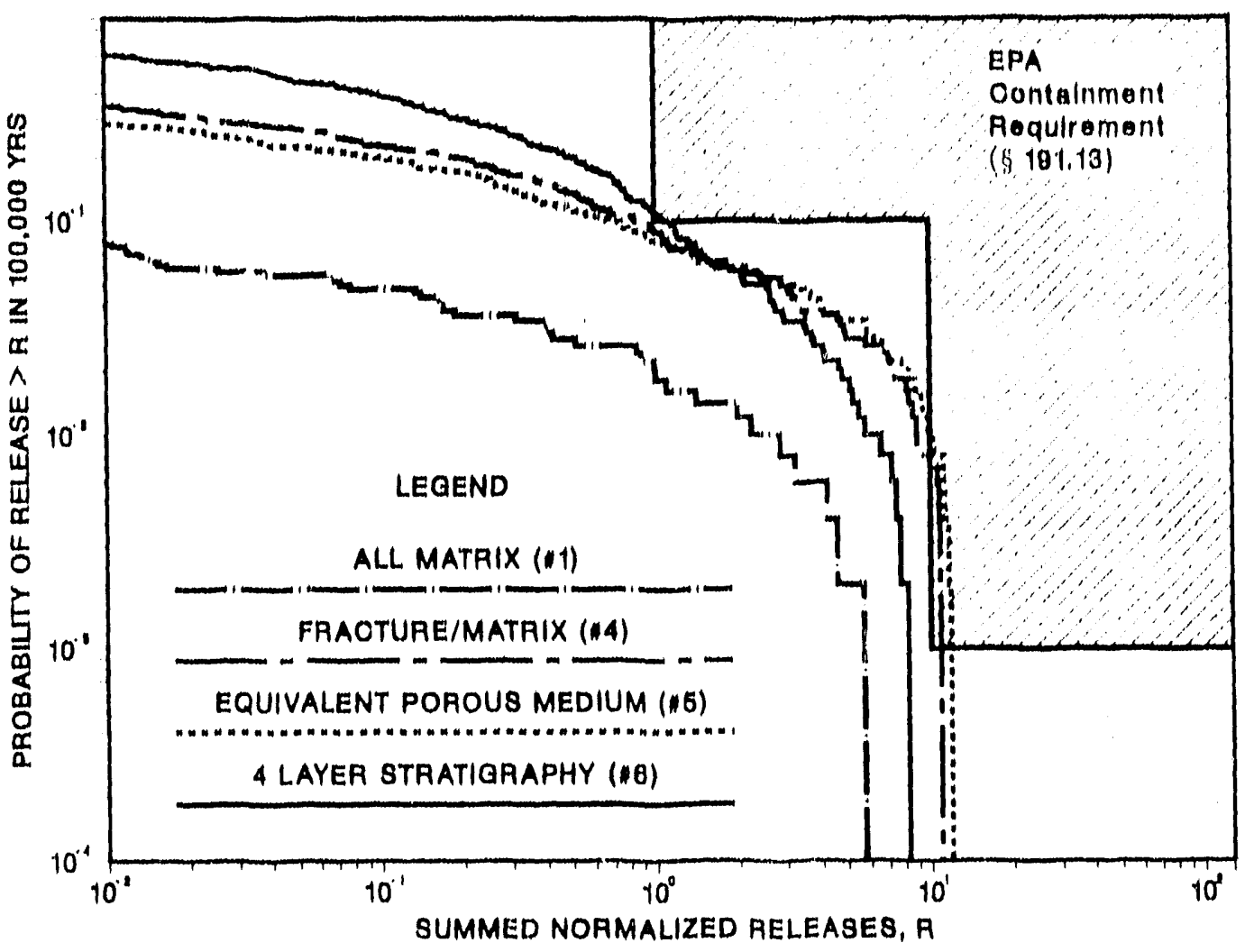

Figure 4.36. CCDF Curves for Conceptual Models That Contain Matrix Flow and Transport (Sample Size $=5()())$

significantly impacted is the all-matrix case. After a certain point, increasing the number of realizations will not result in any higher releases (i.e., convergence will be achieved). If one is comparing with the EPA Containment Reguirements, which requires less than one chance in 1000 of exceeding a given value, then it would be logical to require at least $10(0)$ simulations. A greater number of samples also assists in clarifying information about the behavior in the CCDF curves.

Some trends in the behavior of the CCDF curves for the different conceptual models are evident in Figure 4.36. In this figure, the CCDF for the four-layer stratigraphy model crosses over the CCDFs for the two fifteen-layer stratigraphy models. The trend is not as obvious in Figure 4.34 because there are few realizations beyond the cross-over point. I'te cross over occurs because there is less variability in the results of the four-layer stratigraphy. That is, the four-layer stratigraphy model results in fewer low-release realizations and fewer high-release realizations. (onceptually, this results hecause the release or (breat:through) curves for the four hayer case have, in general, a broader distribution than the fifteen-layer case. The broader distribution in the four-layer catse is the result of effectively greater dispersion. Dispersivily values were assumed to be une-tenth of the leg length, and for the fonr-layer cisse, in NLFTRAN, these were

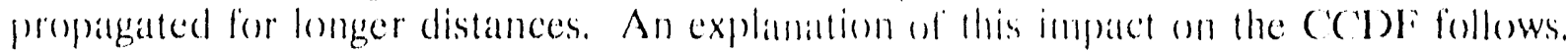

for very short travel times, all solutes would he released, and for very long travel times, 
none of the solute would be released, regardless of the spread in the release curve; however, for intermediate travel times, only a portion of the solutes are released. 'Ilice amount that is released for these intermedlate travel times is a function of the spread in the release curve. fer example, for an intermediate, but somewhat long travel line,

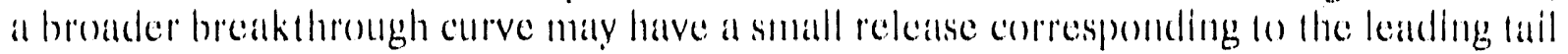
of the curve, whereas a narrower breakthrough corve will have less releatse. 'llie converse is true for intermediate, short travel times; the narrower breakthrough enrve will result in a greater release than the broader breakthrough curve becallse the solutes representing the tralling tail of the broad curve are not released. 'The impace of this behavior on the CCDPF is that the narrower breakthrough enrves will tend to have more "all-or-nothing" release realizations than the broader breakllowgh curves. 'This is exhibited as more variability in the (CD) for the narrower breaklhrough curves.

Similar crossover behavior is evident between the equivalent-porous-medium model and the fracture/matrix model, but for the reasons described earlier (differences in the way velocities and retardation factors were simmpled). 


\subsection{SUMMARY AND CONCLUSIONS}

Some important qualifications have been recognized for the analysis presented. These qualifications are presented in Section 1.3 of this report and were due mainly to the limited scope of this investigation, and also to the numerical and mathematical constraints on the calculational tools applied. These limitations notwithstanding, the comparison between CCDFs has been used to assess the importance of fundamental assumptions on a hypothetical HLW repository site's performance, under a given set of acumptions. This investigation, therefore, directly addresses the issue of conceptual model uncertainty. This is considered to be a critical issue for performance assessment of HLW disposal sites.

Becatuse the CCDF, in general, incorporates all sources of uncertainty (including conceptual, mathematical, and numerical model uncertainty, data and parameter uncertainty, and uncertainty ahout future states of the system) it can be difficult to discern which source(s) of uncertainty contribute most to changes in the CCDF. For this study, however, the same mathematical and numerical models and data and parameter values were used for each of the conceptual models. Also, uncertainty a'sout the future state of the system was not included in the modeling. Consequently, relative changes in the CCDF could be attributed primarily to differences in the fundamental assumptions used in developing the conceptual models.

This investigation does not necessirily suggest that ine conceptual models applied here are correct representation of an HI.W disposal site in unsaturated, fractured tuff. However, this study has shown that fundamental assumptions used in the development of a conceptual model can have a significant impact on a regulatory measure for the performance of a site. In addition, analysis of intermediate results can provide insight as to the reasons why different conceptual models yield different results. It is important to realize that an analysis, such as the performance assessment of an HLW disposal site, must be cognizant of all the modeling assumptions, both explicit and implicit, and the potential impact of the uncertainty in those assumptions, in order to be meaningful. 


\section{REFERENCES}

M.J. Apted, W.J. O'Connell, K.H. Lee, A.T. Maclntyre, T.-S. Ueng, T. H. Pigford, and W.W.-L Lee, 1991. "Preliminary Calculations of Release Rates of ${ }^{(x)} \mathrm{Tc},{ }^{129} \mathrm{I},{ }^{135} \mathrm{Cs}$, and ${ }^{237} \mathrm{~Np}$ from Spent Fuel in a Tuff Repository," I awrence Berkeley Laboratory, Berkeley, CA. Report No. WG2-5-90) (NNA.9()0627.0(5).3)

Barnard, R.W., and Dockery, H.A., editors, 1991. "Technical Summary of the Performance Assessment Calculational Exercises for 1990) (PACE-90), Volume 1: 'Nominal Configuration', Hydrogeologic Parameters and Calculational Results." Sandia National Laboratories, SAND90-2726, Albuquerque, NM. (NNA.910523.(0)(01)

Bonano, E.J., and Cranwell, R.M., 1988. "Treatment of Uncertainties in the Performance Assessment of Geologic High-Level Radioactive Waste Repositories." Mathematical Geology, vol. 20, no. 5, pp. 543-565. (NNA.910128.0134)

Bunanu, E.J., Davis, P.A., Shipers, I.R., Brinster, K.F., Beyeler, W.E., Updegraff, C.D., Shepherd, E.R., Tilton, L.M., and Wahi, K.K., 1989. "Demonstration of a Performance Assessment Methodology for High-Level Radioactive Waste Disposal in Basalt Formations." U.S. Nuclear Regulatory Commission, NUREG/CR-4759, Washington, DC: and Sandia National Laboratories, SAND86-2325, Albuquerque, NM. (NNA.910123.0(1)38)

(amphell, J.F., longsine, D.E., and Reeves, M., 1981. "Distributed Velocity Method of Solving the Convective-Dispersion Equation: 1. Introduction, Mathematical Theory, and Numerical Implementation." Advances Water Resources, v. 4, pp. 102-108. (NNA.910128.0149)

Daris, P.A., Bonano, E.J., Wahi, K.K., and Price, L.L., 1990. "Uncertainties Associated With Performance Assessment of High-Level Radioactive Waste Repositories: A Summary Report." U.S. Nuclear Regulatory Commission, NUREG/CR-5211, Wasthington, DC, and Sandia National Laboratories, SAND88-2703, Albuquerque, NM. (NNA.910531.0106)

H.wi. P.A., and Goodrich, M.T., 1990). "A Proposed Strategy for the Validation of Ground-Water Flow and Transport Models." Proceedings of the GEOVAL 90) Symponium on Verification and Validation of Geosphere Performance Assenment Nidels, Swedish Nuclear Power Inspectorate, Stockholm, Sweden, Maty $14-17$, 1400. (NNA.91013(k.013.3)

de Marsily, G., 1980. Quantitative Hydrogeology. Groundwater Hydrology for Engineers. Academic Press, New York. (NNA.910207.0116) 
de Marsily, G. "Sources of Errors and Uncertainty in the Prediction of the Geologic Behavior of a Nuclear Waste Repository." Proceedings of the Symposium on Safety Assessment of Radioactive Waste Repositories, Organization for Economic Co-operation and Development Nuclear Energy Agency, Paris, France, Octoher 9-13, (1989). (NNA.910128.0145)

Dudley, A., Peters, R., Gauthier, J., Wilson, M., Tierney, M., and Klavetter, F., 198x. "Total System Performance Assessment Code (TOSPAC ') Volume 1: Hhysical and Mathematical Bases." Sandia National Laboratories, SAND85-()0(2), Albuquerque, NM. (NNA.881202.(211)

EPA (Environmental Protection Agency), 1985. "Environmental Standards for the Management and Disposal of Spent Nuclear Fuel, High-Level and Transuranic Radioactive Wastes." Code of Federal Regulations, Title 40, Part 191, U.S. Government Printing Office, Washington, DC. (HQS.880517.3204)

Erickson, K.L., Chu, M.S.Y., Siegel, M.D., and Beyeler, W., 1986. "Approximate Methods to Calculate Radionuclide Discharges for Performance Assessment of HLW Repositories in Fractured Rock." in Waste Milnagement 80, Vol. 2, R.G. Post (ed.), University of Arizona, Tucson, AZ. (NNA.910123.(1)43)

Iman, R.L., and Shortencarrier, M.J., 1984. "A Fortran 77 Program and User's Guide for the Generation of Latin Hypercube and Random Samples for Use with Computer Models." U.S. Nuclear Regulatory C'ommission. NUREG/CR-3624, Washington, DC, and Sandia National Laboratorics. SAND 83.2365. Albuquerque, NM. (NNA.9(0)117.0157)

INTRACOIN, 1986. "International Nuclide Transpon Ciole Interomparison Study Final Reports Levels 2 and 3 - Model Validation and Incertainty Analysis." Swedish Nuclear Power Inspectorate, Skl 80:2, Stockholm, Sweden. (NNA.910405.0036)

INTRAVAL, 1987. "Geosphere Transpont Model Validation - A Status Report." Swedish Nuclear Power Inspectorate, Skl 87:4, Slockholm, Sweden. (NNA.8701916.0)(1)48)

l.eigh, C.D., 1901. "Technical Basis for a conceptual Model in Cinsaturated Tuff for the

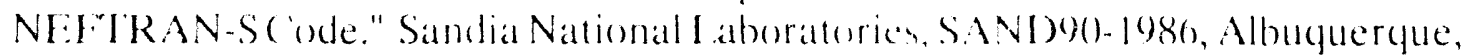
NM. (NNA.92(1).318.(1)(6)7)

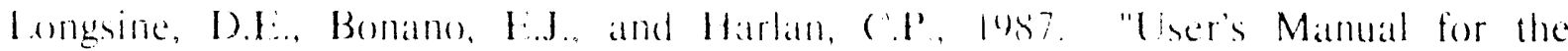
NEFTRAN computer code." H.S. Nuckar Regulatory commission,

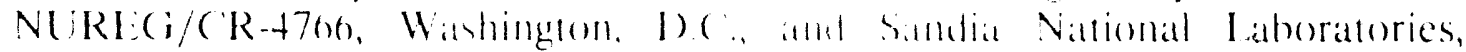

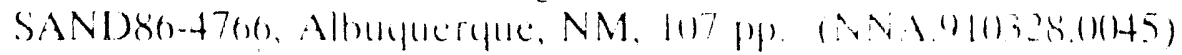


NRC (Nuclear Regulatory Commission), 1986. "Disposal of High-L evel Radioactive Wastes in Geologic Repositories." Code of Federal Regulations, Title 10, Part 60, U.S. Government Printing Office, Washington, DC. (NNA.870325.0172)

NRC (Nuclear Regulatory Commission), 1988. "NRC Model Simulations in Support of the Hydrologic Code Intercomparison Study (HYDROCOIN), Level 1 - Code Verification." U.S. Nuclear Regulatory Commission, NUREG-1249, Volume 1, Washington, DC. (NNA.91(10306.(015))

Olague, N.E., Longsine, D.E., Campbell J.E., and Leigh, C., 1991. "User's Manual for the NEFTRAN II Computer Code." U.S. Nuclear Regulatory Commission, NUREG/CR-5618, Washington, $D C$, and Sandia National Laboratories, SAND90-2089, Albuquerque, NM. (NNA.910531.0115)

Parsons, A.M., Olague, N.E., and Gallegos, D.P., 1991. "Conceptualization of a Hypothetical High-Level Nuclear Waste Repository Site in Unsaturated, Fractured Tuff." U.S. Nuclear Regulatory Commission, NURL:(3/(CR-549), Washington, DC, and Sandia National Laboratories, SAND)89-2965, Albucuerque, NM. (NNA.91062(0.) () 127)

SKI (Swedish Nuclear Power Inspectorate), 199(). "The International HYDROCOIN Project, Groundwater Hydrology Modelling Strategies for Performance Assessment of Nuclear Waste Disposal, Level 2: Model Validation." Nuclear Energy Agency Organisation for Economic Co-Operation and Development (OECD), Paris, FRANCE. (NNA.91(07(0).(0)(0)3)

Thomas, K.W., 1987. "Summary of Sorption Measurements Performed with Yucca Mountain, Nevada, Tuff Samples and Water from Well J-13." I os Alamos National Laboratory, LA-1096(1)-MS, I.os Alames, NM. (NNA.89)(60)2.(1)(26)

Updegraff, C.D., and Lee, (.E., 1991. "DCM.3D - A Dual Continum, ThreeDimensional, Ciround-Water Flow code for Unsaturated, Fractured, Porous Media." U.S. Nuclear Regulatory Commission, NUREG/('R-5536, Washington, $D C$, and Sandia National Iaboratories, SAND)(1)-7()1.5, Albuquerque, NM. (NNA.91(05.31.01(07)

van Genuchten, M. Th., 1980). "A Closed-form Equation for Predicting the Hydraulic Conductivity of Unsaturated Soils." Soil Science 44(5), pp. 892-898. (NNA.89(5) $22 .(1) 287)$ 


\section{APPENDIX \\ Information from the Reference Information Base \\ Used in this Report}

This report contains no information from the Reference Information Base.

\section{Candidate Information for the \\ Reference Information Base}

This report contains no candidate information for the Reference Information Base.

Candidate Information for the

Site and Engineering Properties Data Base

This report contains no candidate information for the Site and Engineering Properties

Data Base. 
1 J.W. Bartlett, Director ( $\mathrm{RW}-1)$ Office of Civilian Radioactive Waste Management

(1.S. Department of Energy

1000 Independence Avenue, S.W. Washington, DC; 20585

1 F. (G. Peters, Deputy Director (RW-2)

office of Civillan Radioactive Waste Management

U.S. Department of Energy

1000 Independence Avenue, S.W. Washington, DC 20585

1 ']' H. Isaacs (RW-4)

office of strategfic Planning and International Programs

()fice of Civilian Radioactive Waste Management

U.S. Department of: Energy

1000 Independence Avenue, S.W.

Washington, DC 20585

1. I. I). Saltzinan (RW-5)

(Iffice of External Relations

(If fice of Civilian Radioactive Waste Management:

U.S. Department of Energy

1000 Independence Avenue, S.W.

Washington, DC 20585

1. Samuel Rousso (RW-10)

Office of Program and Resources Management.

()fice of Civilian Radioactive Waste Management

U.S. Department of Energy

1000 Independence Avenue, S.W.

Washington, DC 20585

I.J. C. Bresee (RW-10)

office of Civilian Radioactive Waste Management

U.S. Department of Energy

loo() Independence Avenue, S.W.

Wisshington, IDC 20585

1 (i. P. Gertz (RW-20)

uffice of Geologic Disposal

uffice of Civiljan Radioactive Waste Maragement

U.S. Department of Energy

1000 Independence Avenue, S.W. Washington, IDC 20585
1 S. J. Brocoum (RW-22)

Analysis and Verification Division

office of Civilian Radioactive Waste Managenent

U.S. Department of Energy

1000 Independence Avenue, S.W.

Wastifington, DC 20585

1 J. Roberts, Acting, Assoc, Dir. $(\mathrm{RW}-30)$

office of systems and Compliance

office of Civilian Radioactive

Waste Management

U.S. Department of Energy

1000 Independence Avenue, S.W.

Washington, DC 20585

$1 \mathrm{~J}$. Roberts (RW-33)

Director, Regulatory Compliance Division

Office of Civilian Radioactive Waste Management:

U.S. Department of Energy

1000 Independence Avenue, S.W.

Washingtion, DC' 20585

1 G. J. Parker (RW-332)

office of Civilian Radioactive Waste Management

U.S. Department of Energy

1000 Independence Avenue, S.W.

Washington, DC 20585

1 R. A. Milner (RW-40)

Office of Storage and lransportation

office of Civilian Radioactive Waste Management

U.S. Department of Energy

1000 Independence Avenue, S.W.

Washington, DC 20585

1 S. Rousso, Acting Assoc. Director (RW- 50 )

office of Contract Business

Management

Office of Civilian Radioactive

Waste Management

U.S. Department of Energy

1000) Indeperidence Averne, S.W.

Washington, IDC 20585 
1. Trudy Wood ( $R W-52$ )

Director, M\&O Management Divislon office of Clvillan Radioactive

Waste Management:

U.S. Department of Energy

1000 independence Avenue, S.W.

Washington, DC 20585

1. D. U. Deere, Chat iman

Nuclear Waste 'Jechuical Revirew Board 1100 WILson Blvd. \#910

Ar1ing,ton, VA 22209-2299

1 Dr. Clarence R. Allen

Nuclear Waste 'lechulcal Review Board 1000 E. Cialifornia Blvd.

Pasadella, CA 91106

1 Dr. John E. Gantlon

Nuclear Waste Technical Roviow Bonal 1795 Bramble Dr.

East Lansing, M1 48823

1 Dr. Melvin W. Carter

Nuclear Waste 'Technical Review Board 4621 Ellisbury Dr: , N.E.

Atlanta, CiA 30332

1 Dr. Donald langmujx

Nuclear Waste Technical Review Board 109 So. lookout Mountain Cir.

(iolden, co 80401

I Dr, D. Warner North

Nuclear Waste Technical Review Board Decision Focus, Inc.

4984 El Canino Real

los Altos, CA 34062

1 Dr. Dennis L. Price

Nuclear Wast Technical Review Board

1011 Evergrentl Way

Blacketarge, VA 24060

I D. Ellis; 1). Verink

Nurlear Waste Techmical Review board 14401 N.W. 18th Place

(ialmosyillo, fil 3\%60)

'C P. Gertz, Project Manager

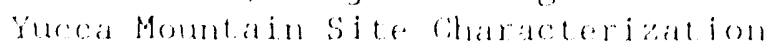
Projeret of fices

U.S. Department of finerly,

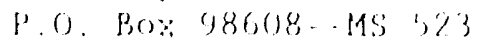

Liats Vegrat; NV 899193-86018
I C. I., West, DIrectol

Office of Lxtermal Affatrs

DoE Field office, Nevada

U.S. Department of Linergy

P.O. Box 98518

Las Vegas, NV 89193.8518

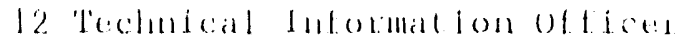

Doti Nevadir lifeld offlee

11. ה. Defortment of Energy

P.1) Box 98518

las: Vegias, NV 89193.8518

1 P. K. Filzsimuons; 'Techndeal

Aclvisiol

Offlee of Assistant Manager for

Envirommental Salety and lleallh

Dofi filald office, Nevalda

U.s. Department of Energy

P. (). Box 98518

l.ats Vogits; NV 89193-8518

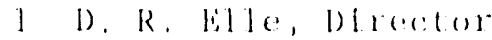

linviromental protection bivision

Dot: Nevada filela office

U.S. Department of Energy

P.O. Box 98518

Las Vegas, NV 89193-8518

1 Repository licensing \& Quality Assurance

Project Directorate

Division of: Waste Managenent:

U.S. Nuelear Regulatory Commission

Washington, 10) 20505

1. Senjor Project Manager tor Yuleca

Mommlain

Repository Projese Hranch

Diviston of Waste Mantagenent

II.S. Nuclear Regulatory Commiasion

Washington, 1) 2055s

1 NRG: Docmunent (ionterol poste

Division ol. Waste Mallagement

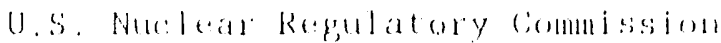

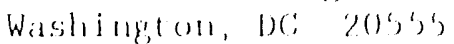

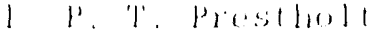

NRO: Bite Represtental ive

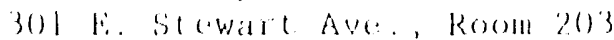

lads Vegias, NV golol

1 E. P. Binnall

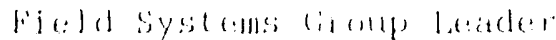

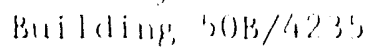

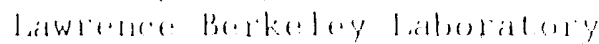

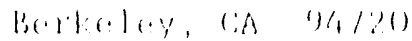


1. Genter for Nuclear Waste

Regulatory Analyses

62.20 Culebra Road

Drawer: 28510

San Antonio, TX 18284

3 W. L., Clarke

Technical Project officer for YMP

Attn: YMP/L.RC

lawrence L.j.vermore National

laboratory

P.O. Box 5.514

lifvermore, CA 94551 .

4 R. J. Herbst:

Technical Project. Officer tor rMp

N-5, Mall Stop .J521

Los Alamos National Laboratory

P.O. BOX 1663

los Alallos, NM 87!45

1 H. N, Kalia

Exploratory Shaft 'lest Manager

Los Alamos National Laboratory

Mail Stop 527

101 Convention (ienter Dr., Suite 820

Las Vegas, NV 89109

1 .I. F. Divine

Assistant Director for

Engineering Geology

U.S. Geological Survey

106 National Center

1.2201 Sunrise Valley Dr.

Reston, VA 22092.

6 L. R. Hayes

Techical Project of ficer

Yucea Mountain Project Branch-MS 425

U.S. Geological Survey

P.O. Box 25046

Denver, co 80225

1 V. R. Schmej der

Asst, Chict Hydrologist - Ms 414

office of Progratll coordination

\&. I'echnical Support

II.S. Cieological Survey

l'? 201 Sumrise valley Drive

Reston, VA 22092
1. J, S, stuckless

Geological Division Coordinator

MS 913

Yucca Mountain Profect

U.S. Geological Survey

P.O. Box 25046

Denver, CO 80225

1. D. H. Appe1, Chief

Hydrologic Investigations Program MS 421

U.S. Geological Survey

P.O. Box 25046

Denver, CO 80225

1 E. J. Helley

Branch of Western Regional Geology MS 427

U.S. Geological Survey

345 Middlefield Road

Menlo Park, CA 94025

1 R. W. Craig, Chlef

Nevada Operations office

U.S. Geological. Survey

101. Convention Center Drive

Suite 860, MS 509

Las Vegas, NV 891.09

1. D. Zesiger

U.S. Geological Survey

101 Convention Center Dr.

Suite 860 - MS 509

Las Vegas, NV 89109

1 R. V. Watkins, Chief:

Project Planning and Management

U.S. Geological Survey

P.O. Box 25046

421 Federal Center

Denver, CO 80225

1 A. L, F1int

U.S. Geological. Survey

MS 721

P.O. BoX $32 \%$

Mercury, NV 89023

1. D. A. Beck

U.S. Ceological. Survey

1500 E. Tropicana, Suite 201

las Vegas, NV 891.1.9 
I I. A. Flancy

II.S. Ceological Survey

Forleral Buldaling, Room 224

(ialson Cilty, NV 89701 .

1. Sherman S. C. Wu

Branch of Astrogeology

U.S. Geological Survey

2.'? N. Gemint Dr.

filgstafl, A\% 86001

1.1. 11. Sass

Branch of Tectonophystos

II.S. Ceological Survey

?2) N. (Gemlni Dr.

filysitalt, AZ 86001

1 Dewayne A. Campbe 11

l'echimical l'roject Officer for YMP

II.s. Burealu of: Reclamation

Ciocle D-3/90

[1.0. Box 250007

1). 11ver, (C) 80225

1 K. W. Cinlusstadux

NIII Roports Chitel

11.5. (itodoglcal survey

l:' fiederal center:

1'.1). 130x 25046

Denere, (10 80225

1. K. keefer

11: Cionlogical Survey

1) 3 federal center

1'.1) Bo: 25046

1) rover, (i) 8022)

1.11. Nolson

Tirlunical Project officer for YMP

siant Applications International. linp.

101 Comvent lon Center Dr.

?:14i1, 4018

l.at: Vogias, NV 89109

2 Snla temss library

Sindr. Applications fnternational $(\because n 1)$

li1 lonvention center Dr.

sinit: 1401

lorl:; Vrg,ats, NV 89109
2. L, D, Foust:

Nevada Sile Manager

TRW binvelrommental Safety systems

101 Convention Center Drive

Suite 540, MS 423

Las Vegas, NV 89109

1. C, E. Ezra

YMP Support Profect Manager

EG\&G Energy Measurements, Ino,

MS V -02

P.O. Box 1912

Las Vegas, NV 89125

1. R. E. Jacksom, Program Mamager

Roy F. Weston, late.

955 L. Entant Plaza, Southwest

Washington, DC 20024

1. Technical Information Center

Roy F'. Weston, Inc.

955 L'Enfant: Plaza, Southwest

Washington, DC 20024

1. D. Hedges, Vice president,

Quality Assurance

Roy F. Weston, Inc.

4425 Spring Mountaln Road, Suite 300

l.as Vegas, NV 89102.

1. D, L, Fraser, Coneral Manager:

Reynolds Electrical \& Englneering (Co.

Mail. Stop 555

P.O. Box 98521

Las Vegas, NV 89193-8521.

1. R. F, Pritohet

Technical Project officer for YMP

Reynolds Electrical d Engineering (io.

MS 408

P.O. Box 9852.1

Las Vegas, NV 89193-8521.

1. B, W, Colston

President/General Manager

Las Vegas Branch

Raytheon Services Nevada

MS 416

P.O. Box 95487

Las Vegas, NV 89193-5487 
I R, L. Bullock

I'ochinfeal profect offleor for YMP Raytheon Servloos Nevada

Sill tee P2.50, MS $4(0) 3$

101. Convention (ienter br.

Lass Vegas, NV 89109

1 R. E. Lowder:

Techulcal profoct offecer for YMP

MAC; T'echnical Services

101. Convention Conter Drtve

Sulte 1.100

las Vegas, NV 89109

1 Pand Es linger, Manager:

PASS Program

Pactife Northwest laboratortes

P.O. Box 999

Rfchland, WA 99352

1 A. T', Tamura

Sicience and 'technology Diviston

of flee of $S c i e n t f f i c$ and Technical Information

U.S. Department of Energy

P. (). BOX 62

()ik Ridge, TN 37831

1 Cirlos (i, Bell, Jr.

Professor of Civil Engtneerting

civil and Mechanfical Englneering lepartinent

Universitty of Nevada, Las Vegas

450 ) South Maryland Parkway

Lats Vegas, NV 891.54

1 C. F. Costa, Director

Nuclear Radiation Assessment. D) iviston

II.S. Environmental Protection Agency

Liuvironmental Monitoring systems laboratory

P. (). BOX 93478

lass Vegas, NV 89193-3478

1 UNWI Library

Bat ted le columbus laboratory

of flce of Nuclear Waste Isolation

b()' King Avenue

Columbus, OH 43201

I 'l. llay, kxecutive Assistant.

offlee of the covernor

State of Nevadia

(aipitol Complex

Ciarson City, NV 89710
$3 \mathrm{R}, \mathrm{R}, \mathrm{L}, \mathrm{OLx}, \mathrm{J}, \mathrm{r}$

Lixecutive D) rector:

Nuclear Waste Project offifee State of: Nevada

Lvergreen Center, sutte 25\%

1802 North Carson Streat

Carson citty, NV 89\%10

1 C. H, Johnson

'lechntcal Program Manager

Nucleas Waste Profect Offlea

State of Nevada

Lvergreen Center, sufte 252

1.802. North Carson Street

Carson City, NV 89710

1. John Fordhain

Water. Resources Center

Desert Research Institute

P.O. Box 60220

Reno, NV 89506

1. Dr. Martin Miffilin

Water Resources denter

Desert Research Institute

250) Chandlet Aventue, Suite 1.

Las Vegas, NV 89120

1 Erle: Anderson

Mountain West: Research-Southwest Inc.

$2901 \mathrm{~N}$. Cientral Ave, \#1.000

Phoentix, AZ 85012-2\%30

1 Department of Comprehensive Planning

Clark County

225 Brldger Avenue, 7 th Floor

Las Vegas, NV 89155

1 Planning Department

Nye County

P.O. Box 153

Tonopah, NV 89049

1. Lincoln County Commission

Lincoln county

P.O. Bo: 90

Ploche, NV 89043

5 Judy Foremaster

City of Caliente

P.O. Box 158

Caliente, NV 89008 
1. Leonomle Davelopment Departinent:

(i) ty of lang Vegas

400 bast Stowat Avanue

las Vagas, NV 8!101

I limmmully Hammlat \& Development: lifly of North lata Vegas

I'. (). Box 4086

North las Vegas, NV 89030

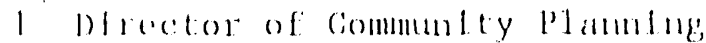
cily of: Boulder Gity

P. (). BOX 367

linulder. (il1y, NV 890(1)!

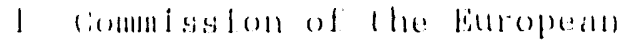

Commun l.t less

200) Rule de! la 1.01

B. $10 / 49$ Brussels

BHISIIIM

? M. 1. Dorsey, Librartan

'Ml' Research and study Center

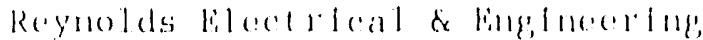
(io, , lole.

MS; 4017

['. (). BOX 9852)

l.15: Vegasi, NV 899193.8521

1. Amy Andersion

Algomor National lableratery

Buillallag, 36\%

9)(o) So. Calssis Ave.

Arforme, I1, 601439

1 S10ve Bradhurst

P. (). BOX I!)

Re(11), NV 8950!

1 hillip Niodze i. Iski-kichmes:

13013 lae Jackson llighway

liairlax, VA 22033

1 Vermont Poo

I') (1). Po: 10\%6

Hawllorme, NV 8941!

1 litsont li lit:i

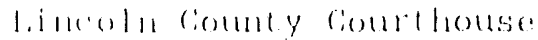

f'imhen NV 890)/3

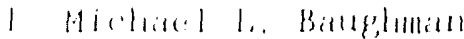

i') (ilirk Rourl

Fistidila, MA (1), IS
1 Glumin Van Ruakul

D) reator: of Commanlty Davelopment:

P.O. BOX 158

(iallante, NV $890(1) 8$

I Ray WIII Ians, II:,

P.O. BOX 10

Aust:111, NV 89310

1 lacomatid . I, filoremal

P.O. Box 2,51

limeka, NV 89316

1 Brad Mull 1111

P. (). Box 330

(iolalllald, NV 890)!3

1 Bjoln Selloluder

190 W. lifist St.

Fa11011, NV $839 / 406$

1 Charles lhist lethwallo, Alch

Assonelate: Plamber

Plamilng, Depallmento

D) awel l,

Independence, (in 93526

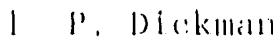

II.s. Dopartement of lintergy

Nevalat Operat loms offlese

P. O. Box yss18

las Vegias, NV 89193.8518

4 U.S. Nuceleal Rogulatory Commission olflee of Nuelear Regulatery Reseatreh

Attu: 'l', I. Meciartin

'I', I. Nicholson

.I. I), Randall

M. SIllollo:l:

$M \& N 1 . / 9-260$

Washlog, (on, 1)(; 2(1)!)

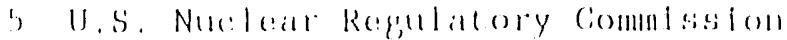

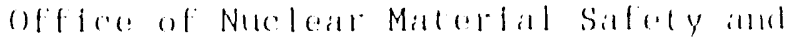
Saltegenards

Atlu: Rollald Ballard

Paull ine Brooks;

R. B. Conlell

Siell Coplan

Norman A. Lifomborg,

$M S 4 \cdot 11 \cdot 3$

Washlng, (1) D), 20)'s

1 Cienger Apostolakis

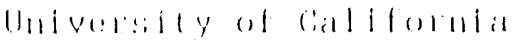

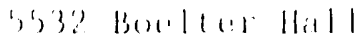

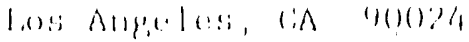


1. H. H. B BIIIIELOH

llarwale laboratory

UnI lead KIngelon Atomle: Enestgy

Allthorltiy

Grlurdahlro OXII OKA

UNI'I'Li) RIN(iD)OM

I R, I., Bras

Ralph Parsons laboratory

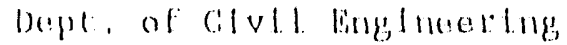

Massachuselts last flute of 'l'ochmology

(amberlage, MA 0213!

I P. Carboneras-Mart Lnez

ENRLISA

Calle limll fo vargens, I

280)i3 Madrla, SPAIN

4 Batlollo Patlle Northwest labl)

All11: (i. colo:

P. (i. Doc:lo1

A. M. lolobetrau

A. Li, Vanl lailk

3lot) Port of Bonlon

Si fema V Buil (llip!

Klehland, WA 993's?

I.J. I. K. Datenent

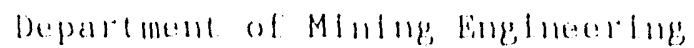

Mnlverally ol Nevada

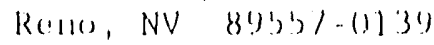

I (i. de Marsally

Unlversilly Plerre et Marle Curle laboratorle de Cieolog, Applique 1. Place Jussten - T'26 - 50 etage b) Parla codes os

l'RANCL:

4 Comber for Nucleas Waster Regulatery Analysuss

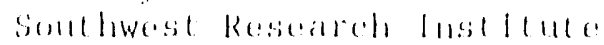

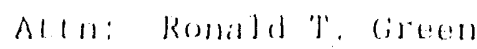

Wosloy Ci, Patrlek

lolin Rusisell

Bullit Silgial

b?'?) (inlelifar Roard

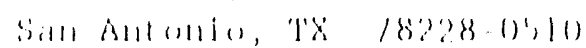

3 Hoiversily ol Arlarmas

beparement of llydrolog,y and Water Rosionteces:

All1: D. 1). Fivalls

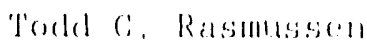

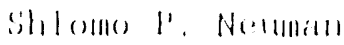

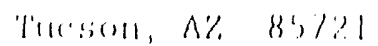

1 Katherine N, Gather

Applled Researoh Tech, Services, Ino. 4300 San Matoo NE, Sulte A220

Albuquerque, NM 87110

1 Cilaudio Pescatore

Nuclatar Energy Agency

Organdzation for Economde Cooperat lon and Development

38, Boulevard Suchet:

F-7501.6 Parta, FRANCE

1. Danlal A, Galson

Intera Information 'Technologles, l.t.l.

Finvlromental Dtviston

l'ark Vlew House

1.43 Burton streat:

Melton Mowbray

Lefchestershlire, $1 . \mathrm{E} 13 \mathrm{AE}$

(JNI'I'LI) KINCIDOM

1. B. W. Coodwin

Alici, Research

Whiteshall Laboratortes

Plinawa, Manl toba ROE 110

CANADA

6 GRAM, IIIC.

Attn: Mark Harrtngton (irotichen C. Newinan Judlth $A$, Rollstin C. David Updegraf: Kr.shan $\mathrm{K}$. Waht. Tony Zlmmerinan

1700 Moon St, $\mathrm{NE}$

Albuquerque, NM 87112

1. A, L. Gut:jahr

Departinent of Mathematios

New Mexico Institute of Mintng, and Technology

socorro, NM 87801

1 Sharlf lloger:

Department of Chemical and Nucleat linglueerling

Undverstity of: New Mexloo

Albupuerque, NM 871.31

I 'T'. I. Summerlling,

INTHRA SClences

Chilltern llouse

45 Station Road

Henley-on-'Thames

Oxlordshlre, RCig I A'T

UNITLII) KINCIDOM 
I H. Si. Hostsaln

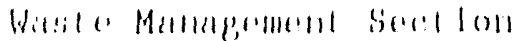

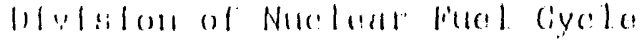

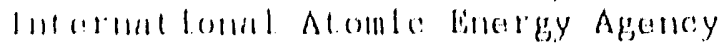

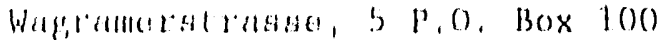

A l, (1) VIamma, AUS'TRIA

I Finllala Kerl

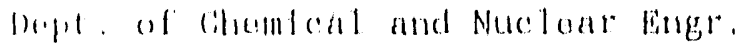

llal vorally al Now Maxleo

Alli1411019110, NM 87131

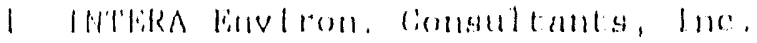

il111: 1). Li. lamg, lno?

M. Ronereat

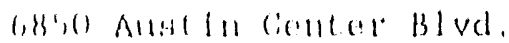

Sill10.30)

Ansil11, '1'x /8131

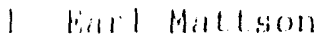

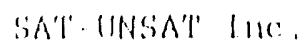

$1:(1) 4,1) 1 \mathrm{R}(\mathrm{y}) \mathrm{Nl}$

Allmallerefue, NM 8712?

$1 A .111+1$

finderal Hintstiy of the binvelroment

Hislare Comservatlon and Nuclear:

Sialloty (BMO)

Rularat RS IIT.6

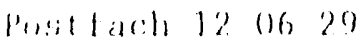

1). $3,3(1)$ B(3)111 ।

(IVKRAN'i

I H.I (i. Mephos

West inghouse llantord

1'. 1). Bor 19\%1)

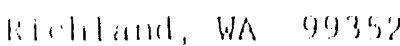

I l' limedo Giarmido

intella de 'teethologela Nuclear

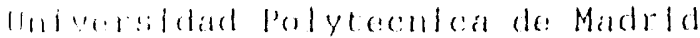

l,ill l, l. lint lelerea Aliaseal, ?

1. $\therefore 81016$, Mathla, GPAIN

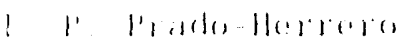

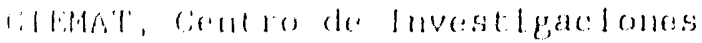

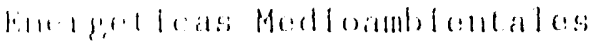

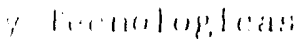

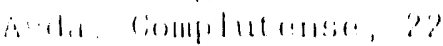

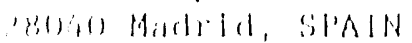

$1 \quad 1 \% 11101$

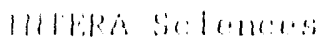

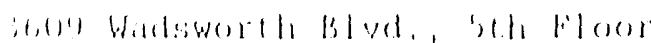

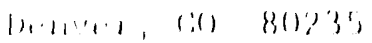

1 (il:allt Shoms:

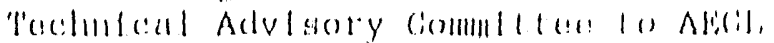

G.S. BIdg. - 2.16

Hamlltom, ontarlo l,8S hkl.

CIANAIDA

1. Janes SLnelalr

AEA Decommlasloning and Radwasto

Harwe!l laboratory

Harwall, oxfordstilea OXI1 ORA

UNI'l'Lil) KIN(i))OM

1 (i. Phogarstion

Nuclear linel'gey Agoncy

Orennlzat lon lor licomemle fooperal fon and Development

38, Bouluvard Suchus

li- bolo paris, francie

I B. (i,.), 'lliompsom

HM Inspectoriate of Pollution

Roumey Honsso

4) Marsihan Street

London SW1P 3PY

UNITLED KINGDOM

1 C. Iorrea-VIdal

Instituto PYRMA

CIEMA'T

Avda, Complutense, 22

28040 Madrid, SPAIN

1 'I', Vience

I'echnlcal Research Center of Fintand P. 0. Box 169

Sifo()(1) \&1 1101:alukl 18

FINIAN!) 


\begin{tabular}{|c|c|}
\hline 6300 & 'I'. O. Hunter \\
\hline 6.301 & E. J. Bontano \\
\hline 6302 & 'T'. Ii, Blajwas' \\
\hline 6312 & fi, W. Blagham \\
\hline 6312 & 11. A. Dockery \\
\hline 6.31 .2 & J, H. Gauthter: \\
\hline 6312 & P. C. Kaplan \\
\hline 6312 & F. G, Lauffet: \\
\hline 6312 & M. L. WLLson \\
\hline 6312 & R. W. Barnard \\
\hline 631.2 & M. P. liawa1.1 \\
\hline 631.3 & L, S, Costin \\
\hline 6316 & R, P, Sandova1. \\
\hline 6318 & $\begin{array}{l}\text { R. J. Macer for: } \\
100 / 1.214 \% / \text { SAND } 90-2882 / \mathrm{NQ}\end{array}$ \\
\hline 6319 & R. R. Rtchards \\
\hline 3141 & S. A. Landenberger: \\
\hline 3145 & $\begin{array}{l}\text { Document Procassing } \\
\text { for Dor/OSTL }\end{array}$ \\
\hline 3151 & (i. C., Cilaycomb \\
\hline 63140 & W. D. Weart \\
\hline 6341 & WM'I Lifrary \\
\hline 6342 & D. R. Anderson \\
\hline 6342 & D. P. Ga1legos \\
\hline 6342 & M. (i. Marietta \\
\hline 63442 & M. S. Tternoy \\
\hline 6342 & R. P. Rechard \\
\hline 6342 & W. E. Beyeler \\
\hline 6.344 & E. D. Gorham \\
\hline 6344 & T. F. Corbet \\
\hline 6,400 & N. R, Ortiz \\
\hline 6.41 .0 & D, A. Dahlgren \\
\hline 6413 & J. C. He 1ton \\
\hline 6416 & S. H. Contrad \\
\hline 6,116 & P. A. Davis \\
\hline 6416 & C. P. Harlan \\
\hline 6416 & M. W. Kozak \\
\hline 6416 & N. E. Olague \\
\hline 641.6 & L. l. Price \\
\hline 6622 & $\begin{array}{l}\text { M. S. Y' Chu } \\
\text { E. B L Indgren }\end{array}$ \\
\hline $\begin{array}{l}6,22 \\
6622\end{array}$ & $\begin{array}{l}\text { E. R. Lindgren } \\
\text { J. 'I' Mocord }\end{array}$ \\
\hline 6622 & $\begin{array}{l}\text { A. T. Mecord } \\
\text { P. I, Pohl }\end{array}$ \\
\hline 1723 & R. G. Knowlton \\
\hline 112.3 & A. M. Parsons \\
\hline 8523.2 & Central Techntcal Flles \\
\hline $922 \%$ & J. P. Orlanes-Gallegos \\
\hline
\end{tabular}




\section{SAND90-2882}

The number in the lower right-hand corner is an accession number used for Office of Civilian Radioactive Waste Management purposes only. It should not be used when ordering this publication. 

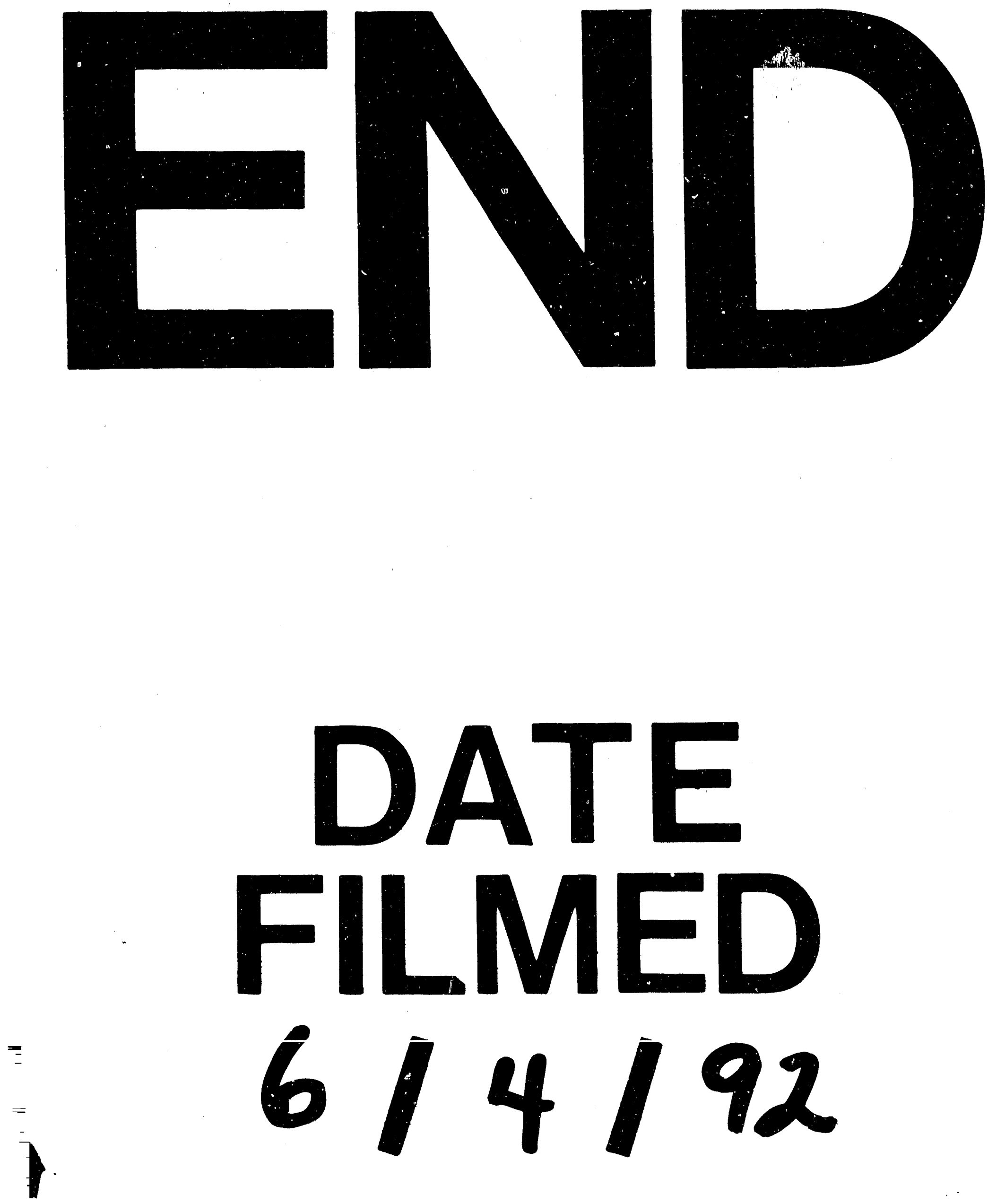


\section{$\equiv$}

